\title{
AB 288 DUAL ENROLLMENT: FROM POLICY TO PRACTICE
}

\author{
A Dissertation submitted to the faculty of \\ AS \\ 35 \\ 2019 \\ San Francisco State University \\ In partial fulfillment of \\ the requirements for \\ EDD \\ 574 \\ the Degree \\ Doctor of Education \\ In \\ Educational Leadership
}

by

Mallory Jean Stevens

San Francisco, California

August 2019 
Copyright by

Mallory Jean Stevens

2019 


\section{CERTIFICATION OF APPROVAL}

I certify that I have read AB 288 Dual Enrollment: From Policy to Practice by Mallory Jean Stevens, and that in my opinion this work meets the criteria for approving a dissertation submitted in partial fulfillment of the requirements for the degree Doctor of Education in Educational Leadership at San Francisco State University.

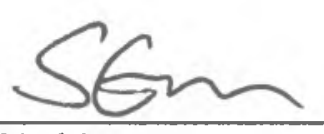

Dr. Sheldon Gen Associate Professor, School of PACE

Public Administration Program Director

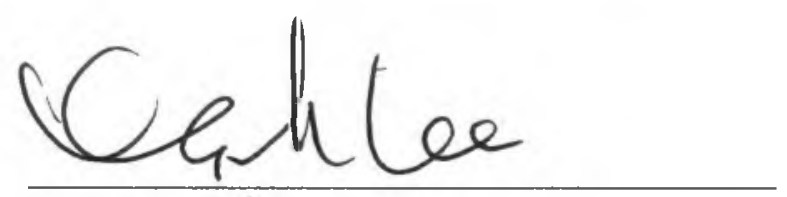

Dr. Ming-Yeh Lee

Professor, Graduate College of Education

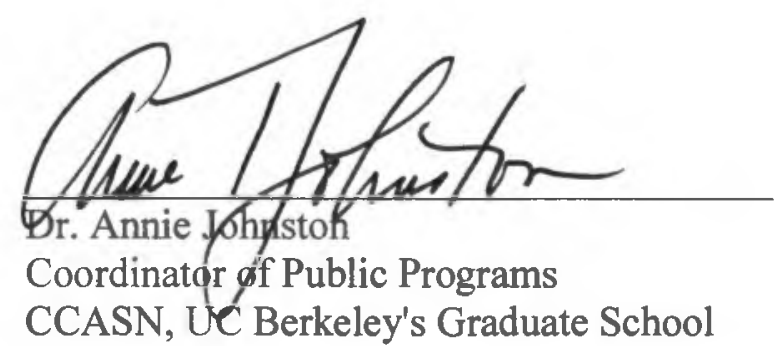




\title{
AB 288 DUAL ENROLLMENT: FROM POLICY TO PRACTICE
}

\author{
Mallory Stevens \\ San Francisco State University \\ 2019
}

This study explores how the legislative goals of AB 288 dual enrollment are understood and externalized by the policy adopters, administrators, and supporters interviewed and what impact these differences in understanding have had on the implementation of CCAP dual enrollment. Three cases were created based on twenty-two interviews with policy adopters, administrators, and supporters, across three community college districts and five high school districts. The findings reveal that implementors' understandings of the intent of the legislation becomes apparent in how they approach three characteristics that differentiate CCAP dual enrollment: dual enrollment access by under-represented student populations, expansion of dual enrollment beyond high performing students, and the creation of defined pathways to support students entering college. A key recommendation is that the discussions about who is being served must be centralized. This study provides context for critical conversations around dual enrollment partnerships, identifying key decision points and influential factors throughout the initial years of a CCAP initiative.

I certify that the Abstract is a correct representation of the content of this dissertation.
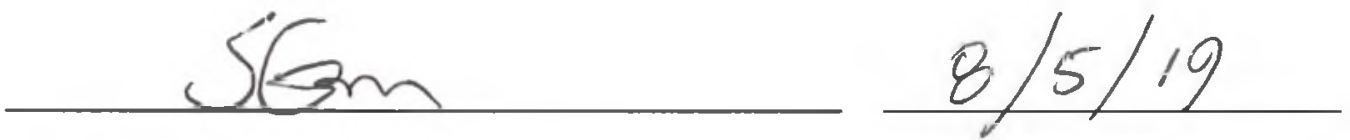

Dr. Sheldon Gen

Chair, Dissertation Committee

Date 


\section{ACKNOWLEDGEMENTS}

I am indebted to my thesis committee, for their generous commitment of time, sharing of knowledge, and patient direction: Dr. Sheldon Gen, Dr. Annie Johnston, and Dr. Ming-Yeh Lee. In addition, I appreciate the support the Get It Done writing group... the comradery, commiseration, and laughter made this possible. Thank you to my daughter Lauren for her patient proof-reading. Finally, and most importantly, I would like to thank my family, and particularly my husband, H.D. Stevens, for their support in this process. 


\section{TABLE OF CONTENTS}

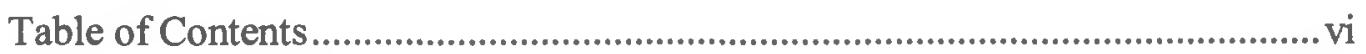

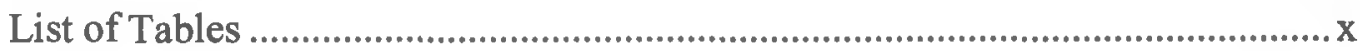

List of Figures ................................................................................................

List of Appendices .................................................................................................

Chapter One: Purpose of the Study......................................................................... 1

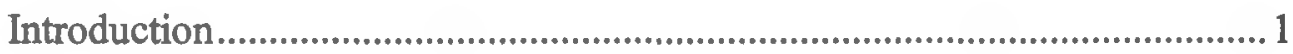

History of Dual Enrollment ..............................................................................2

AB 288 Shifting Dual Enrollment .................................................................... 4

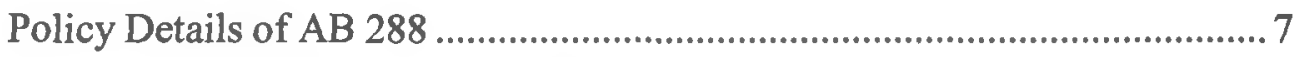

Changes Created by AB 288.............................................................. 9

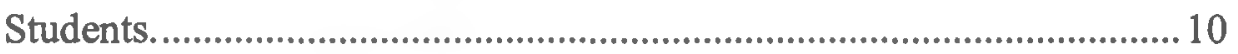

Administration \& funding.................................................................... 13

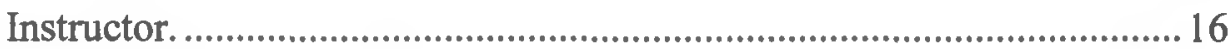

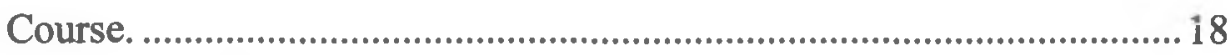

Purpose of the Study ................................................................................ 19

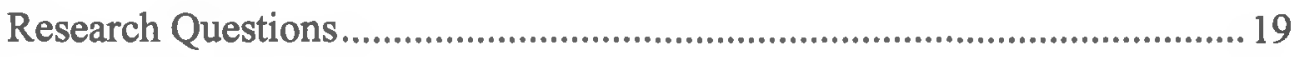

Conceptual \& Theoretical Frameworks .........................................................20

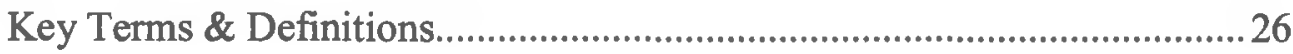

Statement of Delimitations and Scope of Study .............................................22

Justification \& Significance of the Study ................................................28

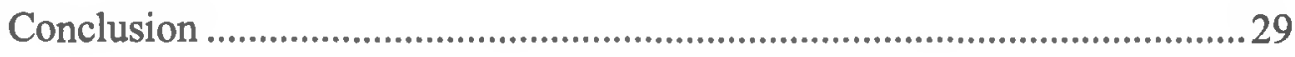


Chapter Two: Literature Review .............................................................. 30

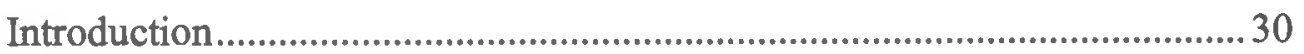

Impact of Dual Enrollment in High School ............................................. 31

Impact of Dual Enrollment in College....................................................... 35

Rigor, Pedagogy, and Student Experience................................................. 42

Dual Enrollment and Student Selection.................................................. 44

Educational Access ............................................................................ 46

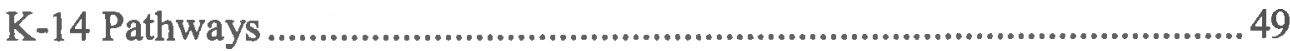

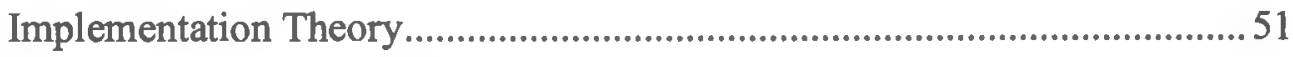

Chapter Three: Methodology ..................................................................5 55

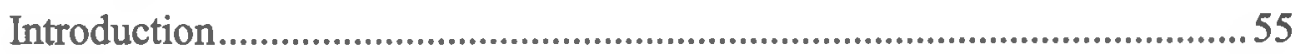

Research Questions............................................................................5 56

Role of the Researcher .................................................................5 58

Design \& Analysis .............................................................................. 58

Case Study Selection......................................................................5 58

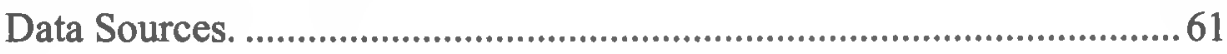

Data Collection. .........................................................................6 63

Demographic data. ..................................................................... 63

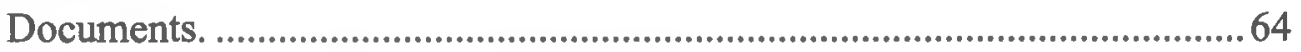

Interviews................................................................................6. 66

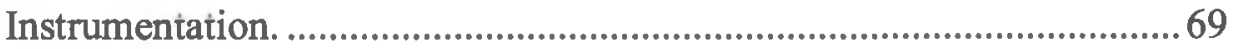

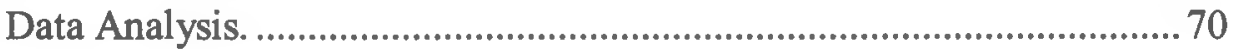

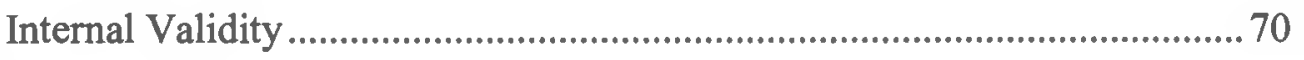

vii 
Generalizability \& Transferability ..................................................... 71

Chapter Four: Report of Findings .......................................................... 72

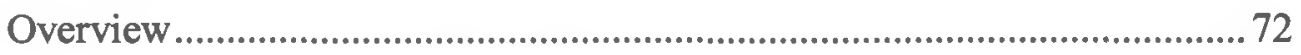

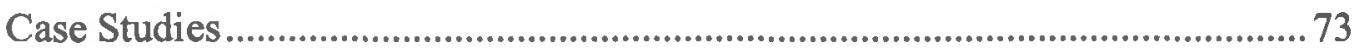

Case Study One: Urban Community College and a Single Large High School District Partner ................................................................................................. 76

Case Study Two and Case Study Three: Two Approaches ........................8 82

Case Study Two: Rural Community College with Team-Based Leadership 82

Case Study Three: Rural Community College with Focused Leadership ....85

Dual Enrollment Policy Adopters, Administrators, and Supporters through a Bottom-up Implementation Lens. ................................................................. 88

Policy Implementers' Understanding and Externalization of AB 288 Goals 90

Supporting Dual Enrollment as a New Initiative .................................... 93

Understandings of equity and program creation...............................93

Administrative staffing decisions. ............................................. 102

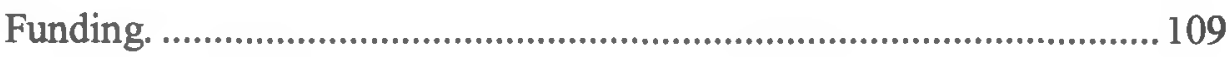

Expanding Access to Underrepresented Student Populations .................. 111

Attention to partnership demographics. ............................................ 113

Student Selection process ......................................................... 117

Expanding the Academic Population Served........................................... 123

Creation of student supports. ...................................................... 123

Exposure to college level coursework. ........................................... 131

Pathway Creation and Program Growth .................................................. 132

Creating clear pathways of aligned, sequenced coursework. .............. 143 viii 
Conclusion

Policy Implementers' Understanding and Externalization of AB 288 Goals 147

Supporting Dual Enrollment as a New Initiative .................................... 147

Understandings of Equity and Program Creation .................................... 147

Expanding the Academic Population Served.......................................... 148

Creation of Student Supports ............................................................ 148

Chapter Five: Discussion and Recommendations........................................ 150

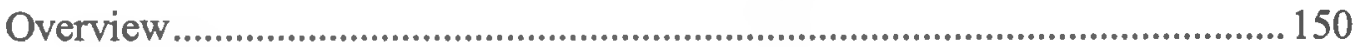

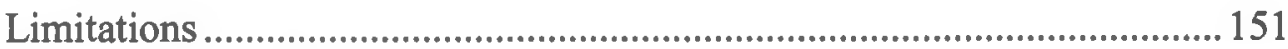

Case Study Variance................................................................... 152

Recommendations for State Level Support ........................................ 152

Recommendations for Policy Adopters ............................................. 155

Recommendations for Dual Enrollment Administrators .......................... 157

Recommendations for Further Study ..................................................... 161

Reflections on the Research Process...................................................... 162

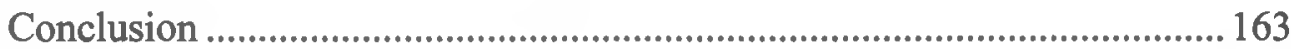

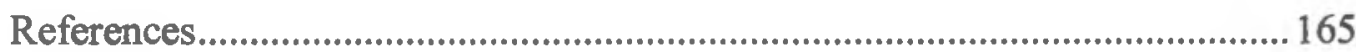

Appendices..................................................................................... 175

ix 


\section{LIST OF TABLES}

Table 1 Theoretical Framework by Role ........................................................................ 26

Table 2 Dual Enrollment Benefits................................................................................. 40

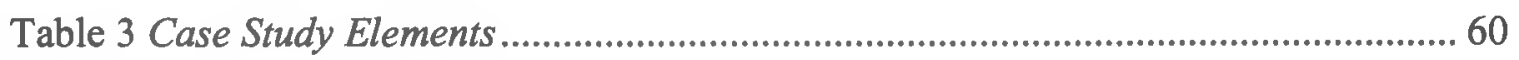

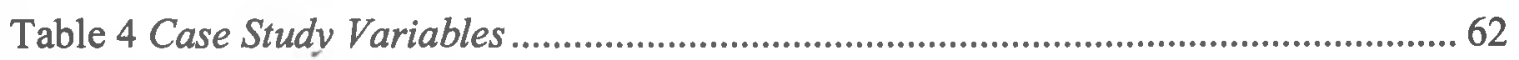

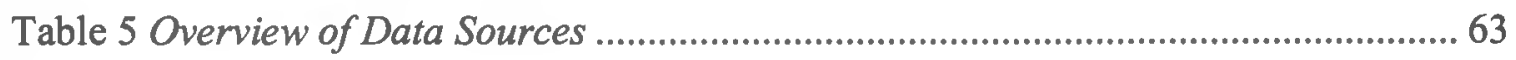

Table 6 Document Data Sources .......................................................................................... 65

Table 7 Sample Interview Variables ................................................................................. 67

Table 8 Interviewee Demographic Information................................................................. 68

Table 9 Case Study One: Urban Single Community College and Large Multiple High

School District ......................................................................................................................... 76

Table 10 Case study two: Rural single community college district with multiple high school districts and team-based administration ............................................................ 84

Table 11 Case study three: Rural, focused administration, single and multiple comprehensive high school districts ............................................................................. 86

Table 12 Understanding of Legislative Goals by Role ................................................... 94

Table 13 Case Study Staffing and Funding Overview ................................................. 103

Table 14 Findings on Funding by Case Study ........................................................ 109

Table 15 Case study one: Demographic comparison of dual enrollment students to all comprehensive high school students ....................................................................................... 122

Table 16 Definition of Student Supports by Role ....................................................... 126

Table 17 Case study one: Overview of course offerings (Spring 2017 \& Spring 2019) 134

Table 18 Case Study Two: Overview of CCAP Courses and Pathways in the Single High School Districts ................................................................................................................... 135

Table 19 Case Study Two: Multiple High School District CCAP Course Offerings.... 136 
Table 20 Case study three - Single High School Districts ........................................... 139

Table 21 Case study three - Multiple High School District ........................................ 139

Table 22 Table of Findings ................................................................................... 147 


\section{LIST OF FIGURES}

Figure 1 Policy-Implementation Process (Van Meter \& Van Horn, 1975, p. 463) .......... 22

Figure 2 Special Admit Enrollment as a Percentage of Total Enrollments by Case Study

Figure 3 Case Study One: Community College Enrollment Patterns................................ 79

Figure 4 Street-level Bureaucrats: High School Districts .................................................... 89

Figure 5 CCAP Dual Enrollment ........................................................................... 123

Figure 6 A Comparison of CTE \& General Education Pathways Across the Multiple

High School District .................................................................................................................. 138

Figure 7 Comparison of CTE and General Education Course Offerings (Case Study One and Case Study Two) 


\section{LIST OF APPENDICES}

Appendix À: Case Study Participant Overview................................................. 175

Appendix B: 2017-2018 Student Demographics ................................................. 176

Appendix C: Data Points for AB 288 Student Selection ........................................ 177

Appendix D: Dual Enrollment Checklist ....................................................................... 178 


\section{Chapter One: Purpose of the Study}

\section{Introduction}

Assembly Bill (AB) 288 for Public schools: College and Career Access Pathways partnerships (CCAP), introduced by Chris Holden and passed in 2016, is a refinement of dual enrollment and dual credit processes that have been available for many decades, expanding access to dual enrollment beyond the high performing students it has historically served. This legislation encourages the removal of barriers and supports the expansion of College and Career Access Pathway partnerships between high school districts and community college districts with the intention of increasing dual enrollment opportunities for student populations that are underrepresented in higher education and for students who are not currently college bound. This legislation introduces changes that are intended to increase access: raising the cap on dual enrollment units from eleven to fifteen units, with a maximum of four courses; allowing for courses offered during the school day on a high school campus to be closed; and allowing both sides to receive apportionment for the same students, although not for the same classes (Holden, 2017). In addition, it requires intentional partnerships between high school and community college districts to offer courses in an academic or a career technical education pathway (CTE) and to provide copies of the agreement and annual reports to the California State Chancellor's Office (Holden, 2017). This is a change from previous dual enrollment initiatives that had no standardized form, no oversight, and no standardized agreement format or reporting requirements. 


\section{History of Dual Enrollment}

Dual enrollment, sometimes called concurrent enrollment, allows students to be enrolled in high school courses and college courses at the same time. Dual credit is a form of dual enrollment through which high school students earn both high school and college credit, although what this looks like varies greatly (Bragg, Maximizing the benefits of tech-prep initiatives for high school students, 2000; Purnell, 2014; Speroni, 2011). These courses may take place on a high school or a community college campus. They may be taught by a high school instructor who meets the minimum qualifications of the college or by a college instructor. Students may participate in a single class or earn as many as fifteen units per semester, potentially allowing high school students to complete several semesters of college work while in high school.

Dual enrollment policy was initiated in California in 1976 (Mokher \& McLendon, 2009). In this earlier form of dual enrollment, courses are required to be offered as open enrollment courses. This means that the enrollment of courses cannot be restricted to only high school students and were generally offered outside of school hours. The courses may be offered as part of a cohesive pathway program or as a single a la carte offering. Courses might be in a CTE pathway or in an academic course, such as math or history. This form of dual enrollment focuses on serving high-performing, predominantly white students, essentially another form of acceleration like advanced placement (AP) courses (Hofmann \& Voloch, 2012; Howley, Howiey, Howley, \& Duncan, 2013; Karp \& Hughes, 2008). In this way, dual enrollment has been used as method to accelerate and support students of high academic ability who excel beyond what the normal curriculum 
can offer them (Karp, Calcagno, Hughes, Jeong, \& Bailey, 2007), a form of "radical acceleration" (Howley, Howley, Howley, \& Duncan, 2013), to allow high-ability students to reach their full potential (Dare, Dare, \& Nowicki, 2017). Dare, Dare, and Nowicki (2017) suggested that dual enrollment provides an important motivation for high achieving students, allowing them to be challenged and work with intellectual peers. Advanced Placement (AP) is used in the same way as dual enrollment, is also based on college level curriculum, and is available to high performing students, but AP tends to be available in larger, high socioeconomic status (high-SES) urban schools and dual enrollment is available in both urban and more rural areas served by community colleges, so the programs are complementary, instead of in competition with one another (Lively \& Klopfenstein, 2012).

The focus of dual enrollment then shifted to the middle performing group of students as a mechanism to address low graduation rates and inadequate academic preparation and to reduce remediation rates (Speroni, 2011). More recently, dual enrollment has been identified as a tool to promote equity, providing opportunities for under-represented student groups and first-generation college students (Hoffman, Vargas, \& Santos, 2009; Jones, Yonezawa, Ballesteros, \& Mehan, 2002; Howley, Howley, Howley, \& Duncan, 2013; Hughes, Rodriquez, Edwards, \& Belfield, 2012; Karp, Calcagno, Hughes, Jeong, \& Bailey, 2007). There are many forces that support the centralization of this initiative. For example, how to address low college completion rates has become the focus of educational reform efforts in the last ten years, driven by a 
recognition that education beyond college is essential for economic success and by a skills gap in the American workforce (Lee, Edwards, Menson, \& Rawls, 2011; White House Press Office, 2009; Shulock \& Offenstein, 2012; The Workforce Alliance (TWA), 2009).

\section{AB 288 Shifting Dual Enrollment}

AB 288 policy draws on research that suggests dual enrollment could be used to support students who are struggling or at risk of dropping out and to provide access for student groups under-represented in higher education (Holden, 2017). The legislation was primarily informed by research funded by the James Irvine Foundation called the Concurrent Courses Initiative, a three-year study done between 2008 and 2011 involving 3,000 low-income youth who were either struggling academically or who are part of groups who are historically under-represented in higher education (Hughes, Rodriquez, Edwards, \& Belfield, 2012), according to Vincent Stewart (2019) who wrote the proposed AB 288 legislation. This study built on previous research on dual enrollment, showing that dual enrollment can be used to improve outcomes for a broad range of students.

Assembly Bill (AB) 288 for Public schools: College and Career Access Pathways partnerships, introduced by Chris Holden, creates a refinement to the dual enrollment options that has been available for many decades, focusing on the removal fiscal penalties and policy barriers to the creation of strong dual enrollment partnerships, by removing "earlier restrictions and then reach[ing] out to students that previously weren't really taking advantage of dual enrollment" (Stewart, 2019). The expectation is that the creation 
of these partnerships will result in savings of time, money, and "scarce educational resources" for both students and the state (Holden, 2017).

The legislation articulates a goal of these partnerships increasing access to higher education for under-represented populations, creating pathways for students who are not currently on a path to college, or increasing college and career readiness for high school students. Changes include assigning higher enrollment priority to students involved in CCAP dual enrollment classes, increasing the number of credit bearing units students may take to 15 units and up to four courses per term, and allowing for closed enrollment limited to high school students for courses offered at the high school (Holden, 2017). While $\mathrm{AB} 288$ shifts the focus of dual enrollment, it also maintains much of the same framework and requirements and promising many similar benefits. It also presents an opportunity and a challenge to leaders: to re-envision dual enrollment in a way that is fundamentally different, welcoming and supporting a broader range of students through a program that is fundamentally different earlier forms of dual enrollment.

The stated intent of $\mathrm{AB} 288$ legislation is to provide benefits to both students and to the state: "reducing the number of high school dropouts, increasing the number of community college students who transfer and complete a degree, shortening the time to completion of educational goals, and improving the level of preparation of students to successfully complete for-credit, college-level courses" (Holden, 2017, p. 92). Participation in dual enrollment has shown to benefit students by increasing knowledge about the requirements of college and how to navigate the system (Kanny, 2015), and 
improving college readiness (An \& Tayior, 2015; Kim, 2014), high school completion (Ganzert, 2014; Plank, DeLuca, \& Estacion, 2008), college GPA (An, 2013; Ganzert, 2014; Cowan \& Goldhaber, 2015), and college completion rates (An \& Taylor, 2015; Ganzert, 2014; Morrison, 2008).

AB 288 dual enrollment expands on existing dual enrollment policy by authorizing the governing board of a community college to create College and Career Access Pathway (CCAP) partnerships with the governing board of school districts. The purpose of these partnerships is to expand dual enrollment opportunities for students who are under-represented in higher education or who may not already be college bound to create a seamless pathway from high school to community college for career technical education or transfer, to improve high school graduation rates, or to increase college and career readiness. This bill was created because review found that dual enrollment can be used to improve outcomes for a broader range of students. Recently the focus of policy makers and educators have turned to dual enrollment as a potential vehicle to support students who are at risk of dropping out or who are struggling academically, as well as to improve completion and transfer rates for participants in the program. AB 288 requires more accountability in the creation of partnerships and in the requirement to provide regular updates to the California Community Colleges Chancellor's Office, but allows for broad interpretation by implementors in key areas, like the definition of student populations beings served and the characteristics and the content of academic pathways. I will be exploring implementation and the interrogating of the intentions and purposes at 
all levels of implementation, considering the sometimes complementing and sometimes competing system requirements which impact the ability of the programs to meet the legislative goals.

Across California, this new form of dual enrollment is being adopted by high schools and community colleges who are working to create partnerships. The intent of my study is to evaluate how these partnerships are being created and how this policy is externalized in practice. This analysis is critical because the interpretations of the policy adopters, dual enrollment administrators, and program supporters will shape the impact of the legislation on the groups that it seeks to serve. I will use Lipsky's (2010) framework of street-level bureaucracy to analyze how policy formed through the practices of the frontline implementers, and a comparison of top-down and bottom-up implementation theory. AB 288 policy creates an opportunity. Each CCAP implementation is a manifestation of the policy and reflects the intentions and focus of the implementors. It is important to understand the perspectives of the participants on both sides of these agreements, because these real-world implementations shape the way policy is realized in the world (Lipsky, 2010).

\section{Policy Details of AB 288}

AB 288 dual enrollment expands on existing law by authorizing the governing board of a community college into create College and Career Access Pathway (CCAP) partnerships for the purpose of:

Offering or expanding dual enrollment opportunities for students who may not already be college bound or who are underrepresented in higher 
education, with the goal of developing seamless pathways from high school to community college for career technical education or preparation for transfer, improving high school graduation rates, or helping high school pupils achieve college and career readiness (Holden, 2017).

The limitations on dual enrollment were based on a history of misuses, according to Vincent Stewart (2019):

There had been abuses by some colleges in terms of which students they were enrolling in dual enrollment and having the colleges as well as the K12 school districts claiming state funding for those students during the same instructional time... [resulting] in, in some rather severe limitations on dual enrollment.

He went on to say: "When we initially conceived of this legislation, in talking with my colleagues in the Chancellor's Office and assembly member Holden, it was a pretty simple, straightforward idea." The public approval process by the partner's governing boards, the administrative requirements around faculty qualifications and against faculty displacement came much later:

Through the legislative process, virtually every step of the way, the partnerships became considerably more complicated, more detailed. There were more requirements and that's the way the legislative process works often (Stewart, 2019). 
AB 288 dual enrollment expands on existing law by authorizing the governing board of a community college into create College and Career Access Pathway (CCAP) partnerships. The stated intent is to provide benefits to both students and to the state: reducing the number of high school dropouts, increasing the number of community college students who transfer and complete a degree, shortening the time to completion of educational goals, and improving the level of preparation of students to successfully complete for-credit, college-level courses (Holden, 2017, p. 92).

AB 288 expands Section 76004 of the Education code to say that community college districts may enter a CCAP agreement "the purpose of offering or expanding dual enrollment opportunities for students who may not already be college bound or who are underrepresented in higher education" (Holden, 2017, pp. 92-93). The goal of this agreement is to create seamless pathways for career technical education (CTE) or in preparation to transfer to 4-year programs, or for improving high school graduation or college and career readiness. Partnerships are given the option to choose any or all of these but must meet at least one (Harris, 2016). The first step is to set a goal for a CCAP partnership and to understand what this new flavor of dual enrollment looks like.

\section{Changes Created by AB 288.}

CCAP dual enrollment agreements differ from non-AB 288 dual enrollment agreements in a variety of ways in terms of administration of the program, and the requirements on the instructor, the course, and the student. To understand the impact of 
$\mathrm{AB} 288$ policy, the changes in each of these areas must be understood and the positive and negative impact of the changes must be considered critically.

\section{Students.}

Students should be at the center of any dual enrollment program created. CCAP agreements are mandated to focus on students, creating pathways for students who are under-represented on college campuses, on students who may not be college bound, and on supporting high school students in the development of college and career readiness. According to Vince Stewart (2019):

The idea of [the Concurrent Courses] initiative was to offer dual enrollment courses to high school students that didn't meet either the high academic achiever definition or vocational education. To look at students who were underrepresented groups in Higher Ed and not academically struggling.

All agreements must focus on at least one of the stated goals. In my opinion, this is a weakness in this legislation. The final focus area, college and career readiness, is a catch-all that may detract from a focus on a mission to support struggling students and create access for students who historically have not been supported in attending college. In creating a partnership, the parties should be clear on both which of these mandates are the focus and how the outcomes and performance on these items will be measured.

Many of the historical requirements for traditional dual enrollment programs are maintained under $\mathrm{AB} 288$. For example, both sides of the partnership are responsible for 
ensuring that students receive support services, such as counseling, placement assistance, assessment, and tutoring. In addition, for all dual enrollment initiatives, the K-12 district is responsible for determining a student's readiness to undertake college-level work and keeping the documentation on file, but the community college retains the right to refuse a student, if the criteria used is not discriminatory. In terms of tracking student in the program, either institution may maintain records of grades, attendance, and achievement, but the records must be made available to the community college. The creation of the partnership must address processes for sharing data that protect student privacy and adhere to FERPA guidelines.

Students also benefit from changes under AB 288 designed to increase the access of high school students to dual enrollment. Under a CCAP agreement, special part-time students may enroll in up to 15 units per semester, but not more than 4 classes. This is an increase from the 11 units allowed under traditional dual enrollment. CCAP students are given Tier 3 enrollment priority, the same as Middle College students. This allows them to enroll for classes earlier and ensure availability, although this is less of an issue when courses are closed to the public, which is allowable under AB 288. Courses offered to students must be included under the CCAP agreement and part of an academic program that is designed to meet the requirements of both the high school program and a community college associates or certificate. This is important in terms of career readiness. Dual enrollment students have ended up taking college courses that do not advance them academically because they were not part of a pathway. This is a challenge 
to educational entities entering into these partnerships. Before a single section of dual enrollment can be offered under a CCAP agreement, it must be clearly laid out as part of a strategic plan that moves students closer both the high school graduation and to a community college degree or certificate. It must be part of an intentional pathway.

If fees are assessed on students in dual enrollment courses, this creates a barrier to students who cannot afford them. AB 288 changes how student fees are assessed. While historically dual enrollment students could be exempted from fees, this was not required. Under CCAP agreements, students must be exempted from any fees prohibited by California Ed Code (EDC) 49011. EDC 94011 states that students may not be required to pay a fee for participation in any educational activity, including all supplies, materials, and equipment. Community college district governing boards must exempt special parttime students from fee requirements. This includes requiring that nonresident special part-time admit students must be exempt from part or all of the community college's nonresident fees, as outlined under EDC 76140. This section of the educational code provides the ability to create exemptions in part of full may be made for nonresidents who enroll in six or fewer units or if there is financial need. This part of the educational code also requires exemption from fees for special subsets of students who have parents who have been deported and meet a set of requirements. This same section outlines that apportionment may not be claimed for non-residents. In February of 2016, the year following the introduction of $\mathrm{AB} 288, \mathrm{AB} 2364$ was enacted, also by Holden. It requires that a community college district to exempt special part-time students, other than a 
nonimmigrant alien, as defined, from fees for dual enrollment programs. This bill constitutes a state-mandated local program because it requires community college districts to determine whether students qualify for exemption from nonresident tuition. This part of AB 288 legislation is critical to access. This opportunity cannot be denied to students by charging them fees that they cannot pay.

\section{Administration \& funding.}

Unlike traditional dual enrollment, that was focused on providing academic and scholastic training for students who were prepared to take on college level work, the purpose and goals of CCAP agreements are focused on expanding the populations reached, focusing on students who are under-represented or not college bound. High schools and community colleges may be offering both traditional dual enrollment courses and courses under a CCAP agreement. Only courses specifically listed in the CCAP agreement are subject to the limitations and benefits of the CCAP agreement.

Agreements must focus on creating pathways that are focused on at least one of the following: CTE or transfer preparation, improved graduation rates, increased college and career readiness. This works in conjunction with the student eligibility requirements created within each partnership. The challenge becomes the lack of clear or consistent policies to establish student eligibility to pursue college-level work (Kim \& Bragg, 2008). It is important that both sides evaluate existing programs to see where synergy and the beginnings of pathways already exist. 
Agreements are between districts and, as an accountability measure, an employer of record must be identified for reporting purposes. Further, the school district cannot enter into a CCAP agreement with a community college in another district unless an agreement approving the partnership outside the district exists with their partner community college. This may be the case where a neighboring district has a program that is clearly linked to a high school program, one which the shared district does not offer.

Where traditional dual enrollment agreements contain standard district contract terms, CCAP agreements must include projections of FTES to be claimed, the scope, nature, time, and location, and listing of courses to be offered, assessment criteria, and a point of contact at both the community college and the school district. These requirements provide a minimum list that should reflect a well-thought out dual enrollment plan. In addition, there must be clarity about how the agreement will be amended as changes in the course offerings or the logistics on either side shift. Another part that provides a significant challenge is around the assessment of students. CCAP agreements must include "criteria to assess the ability of pupils to benefit from [the listed dual enrollment] courses" (Holden, 2017). This wording is very generic. It is important to explicitly document how students are being assessed for participation. This is an area which can intentionally or unintentionally undermine supporting of under-represented student populations.

CCAP agreements must be approved twice. Further, the agreement must be filed with the California Community College Chancellor's Office (CCCCO) and can be voided 
if it does not comply with Ed Code 76004. Once the agreement is created, the high school and community college districts are both required to present the CCAP agreement at a public board meeting twice, first as an informational item and then for comment and for a vote. In most cases, each partner only has board meetings once a month. It is important to create a timeline to project when the agreement will be ready, to ensure that this part of the process doesn't impede offering CCAP dual enrollment courses.

These administrative differences are designed to be accountability measures. This requires coordination across two districts, the high school and the community college. While maintaining student privacy under both State and Federal policy guidelines, both organizations must create protocols for sharing data. This creates both benefits and challenges. On the positive side, there is an opportunity to create standards that will guide dual enrollment relationships, creating consistency and standards. That being said, working across organization can be a challenge. When undertaking a CCAP agreement, it is essential to get a strong team together, representing the interests at all levels on both sides of the equation. This ensures that the stakeholders are clear on what is required and why it is important.

An issue that both sides will be very interested in is who bears the costs and the apportionment for the students in dual enrollment courses. Dual enrollment courses cannot claim average daily attendance and FTEs for the same instructional minutes (McCaskill, 2015). This comes in as an important clarification because historically dual enrollment has been offered outside the school day. Per Education Code Section 46146(b 
and c), a lower average daily attendance (ADA) of 180 minutes is allowable for dual enrollment students, generating a maximum $3 / 4$ of an ADA (McCaskill, 2015). Under this scenario, it is important that the partners be clear on who is seeking reimbursement and to ensure that both are not receiving payment (in the form of FTES for the community college or ADA for the high school). CCAP agreements must list the number of FTES a college will claim. In addition, on the community college side, CCAP FTES cannot exceed $10 \%$ of the total FTES at a community college. It is important to take all of these things into consideration and to be clear about who is claiming apportionment for students enrolled in dual enrollment courses.

\section{Instructor.}

Instructors must meet the minimum qualifications for the community college when teaching either traditional or $\mathrm{AB} 288$ dual enrollment. The reverse is also true. If a college instructor is teaching a dual enrollment course, they must meet the certification requirements for the high school. Meeting minimum qualifications does not address an issue that has been raised in research: faculty may not be qualified to teach at the college level (in the case of high school teachers teaching dual enrollment) or, alternatively, have experience teaching younger student (when community college instructors teach dual enrollment) (Kim, Barnett, \& Bragg, 2003). This concern is left to dual enrollment implementors. In terms of staffing, this is a challenge, because our systems are not in alignment in terms of qualification. One possible workaround to this is a co-teaching model, with a high school teacher as the teacher of record for the high school section and 
a community also college instructor as the teacher of record for the section at the community college. $\mathrm{AB} 288$ expands the requirement on instructor qualifications to include the certification that an instructor has not been convicted of any sex offense or controlled substance offense. When working with student who are minors, this is a protection to answer some of the concerns raised by advocates for these students.

When dual enrollment courses are taught by high school instructors who meet the minimum qualifications, it essential that they teach the course with the same depth, rigor, and level of assessment that is required in a college class. Under traditional dual enrollment, if the dual enrollment course is not being taught by a community college instructor, there must be an agreement that gives the college primary right of instruction and attendance. This is important because these courses are college courses, are part of degree and certificate programs that are approved locally by faculty, and in the case of CTE courses are created based on a labor market justification done by the college. The college is required to provide training the same supports, in the form of training, orientation, and materials that it would to regular instructors.

$\mathrm{AB} 288$ requires that no teachers at the high school or the community college be displaced by the creation of dual enrollment class. This means that the creation of $A B$ 288 classes cannot result in the termination of instructors who teach the same courses at either site. This proactively attempts to address the concerns of the unions which represent both the high school teachers and the community college faculty. Unions on 
both sides have raised concern about dual enrollment. Entering into conversation early and often with representatives in both unions must be part of the agreement planning.

\section{Course.}

Two critical questions when looking at dual enrollment courses are what is being taught and who is being taught. In terms of what is being taught, when implementing dual enrollment for both traditional and dual enrollment courses under a CCAP agreement, course content and rigor must be consistent across all sites. There must procedures in place to ensure that all students are held to the same academic standard. The instructors are responsible for this, but the community college must commit to an assessment plan to evaluate the courses, particularly in the early days of the partnership.

In terms of who is being taught, $\mathrm{AB} 288$ allows sections of dual enrollment to be open only to high school students in schools under the CCAP agreement, a change from traditional dual enrollment, which required that the dual enrollment courses be fully publicized and open to all college students, even if offered on the high school campus. This provision is only in effect for classes under a CCAP agreement, not any traditional dual enrollment courses offered at the school. This allows more flexibility in the scheduling of classes within course hours, allows them to be offered during times when the campus is closed, and removes the concern about having non-high school students in the classroom. Anecdotally, with traditional dual enrollment classes, when adults were offered a section that was not at the high school and not populated with primarily high school students, they were in most cases happy to shift to a new section. 
The courses offered under a CCAP agreement cannot include courses that are wait-listed or oversubscribed. CCAP courses must not reduce access to the same course for adult students at the community college. There must be a process in place for monitoring this. Since many of these pathways are high-wage, high-demand, it is possible that this would be an issue. $\mathrm{AB} 2781$ has been introduced, but not yet approved, to clarify that only oversubscribed courses are subject to certification, which seems to be focused at removing the administrative impact of this part of the legislation. In addition, unless part of a specified pathway, physical education courses are explicitly excluded from eligible CCAP offerings. This is in reaction to past abuses, where high school football teams were provided with college credit through an inappropriate use of dual enrollment (Maitre, 2015; California Community Colleges Chancellor's Office, 2017).

\section{Purpose of the Study}

The purpose of this study is to evaluate the how CCAP partnerships are pursued and implemented to meet the intention of the legislation to increase access of underrepresented student populations to higher education and to support students who are not college bound in completing high school and entering college.

\section{Research Questions}

The research questions that guided this study are:

How are the legislative goals of AB 288 dual enrollment understood and externalized by the policy adopters, administrators, and supporters of dual enrollment in high schools and community colleges? What impact do these differences in understanding and externalizations have on the CCAP dual enrollment programs created? 


\section{Conceptual \& Theoretical Frameworks}

Van Meter and Van Horn (1975) provide a conceptual framework to inform the understanding of the correspondence between created policy and implementation and outcome, allowing for distinct analysis of policy and performance as two separate categories. This framework is useful in this study because it allows for evaluation of the policy, as well as the environment in which it is implemented. The framework provides the opportunity to look at policy typology based on how much change is required from the organizations current activities (major to minor) and how much consensus exists (low to high) within a policy implementation initiative, creating four categories of policy: major change/high consensus, major change/low consensus, minor change/low consensus, minor change/high consensus, with minor change/high consensus and major change/low consensus characterizing a majority of initiatives (Van Meter \& Van Horn, 1975). Understanding these categories is important, because conflict due to low consensus can lead to implementation failure and, although high consensus may lead to implementation success, the overall impact will be low in for initiatives designed to create minor change. These two aspects are forces that directly impact the effectiveness of an implementation.

In this study, the degree of change undertaken by sites, in the form of the scope of the dual enrollment program under a CCAP agreement, will be evaluated. Interview questions will explore the level of consensus between key participants at the community college and the high school. These two forces will create the context through which the potential change may be understood. In site identification, I will be looking for high 
consensus/major change instances because these have the greatest likelihood of being high impact (Van Meter \& Van Horn, 1975). While the authors indicate that policies fall into these categories, given the broad amount of discretion allowed for in $A B 288$ implementations, I assert that the policy and the implementation initiative together, understood through the tenants of street level bureaucracy, create the entity which will fall into one of these categories. The attitudes of those externaiizing the policy through administration leadership, implementation, and delivery, determine the level of organizational change that is being undertaken and the amount of consensus. The position of each case on the two continuums of consensus and the amount of organizational change will be established within the interviews, site profiles, and document review. The amount of organizational change that is undertaken will hinge upon their understanding of traditional dual enrollment and their perceptions about the amount of change AB 288 introduces.

Van Meter and Van Horn (1975) further describe policy-implementation process as encompassing a set of variables that inform the connection between policy and performance (Error! Reference source not found.), which are:

1. The standards, objectives and resources outlined in a policy;

2. The economic, social, and political conditions in which the implementation is taking place;

3. The characteristics of the implementing agency or agencies and the communication and enforcement activities undertaken by these agencies; 
4. The disposition of implementors.

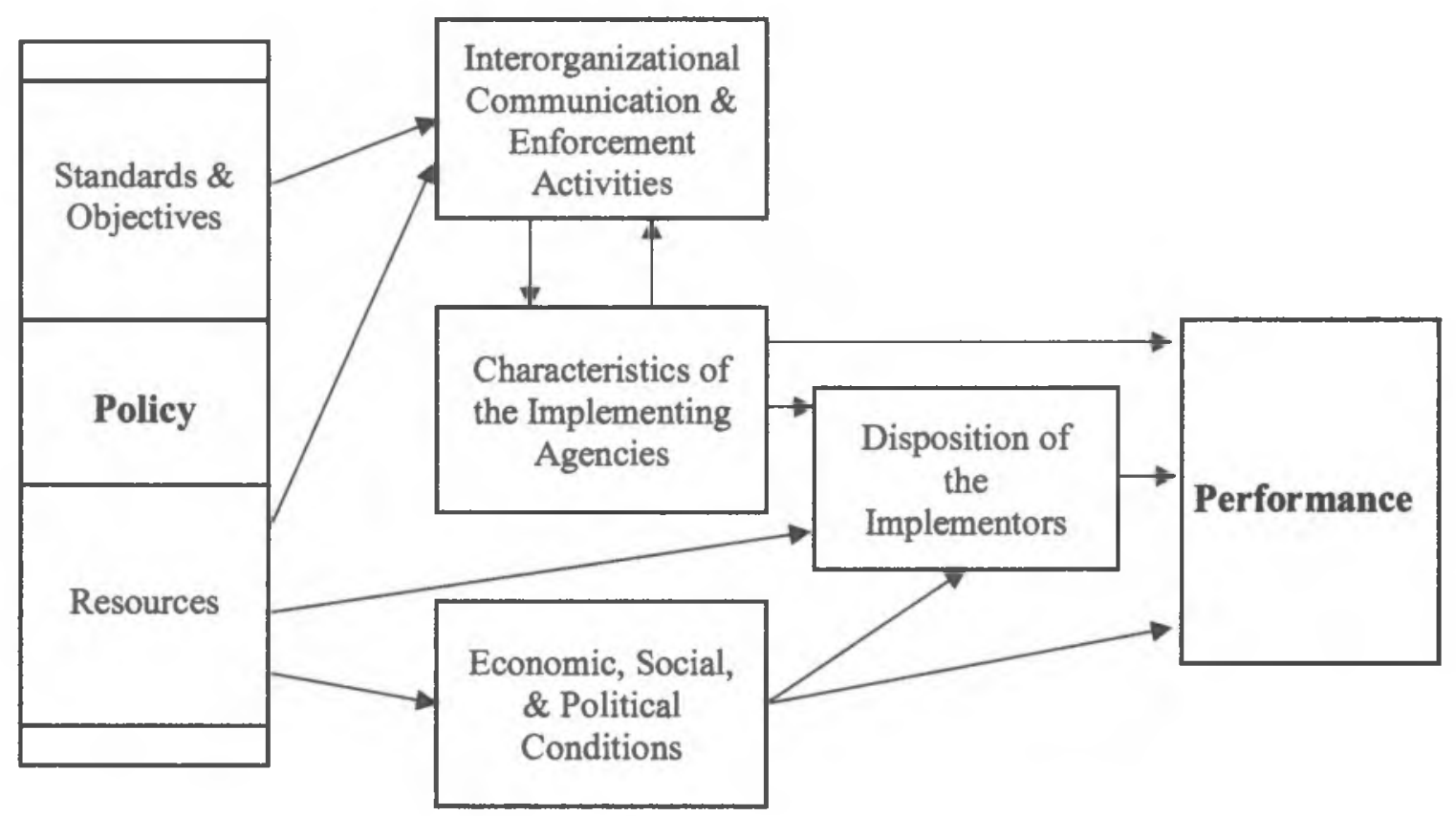

Figure 1 Policy-Implementation Process (Van Meter \& Van Horn, 1975, p. 463)

For the purpose of this study, this conceptual framework informs the approach to interviews, the collection of other data, and to the development of case study profiles. Communication and enforcement activities and the disposition of the implementors will be captured through interviews. Case study profiles will capture the characteristics of the agencies (in this case the high schools and community colleges), as well as the economic, social, and political conditions of the region and the organizations. Performance data will also be collected and analyzed for each case study.

The disposition of implementors who are interacting with dual enrollment students will be understood through the lenses of bottom-up theory of policy implementation and street-level bureaucracy. The theory of bottom-up policy 
implementation focuses on the discretionary power of bureaucrats to shape the impact of policy. In conjunction with top-down implementation theory which focuses on the policy itself as the fundamental driver of change, these theories expand the understanding of the policy in practice.

Street-Level Bureaucracy: Dilemmas of the Individual in Public Service by Michael Lipsky is a seminal work on policy implementation and bureaucratic power. It presents a theoretical framework for understanding how policy is created through the actions of street-level bureaucrats. Street-level bureaucrats are people who work directly with and provide direct services to the public and have discretion in exercising authority (Lipsky, 2010). In this study, these are the program coordinators for dual enrollment programs, the counselors who identify students for the program, and teachers, in cases where teachers have responsibility for identifying potential students or marketing the program. Because of limitations in the bureaucratic work structure, it is not possible to do the job of a street-level bureaucrat according to ideal conceptions, a limitation which leads to coping measures. These measures may be acceptable compromises between the goal of enacted policy and the needs of street-level workers, or it may widen the gap between policy as written and policy in practice. Lipsky suggests that the public service sector induces people to accept the system, including the neglect or inadequacy of social and economic institutions. Echoing Anyon (2011), he says that schools have the role of "socializing the population to the economic order and the likely opportunities for different strata of the population" (Lipsky, 2010, p. 11). 
Street level bureaucracy provides a framework for understanding how counselors and teachers for dual enrollment see the policy and contextualize the tensions between these street-level bureaucrats and their administrators. Street level bureaucracy thrives when mandates are unfunded or under-funded. Both high schools and community colleges must determine how to fund CCAP agreements, strengthening the argument for street-level bureaucracy as a theoretical framework. Further, street-level bureaucrats are intrinsically in conflict with managers and have a relationship of mutual dependence, moderated by incentives and sanctions. Lipsky provides a framework upon which to evaluate the implementation of $\mathrm{AB} 288$ legislation, providing tools to understand the tensions between administrators and implementors which influence how the stated goals of the bill are put into practice. This is supported by the work of Maynard-Moody \& Musheno (2003), who set as their task identifying the decision making that come from the interactions of law, belief, identities, and behavior in street level work. They do these through the construction of two distinct narratives: state-agent and citizen-agent. State agent focuses on adherence to laws, while citizen-agent focuses on normative or cultural abidance in the action of identifying who is worth of service and who is not (MaynardMoody \& Musheno, 2003). These two often-competing narratives inform our understanding of policy implementation and the specific actions of the front-line streetlevel bureaucrats in the case studies.

Lipsky also proposes a vision of the future for street-level bureaucrats, saying that agencies must know what they want workers to do and how to measure worker 
performance, be able to compare workers to one another to establish standards for judgement and have incentives and sanctions capable of disciplining workers. He highlights the need to utilize an enhanced understanding of the motivations and reality of street-level bureaucrats to create the accountability measures and limitations on autonomy and discretion that open the door for unequal application of policy. This is a call to action for $\mathrm{AB} 288$ implementers to create a program evaluation plan that intentionally measures and incents the fulfillment of this legislations promise. These lenses will be applied based on the role of the person being interviewed. Top-down implementation theory illuminates the motivations and actions of those who are responsible for the initiation, approval, or development of a CCAP agreement and the creation of the resulting dual enrollment program.by. Bottom-up theory in the form of street level bureaucracy, will inform the evaluation of the implementation piece, providing a way of looking at the motivations and actions of the implementors of dual enrollment. Street level bureaucrats are defined as those who have daily interactions with participants in dual enrollment programs and control those students' access to the program, so street level bureaucracy (SLB) will inform the understanding of the motivations and actions of these roles ( 
Table 1). 
Table 1 Theoretical Framework by Role

\begin{tabular}{|c|c|c|}
\hline \multicolumn{2}{|c|}{ Top-Down Implementation Theory } & $\begin{array}{c}\text { Street Level Bureaucracy } \\
\text { (SLB) }\end{array}$ \\
\hline Policy Adopters & Administrators & Supporters \\
\hline $\begin{array}{c}\text { Approval, Support } \\
\text { new Initiative }\end{array}$ & $\begin{array}{c}\text { Program Managers, } \\
\text { Coordinators, High School and } \\
\text { Community College Instructors } \\
\text { on the Implementation Team }\end{array}$ & $\begin{array}{c}\text { Counselors, High, School } \\
\text { Instructors responsible for Dual } \\
\text { Enrollment Student Placement }\end{array}$ \\
\hline
\end{tabular}

Key Terms \& Definitions

The following are key terms in the problem or question that are not clear and need to be defined:

a) Access: Access is both the opportunity to competitively apply for college programs and have the skills to enter and complete them successfully.

b) Implementation: "Those actions by public and private individuals (or groups) that are directed at the achievement of objectives set forth in prior policy decisions, [including] both one-time efforts to transform decisions into operational terms, as well as continuing efforts to achieve the large and small changes mandated by policy decisions" (Van Meter \& Van Horn, 1975, p. 447)

c) Under-represented student populations: The preferred term is student populations under-represented in higher education, which does characterize the under-represented status as a characteristic of the student but shifts the onus to the educational entities. This term refers to student populations for which the percentages present in higher education are lower than the percentages in the general population. This could also be considered in terms of student populations in given fields (e.g.) STEM. Given that many dual enrollment programs align with pathway programs in the high schools, the 
under-representation could also be in certain career fields. In Caiifornia, this could be Black, Latinx, or based on income status or gender. Each dual enrollment program must define what under-representation means and it may vary for pathways within each dual enrollment program.

d) Dual Credit: Courses which provide high school students with the opportunity to receive both transcripted high school and college credit immediately upon completion of the class.

e) Dual enrollment: Programs that allow students to take both high school and college courses at the same time.

f) Pathway: A series of courses that lead to an educational goal, including high school graduation or community college certificate, degree, or preparation for transfer.

g) Career Technical Education (CTE) Pathway: A sequence of courses in a high school leading to defined career or career area course sequences, including a combination of introductory, concentrator, and capstone courses.

\section{Statement of Delimitations and Scope of Study}

This study evaluates the decisions made by AB 288 policy adopters, dual enrollment administrators, and dual enrollment supporters in the context of their beliefs and understandings to evaluate the resulting CCAP dual enrollment initiatives in terms of meeting the intended goals of AB 288 legislation. This study evaluates the program characteristics and implementor attitudes through interviews and review of externalized program artifacts. This study focuses on decision-makers and program creators in the high school and community college districts. Outside of the scope of this study, although 
important factors in the evaluation of CCAP dual enrollment programs, are the beliefs and practices of dual enrollment instructors and the beliefs and experiences of dual enrollment students.

\section{Justification \& Significance of the Study}

The stated intent of $\mathrm{AB} 288$ legislation creates momentum away from the historical application of dual enrollment as an accelerator for high achieving students who are typically white, of high socio-economic status, and who are not first-generation college students. This legislation is focused on improving access for under-represented student populations and for students who were not previously college bound. Ensuring that access is always included as a central part of the discussion of $\mathrm{AB} 288$ dual enrollment programs is essential if this legislation is to be an equity tool.

An important part of leadership is identifying important legislation and figuring out how to translate that into practice. The critical evaluation of the intent and implementation of the legislation will determine how intention and evaluation of the policy at both the administration and implementation levels guide actions which impact the outcomes for $\mathrm{AB} 288$ programs. Further, highlighting the process through which these programs are created is essential. Having been a project manager for system implementations, I have observed that a disconnect between leadership and the people on the ground are often a key component of project failure. Often the understanding and motivations of leaders are not coordinated with the reality of the implementors and students who are central in the day-to-day reality. Either the programs designed do not have sufficient accountability or it undermines or is in conflict with the day to day 
motivations, requirements and practices of the users. The process of reviewing how these programs are created and rolled out, who is in the conversation, and what information is provided, as well as how success is defined and measured is critical to ensuring high quality programs which meet the stated goals of the legislation.

Programs may be created through a partnership agreement between the high school and community college or may be individual high school students registering for college classes. Classes created through partnership agreements may take many forms, including being taught by a high school or a community college instructor, being located at either the high school or the community college, and include both career education and academic courses. Dual enrollment courses may be dual credit. In the case off CCAP partnerships, dual enrollment courses are designed as dual credit courses. Throughout the literature, the receipt of college credit, rather than the form of the course, has been the focus of research.

\section{Conclusion}

As dual enrollment moves from focusing on high performing students to providing increased access for under-represented student populations and for students who were not previously college-bound, the understanding and decisions of implementors of dual enrollment create a manifestation of the policy in the form of CCAP dual enrollment programs. Based on a review of literature, the understanding of this initiative will be informed by historical dual enrollment research, research on the development of K-14 pathways and educational access, and implementation theory. 


\section{Chapter Two: Literature Review}

\section{Introduction}

In $\mathrm{AB} 288$, legisiators identify dual enrollment as having the potential to address issues of access in postsecondary education by supporting the development of social and navigational capital for students, and thus improving academic outcomes: "Research has shown that dual enrollment can be an effective means of improving the educational outcomes for a broad range of students" (Holden, 2017, p. 1). According to Vincent Stewart (2019), who authored $A B 288$, the primary piece of research that informed this research came out of the James Irvine Foundation's Concurrent Courses Initiative, which outlined its findings in the report entitled "Broadening the Benefits of Dual Enrollment: Reaching Underachieving and Underrepresented Students with Career Focused Programs" (Hughes, Rodriquez, Edwards, \& Belfield, 2012). This report, unlike previous research on dual enrollment which focused on high achieving students, considered the impact of dual enrollment on a broader range of students.

To critically evaluate the implementation of $\mathrm{AB} 288$ dual enrollment, it is important to first understand the literature around the impact of traditional dual enrollment which served as an impetus. Research has evaluated the impact of traditional dual enrollment participation on both high school and college outcomes. Research on dual enrollment does not typically control for self-selection bias. Recently, propensity score matching has been adopted by some researchers to account for self-selection bias (Giani, Alexander, \& Reyes, 2014; Taylor, 2015; Grubb, Scott, \& Good, 2017). The studies do not differentiate based on program characteristics which can vary widely. For 
example, these dual enrollment studies do not generally differentiate between the insertion of a college instructor into the high school classroom or high school students attending courses at the community college. The focus is on the completion of collegelevel work and the earning of college credit.

The experience of college level material and rigor and participation in a program that connects them to a college program improves academic outcomes for high school students by helping them to develop navigational capital, giving them experience about what is required of them as college students, and helping them to develop both the academic and social skills required in college. These skills are examples of navigational capital or the skills needed to navigate through social institutions, including educational institutions (Yosso, 2005). In addition, as students develop relationships with their peers and with college instructors, they also develop social capital, defined by Tara J. Yosso (2005) as the networks of people and resources required to allow success in college.

Further, evidence suggests that the benefits of dual enrollment participation continue to accrue as students enter college. In general, dual enrollment students demonstrate higher GPAs, lower need for remediation, and increased progress and course load during the initial phase of college, referred to as momentum, leading to higher rates of college persistence and completion. Finally, dual enrollment increases these impacts for Latinx students, including first generation college students.

\section{Impact of Dual Enrollment in High School}

Traditional dual enrollment (DE) has been found to improve high school students' college readiness, reducing the need for remediation. Dual enrollment offers 
opportunities for success for high school students, providing access to challenging college level work, motivating students and helping them to build the skills necessary to succeed in college. In a mixed method study, Kanny (2015) evaluates the experiences of students in a small predominantly Latino charter high school situated in a low-income urban setting. Several benefits emerged based on interviews with 5 dual enrollment students. Benefits of dual enrollment for these students included exposure to a college academic environment that led to a better understanding of college academics and greater self-confidence about their ability to succeed in college. The authors also reported that students learned the hidden curriculum required for academic success in college, like study skills and the ability to communicate effectively with other students and instructors (Kanny, 2015).

An and Taylor (2015) expanded the understanding of the potential benefits of dual enrollment in developing student's academic and social capabilities, looking at students in their first year of college, who had participated in dual enrollment in high school. The longitudinal study used a large national dataset from twenty-four institutions across the United States to evaluate students across four dimensions: academic content knowledge in core areas; cognitive strategies, such as problem formulation, research, interpretation, communication, and verification; learning skills and techniques, including goal setting. motivation, self-efficacy, time management and study skills, and collaborative learning; and transition knowledge, including skills about how colleges operate and how to navigate the system. These skills are forms of capital that have historically not been 
available to all students (Bourdieu, 1977; Yosso, 2005). Both dual enrollment and AP students showed a similar level of college readiness when compared with the nonaccelerators, scoring 0.07 to 0.08 standard deviations higher respectively on all measures except the transition knowledge and skills dimension (An \& Taylor, 2015). In this study, under-represented student populations, characterized as a non-white/non-Asian binary, made up $13 \%$ of the dual enrollment population and $14 \%$ of the non-accelerator (no AP or dual enrollment) population, but only $8 \%$ of the exam-based AP population. Looking at the education of the parents of students in the study, students with parents who had not graduated college made up $13 \%$ of the AP population, $18 \%$ of the dual enrollment population and $23 \%$ of the non-accelerator population (An \& Taylor, 2015). While a modest improvement, this is another potential benefit when considering the overall impact of dual enrollment.

The inclusion of both Advanced Placement (AP) and dual enrollment data illuminates the potential of dual enrollment for students who do not have access to AP offerings. Dual enrollment students show improved college readiness similar to AP students, while demographically more closely matching the students not earning college credit in terms of race, socio-economic status, and parental education. These statistics indicate better access to dual enrollment than AP by both first generation and students in under-represented populations. Dual enrollment may provide access to college credit for students who are not represented in the AP classrooms. Second, the DE group performed better on three of the four college readiness factors, suggesting that it is a vehicle to 
improve college readiness for students that do not have access to AP classes (An \& Taylor, 2015). These two findings combine to suggest that $\mathrm{DE}$ provides access to college credit and to skills which will help students succeed in college, making dual enrollment a possible tool for improved equity for Latinx and first-generation student populations, disrupting the normal pathways and creating new, more accessible ones for these students.

Looking specifically at college readiness elements, research has found that dual enrollment improves (a) academic preparation (Cowan \& Goldhaber, 2015), (b) increases college knowledge (An \& Taylor, 2015), (c) improves graduation rates (Ganzert, 2014), and (d) increases high school success, defined by higher GPA and graduation rates. Cowan and Goldhaber (2015) identified a positive impact on GPA for high school students, finding that students participating in dual enrollment had an average tenth grade GPA (3.23) nearly 0.5 points higher than the state average (2.86). This may be attributed to improved academic skills, like time management and studiy skills, developed by dual enrollment students. In addition, studies have found an $11 \%$ increase in high school graduation rates for dual-enrollment students, in a causal-comparative study (Ganzert, 2014). These studies were not randomized controlled trials, so self-selection bias may have been a factor.

While offering many benefits, participation in dual enrollment is not without challenges for high school students. Negative aspects of dual enrollment for high school students include misalignment with high school graduation requirements, limited 
availability of support systems and monitoring of academic progress at both the high school and the community college, and negative interactions with college faculty who were biased against having high school students, leading to a sense of isolation (Kanny, 2015). Students interviewed by Kanny (2015) also reported lower grades in DE courses than in their standard high school courses, impacting their overall high school GPA, in contrast to the findings by Cowan and Goldhaber (2015). Kanny's study exposes a list of strengths and weaknesses that can inform and improve processes and policies when implementing dual enrollment programs by minimizing the challenges and expanding the opportunity for success. These experiences highlight the need for a strong partnership supported by both the high school and the community college systems, characterized by a strong advising process at the high school, and communication across the systems. A strong dual enrollment program must provide students not just with academic advising, which is critical, but also with support in navigating the unfamiliar community college system, assisting them in developing the cultural capital necessary to navigate college.

\section{Impact of Dual Enrollment in College}

Traditional dual enrollment students have also been found to be more likely to enroll in college. Once students graduate from high school and enroll in college, they continue to benefit from the social, navigational, and academic skills developed through participation in dual enrollment. A longitudinal study using a large data set found that $91 \%$ of dual enrollment students enrolled in college, compared with $63 \%$ of non-dual enrollment students, using propensity score matching to reduce selection bias (Taylor, 2015). Academic preparation and achievement, demographics, extracurricular activities, 
and academic and career aspirations were tracked through twenty-six independent variables used to create a propensity score (Taylor, 2015). Low socio-economic status (low-SES) dual credit students were 30\% more likely to enroll in college than equivalent non-dual enrollment students (Taylor, 2015). Students of color were $26 \%$ more likely to enroll in college and $14 \%$ were more likely to complete college than non-participants in dual enrollment (Taylor, 2015).

Dual enrollment students gain academic momentum from the credits earned, they have lower rates of remediation, and higher college GPAs and graduation rates than their non-DE counterparts. Participation in dual enrollment creates academic momentum for under-represented student groups, positively impacting persistence, and completion. Academic momentum, or the speed at which students proceed through college, is a positive factor in degree completion and is increased by participation in dual enrollment (Davidson, 2015; An, 2012; An, 2013; Wang, Chan, Phelps, \& Washbon, 2015). Dual enrollment students earn college credits while still in high school. This improves the likelihood of persistence and completion once students reach college and lowers the cost of degree completion.

Dual enrollment students show higher rates of enrollment and completion. Using propensity score matching, Taylor (2015) found that $92 \%$ of dual enrollment students of color enrolled in college and $43 \%$ completed college, whereas only $66 \%$ of non-dual enrollment students of color enrolled in college and $29 \%$ completed college. In this study, he controlled for demographic variables and academic history and performance variables. 
Similarly, Grubb, Scott, \& Good (2017) found a positive impact on community college students who participated in dual enrollment for reduction in remediation and improvement in time to graduation. Of the 1,232 students, the 246 who participated in dual enrollment were $9 \%$ or nearly 3.4 times less likely to take remediation, $26 \%$ or nearly two and a half times more likely to graduate in two years, and $28 \%$ or nearly one and a half times more likely to graduate in three years (Grubb, Scott, \& Good, 2017).

Persistence in college is a second issue impacted by dual enrollment. In a study focused on community college students, Wang et al. (2015) controlling for race, gender and participation in student support programs, and exploring the dual enrollment history and course-taking and remediation that occurred prior to enrollment in their postsecondary program, found that students who had participated in dual enrollment during high school entered post-secondary education without delay, attempted more credits, enrolled in summer sessions, and achieved a higher first-year GPA related to higher retention and completion (Wang et al., 2015). This study provides further evidence that the momentum created by dual enrollment and the college credits earned through this process contribute to future academic success for students.

Students who participate in dual enrollment are academically stronger, evidenced by higher college GPAs. Higher academic achievement may be attributable in part to the academic rigor these programs offer to students during high school. Improved college GPA was supported by a study done in North Carolina which found that first-year dualenrolled students had a first-year GPA of 2.178 , compared to 1.632 for students who had 
not been dual enrolled (Ganzert, 2014). In this study, data from 15,527 graduates in the class of $2003,7 \%$ of whom participated in dual enrollment, were evaluated as a straight comparison, and filtered by technical and medical programs (Ganzert, 2014). Only involvement in dual enrollment was tracked, not high school GPA, which is a limitation of the study. Dual enrollment also improves academic preparedness of low-SES students, measured by college higher GPA. Using transcript data from the Beginning Postsecondary Students Longitudinal Study, the researchers looked at the relationship of dual enrollment and college GPA, estimating the impact of participating in dual enrollment on first-year GPA (An, 2012). After controlling student demographic variables, in addition to finding a positive impact in terms of improved GPA and reduced remediation on all students, the GPA of dual of dual enrollees was .11 points higher than non-dual enrollees (An, 2012), showing a beneficial impact of these programs on lowSES students and indicating that DE is a promising part of a cohesive plan to support low-SES students.

Academic momentum and higher GPAs lead to better college completion rates. Davidson (2015) found that first-time, full-time degree seeking undergraduates in Kentucky who earned 30 credits hours by the end of the first year were three times more likely to complete an associate degree or transfer. Higher completion rates could be for one of several reasons: the cost of education is reduced because students need to complete fewer credits; lower remediation rates also reduce the cost of degree completion and improved academic and navigational skills decrease the likelihood of needing to 
retake courses. In an Illinois-based study, dual enrollment students had higher enrollment and completion rates than their non-dual enrollment peers: fifty-two percent of dual enrollment students completed college, compared with $29 \%$ of non-dual enrollees (Taylor, 2015). This study further found that low-income dual credit students were $30 \%$ more likely to enroll in college and $16 \%$ more likely to complete college than equivalent non-dual enrollment students, identified through propensity score matching (Taylor, 2015). Similarly, Morrison (2008) found students participating in dual enrollment were $61 \%$ more likely to graduate. Ganzert (2014) looked specifically at two career pathways, finding the completion of dual enrollment credits supported the successful completion of these technical pathways, with $67.8 \%$ of medical pathway students with dual enrollment credits graduating, compared to only $51.9 \%$ of students who did not earn early college credit, suggesting that career pathways and dual enrollment have synergy which improved student outcomes.

Dual enrollment also has a positive relationship to degree completion for low-SES students. An (2013) also reported improved graduation rates for first-generation dual enrollment students, finding that first generation college students who participate in dual enrollment are $8 \%$ more likely to obtain a post-secondary degree and $7 \%$ more likely to obtain a bachelor's degree.

Poor academic preparation has been found to have the largest negative impact on degree completion, a larger impact than under-representation: low-income were $62 \%$ less likely to earn an associate degree or transfer, while students who were underprepared 
were $151 \%$ less likely (Davidson, 2015). Dual enrollment reduces the need for remediation, which indicates a higher level of academic preparation. An (2012) finds a $6 \%$ reduction in remediation for dual enrollment participants. Community college students who had participated in dual enrollment were $9 \%$ or nearly 3.4 times less likely to need remediation (Grubb, Scott, \& Good, 2017). This reduced need for remediation, had a discernable impact on completion rates: $26 \%$ or nearly 2.5 times more likely to graduate in two years, and $28 \%$ or nearly 1.5 times more likely to graduate in 3 years (Grubb, Scott, \& Good, 2017).

Remediation is correlated with lower completion rates, so reductions in remediation have positive effects on completion. These findings support the use of dual enrollment as a potential remediation tool, as is proposed in $\mathrm{AB} 288$, but do not evaluate the academic supports and instructors provided as part of the dual enrollment programs (See .

Table 2 for overview of dual enrollment benefits). 
Table 2 Dual Enrollment Benefits

\begin{tabular}{|c|c|}
\hline \multicolumn{2}{|c|}{ Navigation } \\
\hline & $\begin{array}{l}\text { Exposure to the college environment, learning the hidden curriculum } \\
\text { (required skills for academic success), independence \& freedom (Kanny, } \\
2015 \text { ) } \\
\text { Academic content knowledge in core areas: cognitive strategies; learning } \\
\text { skills and techniques - .07 standard deviations higher than non-accelerators } \\
\text { (An \& Taylor, 2015) }\end{array}$ \\
\hline \multicolumn{2}{|c|}{ Reduced Remediation } \\
\hline & $\begin{array}{l}\text { ual enrollment participants (An, 2012) } \\
\text { es less likely to need remediation (Grubb, }\end{array}$ \\
\hline \multicolumn{2}{|r|}{ 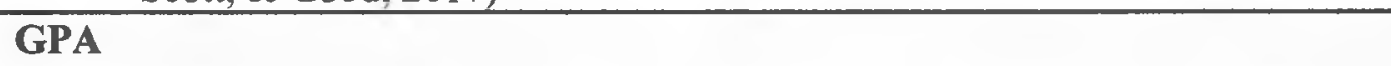 } \\
\hline & $\begin{array}{l}\text { First-year college GPA: } 2.178 \text { for DE compared to } 1.632 \text { non-DE (Ganzert, } \\
\text { 2014) } \\
\text { College GPA of dual of dual enrollees was . } 11 \text { points higher than non-dual } \\
\text { enrollees (An, 2012) } \\
\text { High School 10th Grade GPA } 0.5 \text { points higher (Cowan \& Goldhaber) }\end{array}$ \\
\hline \multicolumn{2}{|c|}{ Enrollment } \\
\hline & $\begin{array}{l}91 \% \text { enrollment in college for DE, compared with } 63 \% \text { enrollment for non- } \\
\text { DE (Taylor, 2015) } \\
\text { Low-SES DE students } 30 \% \text { more likely to enroll in college than equivalent } \\
\text { non-DE (Taylor, 2015) }\end{array}$ \\
\hline \multicolumn{2}{|c|}{ Completion } \\
\hline & $\begin{array}{l}52 \% \text { of dual enrollees vs. } 29 \% \text { of non-dual enrollees completed college \& } \\
\text { low-SES Dual enrollment students } 16 \% \text { more likely to complete college } \\
\text { (Taylor, 2015) } \\
11 \% \text { increase in high school graduation rates (Ganzert, 2015) } \\
\text { DE participants are } 61 \% \text { more likely to graduate than non-DE students } \\
\text { (Morrison, 2007) } \\
\text { Dual enrollment students ( } 33.7 \% \text { ), students with articulation credit (28.3\%) } \\
\text { and non-accelerated students (22.5\%) (Ganzert, 2015) } \\
\text { First generation } 8 \% \text { more likely to obtain a post-secondary degree and } 7 \% \\
\text { more likely to obtain a bachelor's degree (An, 2013) } \\
\text { DE participants } 26 \% \text { or nearly } 2.5 \text { times more likely to graduate in } 2 \text { years, } \\
\text { and } 28 \% \text { or nearly } 1.5 \text { times more likely to graduate in } 3 \text { years (Grubb, } \\
\text { Scott, \& Good, 2017) }\end{array}$ \\
\hline
\end{tabular}


Dual enrollment offers the opportunity to provide positive short, mid-, and longterm effects on students. High school students benefit academically and develop navigational capital that will allow them to successfully enter college. The momentum offered by reduced remediation and earned dual enrollment credit leads to higher persistence and completion rates. These benefits create an opportunity to increase access and support the success of under-represented student populations, including low-SES, students of color and first-generation students, who experience even greater benefits from these programs. Understanding the benefits of dual enrollment, high schools and community colleges should thoughtfully create robust dual enrollment programs to support students and which are equally accessible to all students.

\section{Rigor, Pedagogy, and Student Experience}

Exposure to the college system and the rigor of college-level work is cited as a benefit of dual enrollment (Golann \& Hughes, 2008; Lewis \& Overman, 2008; Karp \& Hughes, 2008; Bailey \& Karp, 2003; Wozniak \& Palmer, 2013). In the high school environment, exposure to high rigor classes happens in a variety of ways, including Advanced Placement (AP) and dual enrollment. Exposure to advanced coursework is a key element in the Every Student Succeeds Act (ESSA), motivating high school leadership to look critically at their offerings in these areas. AP provides exposure to increased rigor, but dual enrollment provides some benefits over AP, as reviewed by Khazem \& Khazem (2014): a higher percentage of students received college credit and a more authentic post-secondary student experience than in AP courses. 
Rigor is often based on the perception of the instructors, as is seen in a study of fifteen instructors at a community college to evaluate perceptions of rigor across three types of courses: individual dual enrollment courses, accelerated courses which were a defined series of dual enrollment courses in a set pathway, and standard community college courses (Ferguson, Baker, \& Burnett, 2015). This study was particularly interesting because it differentiated between individual dual enrollment courses and dual enrollment courses that were part of a defined pathway. Review of syllabi and instructor interviews resulted in several conclusions: the dual enrollment courses were at least as rigorous as standard courses, accelerated pathway students were perceived as having higher academic ability than either dual enrollment or community college students, and the students' level of maturity was perceived to be lower (Ferguson, Baker, \& Burnett, 2015). This lower level of maturity level is cited as a central component in the cultural divide between high school and community college (Tinberg \& Nadeau, 2011). The positive outcomes from dual enrollment do not give insight into the experience of these students in the dual enrollment classroom or the rigor of the courses.

The positive outcomes from dual enrollment do not give insight into the experience of these students in the dual enrollment classroom or the rigor of the courses. Students' post-secondary experience is made up of a combination of factors: the instructor, the pedagogy, and the curriculum in the classroom. In the dual enrollment environment, this relationship becomes more complicated by the impact of course location and the impact of high school expectations on what is included in the curriculum 
(Tinberg \& Nadeau, 2011). Tinberg and Nadeau (2011) explore the difference between high school and college contexts in the context of composition classes. They find that a clear understanding of "the core principles, practices, and outcomes" was an essential ingredient of success in dual enrollment programs (Tinberg \& Nadeau, 2011, p. 710). The pedagogical practices named as typical in a college course in this study and as standards in the realm of composition are centrality of the subject, frequent demonstration of understanding, a process pedagogy that focuses on the creation of a written work, and the use of scholarly sources. They are contrasted with a more formulaic approach in high school (Tinberg \& Nadeau, 2011).

The decision about what form of early college credit to offer is complex. AP courses can be undertaken by a high school without the need to create a partnership with another system with its own rules and motivations, as is required by dual enrollment. In a study that surveyed 411 stakeholders at high schools and community colleges in Michigan, Wozniak and Palmer (2013) find that there is support for expansion of AP by high school administrators, while college administrators supported increased support of dual enrollment and application of increased services for these students. This support is based on retention of programmatic control and funding (Wozniak \& Palmer, 2013). Programmatic control directly impacts the availability of early college credit options for students.

\section{Dual Enrollment and Student Selection}

Few studies of dual enrollment have controlled for self-selection bias, or the possibility that students who choose dual enrollment may be more likely to succeed with 
or without dual enrollment than those who do not enroll in dual enrollment ciasses (An, 2013; An, 2012; Allen \& Dadgar, 2012; Karp, Calcagno, Hughes, Jeong, \& Bailey, 2007). These studies do not look at what characteristics of programs that encourage selfselection, true of many dual enrollment studies which do not include student selection variables (The Center for Student Success; The RP Group; The Academic Senate for California Community Colleges, 2009). While affirming the effect of dual enrollment, these findings also highlight the importance of looking at the impact of dual enrollment through the lens of student characteristics and the student selection process, focusing on access as a goal.

Morrison (2008) evaluated a data set of 9,233 students of which $19.67 \%$ participated in dual enrollment, and controlled specifically for high school GPA, looking at the impact of acceleration on upper, middle, and lower quartile students on college graduation. A positive effect on college graduation was found for students at all GPA levels, who were $61 \%$ more likely to graduate (Morrison, 2008). Interestingly, the effect was strongest on females in the middle quartile of GPA, improving graduation rates by $11.87 \%$, from $44.51 \%$ to $56.38 \%$, and lowest for the lowest quartile males, having a $2.39 \%$ effect, from $6.57 \%$ from $4.18 \%$ (Morrison, 2008 ).

In response to the limited control for self-selection bias, An (2013) included a sensitivity analysis accounting for student, family, schooling achievements, and school context factors, finding that the positive results of dual enrollment are robust and would require a large confounder to undermine them (An, 2013), creating an argument that dual 
enrollment can have a small benefit a wider variety of students than the students who have historically been enrolled. Similarly, Giani, Alexander, \& Reyes (2014), Taylor (2015) and Grubb, Scott, \& Good (2017) used propensity score matching to account for self-selection bias, pairing dual credit students with students who did not select dual credit based on sets of observable characteristics. The potential for bias is not completely removed, because unobserved characteristics, like college aspirations or mindset, are taken into account (Giani, Alexander, \& Reyes, 2014).

Dual enrollment programs differ from other college credit programs like AP because they depend on collaboration between the high school and community college. These partnerships vary widely and no rigorous study of the characteristics of the programs or the supports provided in the dual enrollment context has been done.

\section{Educational Access}

AB 288 seeks to improve access to higher education for student populations which have historically been denied access to and who are under-represented in higher education. Pretlow and Wathington (2014) in a study in Virginia found an increase in dual enrollment in at least one class between 2004 and 2006 for Black and Hispanic students. Black students increased from 1,359 to 1,707 and Hispanic students increased from 32 to 50 . Although presented as a growth, these students, particularly Hispanic students, were significantly under represented, while white students, who also saw a gain, were over-represented (Pretlow \& Wathington, 2014). Since the AB 288 policy was adopted in 2016, no specific research has been done on the impact of this legislation. The question becomes whether the dual enrollment programs are truly being created in a way 
that is accessible for the students they should be seeking to serve. Access literature allows us to critique approaches to improving access and to consider what are the characteristics of promising programs and the limitations that have been found when seeking to provide access. Given the growing Latino population across California, the focus of the access literature has been on Latino educational access.

It is critical to understand what supports access for student populations who have been previously denied access to higher education to inform the evaluation of programs which seek to improve access. A variety of programs have been created over the years to address the issue of access for a variety of student populations and still the disproportionate levels of access persist (Fry, 2002). In a study of what initiatives are being leveraged to reach underserved students, all states reported having dual enrollment and AP programs, forty-five states were found to have policy that supported dual enrollment (Bragg, Kim, \& Barnett, 2006). Forty-five states report leveraging Advanced Placement and twenty-nine report using dual enrollment or dual credit for the purpose of reaching under-served students (Bragg, Kim, \& Barnett, 2006). This study also finds that access to dual enrollment has been dependent on demographic, geographic, and economic variables, being more available in larger schools, in more urban schools, and in schools with underserved student populations (Bragg, Kim, \& Barnett, 2006), indicating that there is still a need for broader application of dual enrollment as a tool for increased access. 
To leverage the possibilities of dual enrollment for a wider set of students, it is essential to understand how students are either encouraged entry into or denied access to dual enrollment courses. This is a complex issue. For example, high school completion rates in California have shown the largest improvements for Latino students (Caifornia Competes: Higher Education for a Strong Economy, 2018). There have also been increases in the number Latino students taking the ACT (Gonzalez, Cavanaugh, Taylor, Stein, \& Mayton, 2017) and higher rates of college enrollments (Krogstad, 2015). While this is a step in the right direction, access is also skewed by income status and whether the student was born in the United States. High school graduates from lower-income groups have a $49 \%$ rate of college entry, compared to $80 \%$ for their higher income counterparts and students born outside the U.S. have higher drop-out rates and lower post-secondary enrollment rates (Gonzalez, Cavanaugh, Taylor, Stein, \& Mayton, 2017). This indicates that it is essential to look at student holistically, focusing on a variety of characteristics and creating supports which will flexibly support a broad range of students.

There are a variety of factors which may impact students' entry into dual enrollment, including how the program is accessed, how the program is marketed, who is teaching in the program, and the attitudes and beliefs of the students themselves. Understanding the historical research informs the understanding of the current legislation, first for all students and then for certain populations of students. Access literature will allow us to evaluate the identified impacts of dual enrollment to understand their role in 
shifting access for identified student populations. High rates of remediation, low rates of student completion are a barrier to access for under-represented student groups, such as Latino students in California. Dual enrollment can be an important part of a larger plan to improve access for students (Collins, Weinbaum, Ramón, \& Vaughan, 2009). Kurlaender and Larsen (2013) identify high rates of remediation, which AB 288 seeks to address, as a sign of mis-alignment of school systems. Separation between the K-12 system and colleges can create a serious barrier to access for Latino students (Oliva, 2004), highlighting the need for the K-14 pathways created through dual enrollment partnerships between high schools and community colleges.

\section{K-14 Pathways}

AB 288 supports the creation of pathways between high schools and community college to create access for under-represented student populations and for students who might not be college bound. An Illinois task force identified these partnerships as the highest priority for dual credit initiatives, because it was foundational for other high priority program development focuses. Focus on States like California with high percentage of higher education enrollments in community colleges, makes them ideal for the adoption of dual enrollment partnerships, allowing community colleges to develop and attract a broader range of students who have proven themselves capable of succeeding in that environment (Mokher \& McLendon, 2009).

Collaborations between secondary and post-secondary institutions can be used to promote college access (Kurlaender \& Larsen, 2013; Núñez \& Oliva, 2009; Collins, Weinbaum, Ramón, \& Vaughan, 2009). AB 288 legislation positions strong partnerships 
between secondary and post-secondary institutions as a way of creating access. In creating these partnerships, it is essential to look critically at the limitations and potentials of these relationships. A study of guided pathways, which is closely related to the dual enrollment initiative because they work in concert to create student pathways, uses the dimensions of program prescription, program alignment, access to information, and student advising and support to understand what characteristic of the program best supported the stated intentions of the program (Van Noy, Trimble, Jenkins, Barnett, \& Wachen, 2016). This study provides support for my approach by using a similar methodology of interviews and website review to understand this program which is closely related to CCAP dual enrollments. This qualitative case study looks at the structure of career technical education programs at a community college along four dimensions: program prescription or the amount of structure in program pathways; program alignment with labor markets and local employers; access to information that support good decision making; and active advising and support for overcoming barriers encountered. These factors are critical to CCAP dual enrollment under AB 288 because the legislation requires structure in the dual enrollment partnership and resulting programs that was not legislated historically for dual enrollment.

In addition, development of pathways between high schools and community colleges and the literature around that will create the context for the support of partnerships pathways as part of $A B 288$ dual enrollment. The bill outlines potential benefits "to both the pupils and the state, such as reducing the number of high school 
dropouts, increasing the number of community college students who transfer and complete a degree, shortening the time to completion of educational goals, and improving the level of preparation of students to successfully complete for-credit, college-level courses" (Holden, 2017). These identified benefits will provide the categories of evaluation around the benefits of dual enrollment in literature. Studies of dual enrollment have in some cases been disaggregated most often by socio-economic status (SES), but also in terms of first-generation college students, to understand how the impact may vary for these populations. This requires an understanding and explanation of college access and the barriers to it.

In the literature, the terms pathway and pipeline are often used. Pitcher and Shahjahan (2017) critique this metaphor, suggesting that it has limitations and consequences when used in policy and practice that are not neutral, and instead conceal social justice problems, dehumanize students, and do not allow for the consideration of radical solutions by focusing only on the accumulation of educational capital. This opens the possibility of challenging the assumed educational process, to identify attitudes and approaches which create opportunity, and gives a wider lens with which to evaluate dual enrollment implementations and the partnerships which are central to them.

\section{Implementation Theory}

A thorough understanding of implementation theory will provide a context for the evaluation of the decision-making and power structures at play in $\mathrm{AB} 288$ implementations. The motivation of the front-line implementors will be understood through a lens of street-level bureaucracy (Lipsky, 2010; Maynard-Moody \& Musheno, 
2003) and bottom-up implementation (Riley \& Brophy-Baermann, 2006; Thomann, van Engen, \& Tummers, 2018). Top-down provides a framework for understanding the intents of policy makers and bottom-up looks critically at the motivations of intents of the implementors and deliverers. The connection between policy and practice and the barriers to implementing dual enrollment must be understood to inform practice.

The theory of bottom-up policy implementation focuses on the discretionary power of bureaucrats to shape the impact of policy. In conjunction with top-down implementation theory, which focuses on the policy itself as the fundamental driver of change, these theories expand the understanding of the policy in practice.

Street-level bureaucracy: Dilemmas of the individual in public service by Michael Lipsky is a seminal work on policy implementation and bureaucratic power. It presents a theoretical framework for understanding how policy is created through the actions of street-level bureaucrats. Street-level bureaucrats are the program coordinators for dual enrollment programs, the counselors who identify students for the program, and teachers, in cases where teachers have responsibility for identifying potential students or marketing the program. Lipsky (2010) highlights that these are people who work directly with and provide direct services to the public and have discretion in exercising authority. Because of limitations in the bureaucratic work structure, it is not possible to do the job of a streetlevel bureaucrat according to ideal conceptions, a limitation which leads to coping measures. These measures may be acceptable compromises between the goal of enacted policy and the needs of street-level workers, or it may widen the gap between policy as 
written and policy in practice. Lipsky suggests that the public service sector induces people to accept the system, including the neglect or inadequacy of social and economic institutions. Echoing Jean Anyon (2011), he says that schools have the role of "socializing the population to the economic order and the likely opportunities for different strata of the population" (Lipsky, 2010, p. 11). Thomann, van Engen, \& Tummers (2018) suggest that a frontline workers commitment to the implementation of a policy are made up of a combination of their perception of their own powerfulness, or ability to make an impact, and their belief the policy is meaningful.

Street level bureaucracy provides a framework for understanding how counselors and teachers for dual enrollment see the policy and contextualize the tensions between these street-level bureaucrats themselves and their administrators. Street level bureaucracy exists in an environment of unfunded or under-funded mandates. Although AB 288 creates the ability for both sides to realize apportionment for their shared students, the policy requires focused administration and support, creating a cost to implementation that is not funded. Under AB 288, CCAP dual enrollment allows both the high schools and the community colleges to claim apportionment, but the increased administrative and student support overhead is underfunded.

Both high schools and community colleges must determine how to fund CCAP agreements, strengthening the argument for street-level bureaucracy as a theoretical framework. Further, street-level bureaucrats are intrinsically in conflict with managers and have a relationship of mutual dependence, moderated by incentives and sanctions. 
Lipsky provides a framework upon which to evaluate the implementation of $\mathrm{AB} 288$ legislation, providing tools to understand the tensions between administrators and implementors which influence how the stated goals of the bill are put into practice. This is supported by the work of Maynard-Moody \& Musheno (2003), who set as their task identifying the decision making that come from the interactions of law, belief, identities, and behavior in street level work. They do these through the construction of two distinct narratives: state-agent and citizen-agent. State agent focuses on adherence to laws, while citizen-agent focuses on normative or cultural abidance in the action of identifying who is worth of service and who is not (Maynard-Moody \& Musheno, 2003). These two oftencompeting narratives inform our understanding of policy implementation and the specific actions of the front-line street-level bureaucrats in the case studies.

Lipsky also proposes a vision of the future for street-level bureaucrats, saying that agencies must know what they want workers to do and how to measure worker performance, be able to compare workers to one another to establish standards for judgement and have incentives and sanctions capable of disciplining workers. He highlights the need to utilize an enhanced understanding of the motivations and reality of street-level bureaucrats to create the accountability measures and limitations on autonomy and discretion that open the door for unequal application of policy. This is a call to action for $\mathrm{AB} 288$ implementers to create a program evaluation plan that intentionally measures and incentivizes the fulfillment of this legislations promise. 


\section{Chapter Three: Methodology}

\section{Introduction}

This study is a multiple case study of CCAP dual enrollment programs in three community college districts serving the high school districts within their service area. It considers how $\mathrm{AB} 288$ dual enrollment moves from policy to practice and the characteristics of the resulting programs based on how $\mathrm{AB} 288$ legislation is understood and externalized by the policy adopters, dual enrollment administrators, and program supporters at each site. The study includes a cross-case presentation and analysis of the individual cases. CCAP partnership are between a single high school district and a single community college district and define the courses covered under the agreement, which could be across multiple programs within the high school districts and community college district, as well as the location of the course and the source of instructors. The cases are created through interviews with dual enrollment policy adopters, administrators and supporters responsible for the implementation and oversight of active $A B 288$ dual enrollment initiatives in the San Francisco Bay Area and surrounding areas. The programs are defined by the College and Career Access Partnerships (CCAP) agreements between the community college and high schools. The understanding of these partnerships is supported by review of relevant documentation, including the CCAP agreements, the community college district and school district and school level websites, presentations, and dual enrollment program documentation and forms. The districts cover both rural and urban environments and the associated high school partnerships represent varying levels of complexity. 
AB 288 dual enrollment represents a relationship between a high school district and a community college district, so key informants on both sides of the partnership have been interviewed. These include the dual enrollment policy adopters at the high school, as well as dual enrollment administrators and supporters at both the community college and the high school. Front-line supporters are the faculty or staff who have responsibility for making implementation decisions that shape the dual enrollment initiative. Depending on the site, this may be a coordinator, a counselor, or a dual enrollment instructor. Dual enrollment administrators on both sides have responsibility for defining the characteristics of the programs and how the CCAP agreement will be externalized in the dual enrollment program.

High schools and community colleges may undertake these partnerships for a variety of complex reasons, but under $\mathrm{AB} 288$ legislation, the intended purpose of these partnerships is to expand dual enrollment opportunities for students who are underrepresented in high education or who may not already be college bound to create a seamless pathway from high school to community college for career technical education or transfer, to improve high school graduation rates, or increase college and career readiness. Interview questions will be focused on determining how the legislation is understood at the administrative and the implementation level, the goals set for the program, the pathways chosen, and how student groups are explicitly identified and served.

\section{Research Questions}

The research questions that guided this study are: 
How are the legislative goals of $\mathrm{AB} 288$ dual enrollment understood and externalized by the policy adopters, administrators, and supporters of dual enrollment in high schools and community colleges? What impact do these differences in understanding and externalizations have on the CCAP dual enrollment programs created?

This study explores these questions by testing the following related propositions which guided the interview questions:

1. Design: The various designs of dual enrollment will provide varying levels of access to underrepresented student populations.

2. Role: Dual enrolilment policy adopters, administrators, and supporters may have conflicting understandings of the purpose and intention of $A B 288$ dual enrollment programs may be in conflict between educational entities in the partnership.

3. Partnership: Within a dual enrollment partnership between educational entities, each has individual intents and forces at play that impact dual enrollment program implementation in terms of student and course selection, and creation of supports.

4. Intention: Agreement and clear communication at all levels about the intention and purpose of dual enrollment will influence these programs' impact on access by student populations currently under-represented in high education.

Factors which might affect $\mathrm{AB} 288$ dual enrollment programs and their success in these environments include access of students to other types of early college credit, including Advanced Placement (AP) or International Baccalaureate (IB), early middle 
college programs, articulation, and/or traditional dual enrollment/concurrent enrollment; student perceptions of the career pathways that are integrating dual enrollment; and the level of parent education leading to increased participation by populations other than the intended target populations. When characterizing the sites being evaluated, these variables will be tracked. Variables regarding the implementation choices which will be accounted for include whether courses are taught by a high school teacher, a community college instructor or co-taught by one of each, whether students take the class at the high school or the community college, and the type of course, either career education or academic courses, being offered.

\section{Role of the Researcher}

In the interviews, I position myself as a knowledgeable colleague and fellow practitioner and as a scholar who is interested in $\mathrm{AB} 288$ dual enrollment initiatives. I did not interview any people I worked with directly, but I am acquainted with some of the participants through our mutual participation in the Bay Area Dual Enrollment task force or through attendance at subject area conferences. In addition, I am newly affiliated with a community college in the same district as two of the community colleges, as a dual enrollment administrator, which I disclosed to participants.

\section{Design \& Analysis}

\section{Case Study Selection.}

Three cases have been analyzed in this multiple case study. Each case study represents a CCAP dual enrollment program at a community college district, serving the high school districts in their service area. Each case studies encompasses between one 
and five CCAP agreements, depending on the number of high school districts in the service area who have undertaken a CCAP partnership with their community college partner. Potential case studies were identified through review of all CCAP agreements submitted to the California Community College Chancellor's Office, as required by the legislation. Agreements from the North Bay, East Bay, Mid-peninsula, and Santa Cruz/Monterey regions were reviewed. A total of six districts, out of eleven identified, had CCAP agreements filed with the California Community Colleges Chancellor's Office. The final cases were chosen based on having an active CCAP dual enrollment initiative and to be theoretical replications to evaluate contrasting results based on the differences between them (Yin, 2018). Contrasts between the case studies exist in the number of high school partners, the total comprehensive high schools within the largest partner district, and the total enrollment of the community colleges. In addition, the case studies represent both rural and urban environments ( 
Table 3). 
Table 3 Case Study Elements

\begin{tabular}{|l|c|c|c|c|c|}
\hline $\begin{array}{l}\text { Case } \\
\text { Study }\end{array}$ & Context & $\begin{array}{c}\text { College } \\
\text { FTES }\end{array}$ & $\begin{array}{c}\text { CCAP } \\
\text { Agreements/High } \\
\text { School District } \\
\text { Partners }\end{array}$ & $\begin{array}{c}\text { Comprehensive } \\
\text { High Schools } \\
\text { in Largest } \\
\text { District }\end{array}$ & Complexity \\
\hline 1 & Urban & $34 \mathrm{k}$ & 1 & 12 & Highest \\
\hline 2 & Rural & $8.5 \mathrm{k}$ & 3 & 3 & Lowest \\
\hline 3 & Rural & $10 \mathrm{k}$ & 5 & 4 & Medium \\
\hline
\end{tabular}

The initial evaluation of the sites involved a review of the CCAP agreements which provided insight into the type of courses covered and the extent of the agreement, which allow for the categorization into the three site contexts above. Five potential sites in the region were identified. Two community college districts were excluded because, while a CCAP agreement was in place, the courses had not yet been scheduled or undertaken. A third was discarded because it was not possible to identify the key particants for the CCAP dual enrollment initiative because of staff and leadership changes. These cases represented cases where there were two or three colleges in the district. The remaining case studies encompassed both rural and urban districts. They were all single community college districts. They varied in size and the complexity of CCAP dual enrollment partnerships undertaken. The high school partners were both in single high school districts and districts with multiple comprehensive high schools.

Community colleges may have multiple high school districts in their service area. Given this variation, each case focuses on the community college district and the high school districts it serves. All case studies are in single community college districts, which account for $69 \%$ of the community college districts in California. Within in each case study, high school partners are characterized by the number of comprehensive high 
schools in their district. Single comprehensive high school districts represent a low level of complexity in terms of partnership. The level of complexity within the partnership grows of the number of comprehensive high schools in the district grows, so multiple high school districts are looked at as a second more complex type of partnership.

Review of the CCAP agreements created under AB 288 in each of these partnerships reveals that a standard CCAP template is employed to meet the legislative content requirements for the agreement. In these three case studies, districts had undertaken between one and five CCAP agreements. A single community college undertakes multiple $\mathrm{AB} 288$ agreements, one per high school district in their service area.

\section{Data Sources.}

A rich understanding of each case study comes from the review of data from a variety of sources. These include a broad a variety for each site, including twenty-two interviews with key participants, demographic data for the high school and community college districts, the CCAP agreements, marketing documents, meeting notes, and meeting agendas and minutes, and dual enrollment program documentation. This data is the source of the case study variables used to inform the case studies ( 
Table 4). Where possible, multiple sources were used to confirm the case study variable data.

Table 4 Case Study Variables

\begin{tabular}{|c|c|c|c|c|}
\hline & $\begin{array}{l}\text { Variable } \\
\text { Name }\end{array}$ & Deacripton & Coding & Data Source(s) \\
\hline \multirow{2}{*}{ 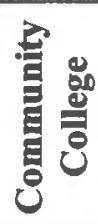 } & \begin{tabular}{|l} 
Student \\
Population
\end{tabular} & $\begin{array}{l}\text { Demographics of population of } \\
\text { the community college }\end{array}$ & $\begin{array}{l}\text { Race, gender, socio- } \\
\text { economic status }\end{array}$ & DataMart \\
\hline & Size & \# of FTES & Number & DataMart \\
\hline \multirow{4}{*}{$\begin{array}{l}\overline{8} \\
\overline{8} \\
0 \\
\overline{0} \\
0\end{array}$} & \begin{tabular}{|l|} 
Student \\
Population
\end{tabular} & $\begin{array}{l}\text { Demographics of population of } \\
\text { the high school. }\end{array}$ & $\begin{array}{l}\text { Race, gender, socio- } \\
\text { economic status }\end{array}$ & DataQuest \\
\hline & Pathway(s) & $\begin{array}{l}\text { Academic pathway(s) } \\
\text { associated with the dual } \\
\text { enrolment enrollment program. }\end{array}$ & $\begin{array}{l}\text { Industry sector, } \\
\text { pathway, course } \\
\text { series }\end{array}$ & $\begin{array}{l}\text { Interviews, } \\
\text { Website }\end{array}$ \\
\hline & Size & $\begin{array}{l}\text { \# of students at school and in } \\
\text { district }\end{array}$ & Number & DataQuest \\
\hline & $\begin{array}{l}\text { Traditional } \\
D E\end{array}$ & Does offer traditional DE? & $\begin{array}{l}\text { Yes/No. Size of } \\
\text { traditional dual } \\
\text { enrollment initiative }\end{array}$ & $\begin{array}{l}\text { Interviews, } \\
\text { Website }\end{array}$ \\
\hline \multirow{2}{*}{ 递 } & $\begin{array}{l}\text { Site for } \\
\text { Course }\end{array}$ & $\begin{array}{l}\text { Location where dual enrollment } \\
\text { course takes place }\end{array}$ & $\begin{array}{l}\text { Community college, } \\
\text { High School }\end{array}$ & $\begin{array}{l}\text { CCAP } \\
\text { agreement, } \\
\text { Interviews }\end{array}$ \\
\hline & $\begin{array}{l}\text { Instructor } \\
\text { Model }\end{array}$ & $\begin{array}{l}\text { Primary teacher for the dual } \\
\text { enrollment course. }\end{array}$ & $\begin{array}{l}\text { CC, HS, Co- } \\
\text { Teaching }\end{array}$ & $\begin{array}{l}\text { CCAP } \\
\text { agreement, } \\
\text { Interviews }\end{array}$ \\
\hline 晃 & Courses & $\begin{array}{l}\text { List of all dual enrollment } \\
\text { courses offered. }\end{array}$ & $\begin{array}{l}\text { HS course title \& } \\
\text { CC course title }\end{array}$ & $\begin{array}{l}\text { CCAP } \\
\text { agreement, } \\
\text { Interviews, } \\
\text { Presentations } \\
\text { and reports }\end{array}$ \\
\hline
\end{tabular}




\begin{tabular}{|l|l|l|l|l|}
\hline Sections & $\begin{array}{l}\text { \# of dual enrollment sections by } \\
\text { pathway }\end{array}$ & Number of sections & $\begin{array}{l}\text { CCAP } \\
\text { agreement, } \\
\text { Interviews, } \\
\text { Presentations } \\
\text { and reports }\end{array}$ \\
\hline $\begin{array}{l}\text { Evaluation } \\
\text { Plan }\end{array}$ & $\begin{array}{l}\text { Plan for evaluation of the AB } \\
288 \text { dual enrollment program. }\end{array}$ & Statistics & $\begin{array}{l}\text { Website, } \\
\text { Interviews }\end{array}$ \\
\hline Phase & $\begin{array}{l}\text { Phase AB 288 of } \\
\text { implementation }\end{array}$ & $\begin{array}{l}\text { Planning, 1st year, } \\
\text { 2nd year }\end{array}$ & $\begin{array}{l}\text { CCAP } \\
\text { agreement, } \\
\text { Interviews }\end{array}$ \\
\hline
\end{tabular}

A total of one hundred and forty-four documents were collected.

Table 5 provides an overview of all data sources by case study and site and interviews by site and role. All data was collected and organized by site, with a naming convention that identified the case study, organization, and source of the data. Website pages were converted to a PDF format. Documents stored on the website were downloaded and converted to PDF, if necessary.

Table 5 Overview of Data Sources

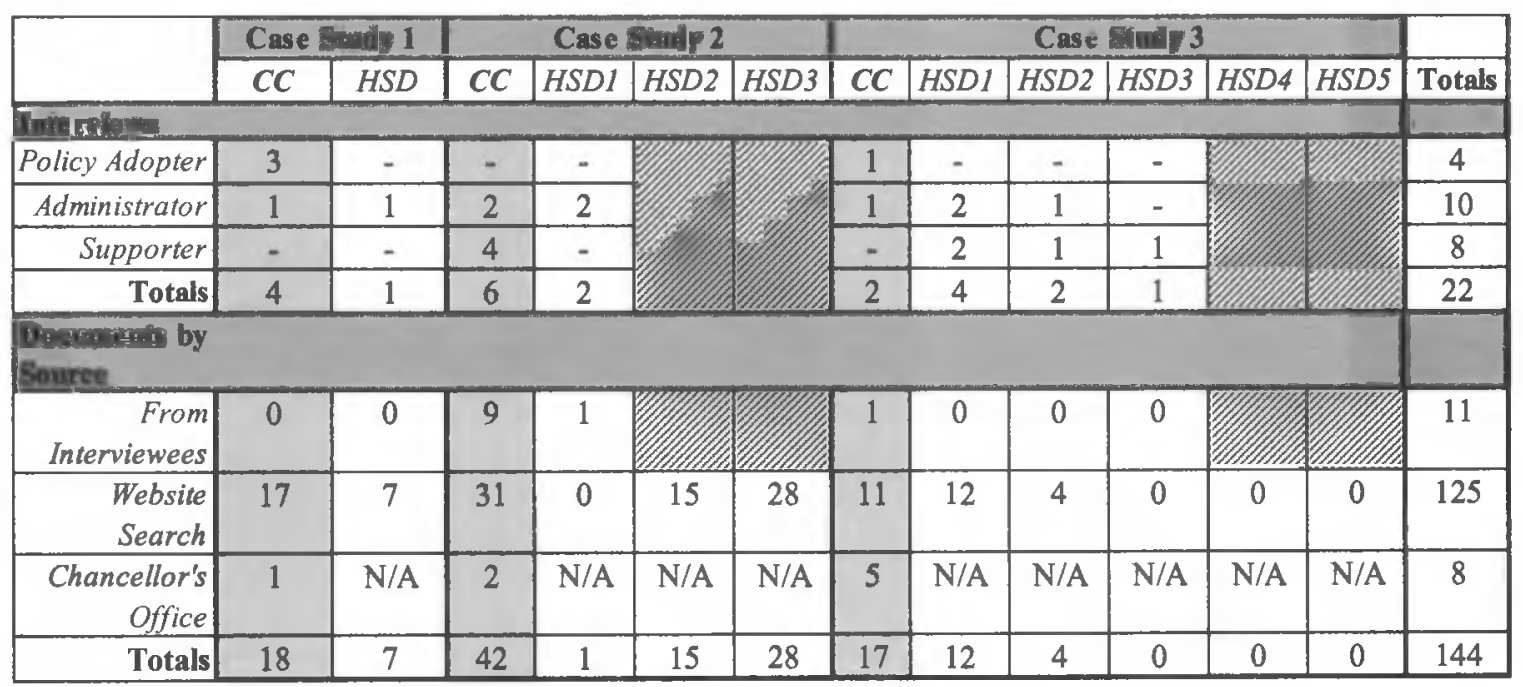




\section{Data Collection.}

\section{Demographic data.}

For each of the community colleges, demographic data for the 2017 to 21018 school year was obtained from the California Community Colleges Chancellor's Office DataMart, including enrollments and demographics of the student populations. This represented the most recent data available. In addition, special admit data, which tracks high school student enrollments in the community college environment, were obtained for Fall 2015 through Fall 2018. Demographic information for all high school districts was obtained from the California Department of Education DataQuest system. The data was based on 2018 to 2019 school year enrollments and outlined the student populations broken down by ethnicity for all districts and schools. Data was downloaded from these systems for summarization and review.

\section{Documents.}

Documents were gathered for each site in two ways. First, documents were identified through searches on both the community college website and district and the school level websites in the high school districts. Consistent search terms were used for all sites. Search terms included CCAP, dual enrollment, concurrent enrollment, early college credit, high school (on the community college website), and community college and the name of the community college partner (on the high school websites). Searches were undertaken at the beginning and the end of the study to capture updates to the available documentation. Additional case specific search terms were identified based on review of interview transcripts, to find documents associated with specific case study 
CCAP implementation. Examples of these are specific high school CTE, grant names that were used to fund dual enrollment, and the names of student supports and programs that were leveraged by the CCAP dual enrollment initiative. In addition, all participants were asked to share any documents that they felt were relevant to the CCAP dual enrollment initiative and any documents or tools that they specifically referenced in the course of the interview. 
Table 6 Document Data Sources

\begin{tabular}{|c|c|c|}
\hline Data Source & Data and Information & Purpose \\
\hline $\begin{array}{l}\text { CCAP } \\
\text { agreements }\end{array}$ & $\begin{array}{l}\text { Required by legislation: } \\
\text { - \# of FTES students projected to be } \\
\text { claimed by community college } \\
\text { - Scope, nature, time, and location, and } \\
\text { listing of courses to be offered } \\
\text { - Criteria to assess the ability of pupils } \\
\text { to benefit from courses } \\
\text { - Identified points of contact for } \\
\text { community college partner and } \\
\text { school district partners }\end{array}$ & $\begin{array}{l}\text { Interorganizational } \\
\text { Communication \& } \\
\text { Enforcement } \\
\text { Activities } \\
\text { Site Characteristics }\end{array}$ \\
\hline $\begin{array}{l}\text { Marketing } \\
\text { documents }\end{array}$ & $\begin{array}{l}\text { - Focus of marketing } \\
\text { - Expectations are being set around the } \\
\text { program } \\
\text { - Benefits and responsibilities } \\
\text { - Includes presentations done both the } \\
\text { high school and community college } \\
\text { communities and to prospective } \\
\text { parents and students. }\end{array}$ & $\begin{array}{l}\text { Interorganizational } \\
\text { communication }\end{array}$ \\
\hline Meeting notes & $\begin{array}{l}\text { The focus of implementation meetings, } \\
\text { attitudes of participation, for } \\
\text { triangulation with interview data. } \\
\text { Level of consensus. }\end{array}$ & $\begin{array}{l}\text { Interorganizational } \\
\text { communication }\end{array}$ \\
\hline $\begin{array}{l}\text { Website data } \\
\text { for community } \\
\text { college and } \\
\text { high schools }\end{array}$ & $\begin{array}{l}\text { Information about the program and } \\
\text { characteristics of the LEAs. } \\
\text { - Parent and student facing dual } \\
\text { enrollment marketing and support } \\
\text { information } \\
\text { - Updates on dual enrollment to the } \\
\text { larger community }\end{array}$ & $\begin{array}{l}\text { Interorganizational } \\
\text { Communication } \\
\text { Characteristics of } \\
\text { the implementing } \\
\text { agencies }\end{array}$ \\
\hline $\begin{array}{l}\text { Dual } \\
\text { Enrollment } \\
\text { Program } \\
\text { Documentation }\end{array}$ & $\begin{array}{l}\text { Includes program documentation, } \\
\text { handbooks, forms used to support the } \\
\text { dual enrollment initiative, and } \\
\text { orientation presentations for dual } \\
\text { enrollment students and parents. }\end{array}$ & $\begin{array}{l}\text { Interorganizational } \\
\text { Communication \& } \\
\text { Enforcement } \\
\text { Activities } \\
\text { Disposition of the } \\
\text { implementors }\end{array}$ \\
\hline
\end{tabular}




\section{Interviews.}

Interviews were conducted using a semi-structured format, using sets of questions focused by role (policy adopter, administrator, supporter). A total of twenty-two interviews were completed: four policy adopters, ten administrators, and eight supporters (see

Table 5 on page 70). Interviews were divided between the two sides of the partnership: ten interviews were with high school personnel, eleven were with community college, and a single interview was done with a non-profit supporting the initiative. Policy adopters were only found at the community colleges, because high school superintendents supported the approval of the CCAP dual enrollment agreements but had limited day to day interaction with the program's implementation. The policy adoption at the community college drove the discussion of CCAP dual enrollment implementation more, because the policy adopter's beliefs and priorities informed interaction with multiple high school district partners. The staffing of the initiative, the focus of varied widely between case studies, drove the roles included in the interview. A higher number of supporters are found in environments where there is less staffing on the other side of the partnership. In one case study, all four supporters are on the community college side. In another, all are on the high school side.

The list of question was created by considering the propositions outlined above aligning questions with each to create four categories: 1.) design, 2.) role, 3.) partnership, and 4.) intention. For each group of questions, the resulting answers represent variables in 
these categories (Table 7). Not all questions are appropriate for all categories of interviewees, but the questions were asked across roles as appropriate to identify where agreement exists or where intentions may diverge.

Table 7 Sample Interview Variables

\begin{tabular}{|c|c|c|c|c|}
\hline & & $\begin{array}{c}\text { Policy } \\
\text { Adopter }\end{array}$ & $\begin{array}{c}\text { Dual } \\
\text { Enrollment } \\
\text { Administrator }\end{array}$ & $\begin{array}{c}\text { Dual } \\
\text { Enrollment } \\
\text { Supporter }\end{array}$ \\
\hline \multirow{7}{*}{ 最 } & $\begin{array}{l}\text { How are dual enrollment students } \\
\text { supported? }\end{array}$ & $X$ & $X$ & $X$ \\
\hline & $\begin{array}{l}\text { How is dual enrollment evaluated at } \\
\text { your site? }\end{array}$ & $\mathrm{X}$ & $\mathrm{X}$ & $X$ \\
\hline & $\begin{array}{l}\text { How is the dual enrollment program } \\
\text { marketed? }\end{array}$ & $X$ & $X$ & $X$ \\
\hline & $\begin{array}{l}\text { What have been the challenges you } \\
\text { have faced during the rollout of this } \\
\text { program? }\end{array}$ & $X$ & $X$ & $\mathrm{X}$ \\
\hline & $\begin{array}{l}\text { How were the community, students } \\
\text { and parents involved in the } \\
\text { development of your dual enrollment } \\
\text { program? }\end{array}$ & $X$ & $X$ & $X$ \\
\hline & $\begin{array}{l}\text { What dual enrollment courses are } \\
\text { offered? How were the courses } \\
\text { selected? }\end{array}$ & & $X$ & \\
\hline & $\begin{array}{l}\text { Do you also offer traditional dual } \\
\text { enrollment classes? }\end{array}$ & & $X$ & \\
\hline \multirow{3}{*}{$\frac{0}{2}$} & $\begin{array}{l}\text { Describe the positions that are } \\
\text { responsible for supporting dual } \\
\text { enrollment in our organization. }\end{array}$ & & $X$ & $X$ \\
\hline & $\begin{array}{l}\text { When and how did you become } \\
\text { involved with this dual enrollment } \\
\text { initiative? }\end{array}$ & $X$ & $X$ & $X$ \\
\hline & $\begin{array}{l}\text { What kind leadership support is } \\
\text { critical for the success of this dual } \\
\text { enrollment initiative? }\end{array}$ & $X$ & $X$ & $X$ \\
\hline \multirow{3}{*}{ 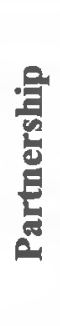 } & $\begin{array}{l}\text { Describe your organizations } \\
\text { partnership with the CC/HS. }\end{array}$ & $X$ & $X$ & $X$ \\
\hline & $\begin{array}{l}\text { What expectations did you have about } \\
\text { the outcome of your CCAP } \\
\text { partnership? }\end{array}$ & $\mathrm{X}$ & $\mathrm{X}$ & $X$ \\
\hline & $\begin{array}{l}\text { How is the dual enrollment initiative } \\
\text { being funded? }\end{array}$ & $X$ & & \\
\hline
\end{tabular}




\begin{tabular}{|l|l|c|c|c|}
\hline & $\begin{array}{c}\text { Policy } \\
\text { Adopter }\end{array}$ & $\begin{array}{c}\text { Dual } \\
\text { Enrollment } \\
\text { Administrator }\end{array}$ & $\begin{array}{c}\text { Dual } \\
\text { Enrollment } \\
\text { Supporter }\end{array}$ \\
\hline \multirow{2}{*}{$\begin{array}{l}\text { Wh 288 dual enrollment? } \\
\text { How are students selected? } \\
\text { Hompetition, recruitment, self- } \\
\text { Colection }\end{array}$} & $\mathrm{X}$ & $\mathrm{X}$ & $\mathrm{X}$ \\
\cline { 2 - 4 } & $\begin{array}{l}\text { What concerns were raised, if any, } \\
\text { about embarking on dual enrollment? }\end{array}$ & $\mathrm{X}$ & $\mathrm{X}$ & $\mathrm{X}$ \\
\cline { 2 - 5 } & $\begin{array}{l}\text { What are the greatest challenges of AB } \\
\text { 288 dual enrollment? }\end{array}$ & $\mathrm{X}$ & $\mathrm{X}$ & $\mathrm{X}$ \\
\hline $\begin{array}{l}\text { What is the potential for AB 288 dual } \\
\text { enrollment? }\end{array}$ & $\mathrm{X}$ & $\mathrm{X}$ & $\mathrm{X}$ \\
\cline { 2 - 5 } & $\begin{array}{l}\text { Which students are invited? Excluded? } \\
\text { Based on what criteria? }\end{array}$ & $\mathrm{X}$ & $\mathrm{X}$ & $\mathrm{X}$ \\
\hline
\end{tabular}

Demographic information was be collected for each participant (Table 8). Study codes were used on data documents instead of recording identifying information and names were replaced with study codes during the review of transcripts. The list of participants and associated study codes is kept separate and password protected.

Table 8 Interviewee Demographic Information

\begin{tabular}{|l|l|l|}
\hline $\begin{array}{l}\text { Variable } \\
\text { Name }\end{array}$ & Beseriptian & Coding \\
\hline Role & Role in dual enrollment initiative & $\begin{array}{l}\text { Administrator, Implementor, } \\
\text { Recommender }\end{array}$ \\
\hline $\begin{array}{l}\text { Level of } \\
\text { experience }\end{array}$ & $\begin{array}{l}\text { Length of participation in dual } \\
\text { enrollment initiative. }\end{array}$ & $\begin{array}{l}\text { Less than 6 mos., 6 mos. to 1 year, } \\
\text { over 1 year }\end{array}$ \\
\hline Age & Age & Number \\
\hline Race & $\begin{array}{l}\text { Race, to evaluate alignment with } \\
\text { student population. }\end{array}$ & As defined for student population. \\
\hline Gender & Gender & Male/Female \\
\hline
\end{tabular}


Interviews were conducted in person, at the worksite of the interviewee or at a place of their choosing, or through video conferencing.

a. Describes and justifies the context and setting chosen for the study.

b. Describes the procedures for gaining access to participants.

c. Discusses methods of establishing a researcher-participant working relationship.

\section{Instrumentation.}

Interviews were recorded with a manual recorder, in cases where interviews were done in person, and through ConferZoom, for virtual interviews. All interviews were transcripted using automated transcription, either Temi or Trint, and then reviewed and exported as written transcripts.

Coding was done in Dedoose. All data documents were imported into Dedoose for coding. Descriptors were applied to all data to allow for deeper analysis and identification of trends within and across the data. Imported data was tagged with two sets of descriptors. All documents were also coded with a second set of descriptors, allowing for code analysis by case study, partner (high school district or community college district), and partnership within the case study. The second set of descriptors applied only to interview data and captured the interviewee demographics (Table 8), allowing for review of codes by age, race, gender, role, and case study. 


\section{Data Analysis.}

Initial code sets were created based on the conceptual framework. In the course of coding, additional codes were added to reflect emerging themes. The first cycle of coding focused on initially on interview transcripts, followed by document provided by participants and then on coding of documents identified in website searches. After the first cycle of coding, all codes were reviewed and regrouped, to combine code sets with overlapping themes.

\section{Internal Validity}

A consistent set of questions based on the conceptual framework (Error! Reference source not found.) was used across all interviews for all case studies, with modifications to accommodate differences of positions and roles within the organization. These questions created a construct for pattern matching across the case studies, as recommended by Yin (2018) as a method to increase internal validity. Pattern matching can also be used to identify rival explanations (Yin, 2018). Documents from multiple sources gave voice to perspectives that either complimented or contrasted with those of the interview participants.

Triangulation across interviews and documents from the participants and from the organizations' websites, as well as among the interviews, provided a richer understanding of emerging themes, as well as providing validity for the data, confirming or disconfirming emerging codes. This triangulation also allowed for the confirmation of information provided about the details of the CCAP dual enrollment programs created. 


\section{Generalizability \& Transferability}

My study provides a framework for looking at the implementation process and characteristics across the case studies chosen to represent CCAP dual enrollment in California. It allows for critical analysis of whether the intention of the policy is being realized in the implementation and increased awareness the challenges encountered and practices that will support alignment with intent of the legislation. The cases are evaluating a range of environments, both in terms of the characteristics of the high school districts and the college districts, as well as the characteristics of the resulting dual enrollment programs. In understanding how the intentions of policy are shaped by the implementors, this study will provide a perspective for the critical analysis of $A B 288$ implementations. 


\section{Chapter Four: Report of Findings}

\section{Overview}

AB 288 legislation seeks to increase access to higher education by students who have historically been underrepresented in higher education. This expands the focus of dual enrollment programs to effectively serve a broader group of students, particularly those in groups that are underrepresented or not college bound. In creating CCAP partnerships, both community colleges and high schools work together to define the program characteristics and focuses that will meet the needs of their community based on the goals of each partner and their understanding of the legislation. This is a complex decision, taking into account many factors, including the population of the high schools, the programs available at the community college, the needs of the high school as perceived by administrators, the perceived attitudes of parents and students, and the regional labor market needs and opportunities. The resulting programs reflect the understandings of the policy adopters and administrators who gave them shape, within the confines of competing requirements across the partnership. This study seeks to answer the following questions: How are the legislative goals of $\mathrm{AB} 288$ dual enrollment understood and externalized by the policy adopters, administrators, and supporters of dual enrollment in high schools and community colleges? What impact do these differences in understanding and externalizations have on the CCAP dual enrollment programs created?

The first section of the chapter lays out three case studies introducing dual enrollment initiatives and giving insight into the environments in which CCAP dual 
enrollment implementations are taking place. ${ }^{1}$ In each case study the characteristics of each environment and the current CCAP dual enrollment initiative are described. Characteristics include a description of the environmental factors which shape the dual enrollment initiative, ranging from the size and demographics of the populations to awareness of and attitudes about and previous experience with traditional forms of dual enrollment.

In the second and third sections, a cross-case analysis of the resulting programs per Yin's method is provided, considering the understanding of the legislative goals, both as stated and based on a consideration of behavior, as well as the impact of these understandings on the resulting CCAP programs. Details of the resulting program are provided to create a context for discussion findings across the cases. The differences in resulting CCAP dual enrollment programs and the ability of those programs to fulfill the intention of the legislation will be examined by looking closely at and comparing the characteristics of the resulting programs, as well as system requirements, goals of each partner, and other forces that impacted the implementation decisions made.

\section{Case Studies}

The three case studies presented describe the environments on both sides of partnerships, based on legislation which seeks to provide early college credit to high school students who have not historically been afforded access. Out of the one hundred

\footnotetext{
' See Appendix A for an overview of Organization, Roles, and Titles by case study.
} 
and fifteen schools in the California Community College system, the community college partners were selected to represent single college districts in both urban and rural settings. Sixty-nine percent of the community colleges in California are single-college districts, making these three districts representative. The case studies provide context to understand similar implementations across most California community colleges and their single and multiple high school partner districts.

Through the initiation of CCAP agreements, these community colleges created partnerships with high schools both in districts with a single comprehensive high school and in complex districts with many high schools. The complexity of the high school district increases the complexity of the partnership. CCAP agreements are district to district agreements, but the needs and demographics within a single high school district can vary greatly, as will be seen in the case studies presented. Both the high school partner and the community college decide how to invest resources to staff and support their individual CCAP dual enrollment initiative, a decision directly related to the level of commitment to and understanding of the complexity of CCAP agreements.

Based on special admit data from the California Chancellor's Office data mart, consideration of the number of special admit students for each community college provides a view of the number of high school students participating in any course at the community. This gives insight into the scope of programs focused on high school students as a group at each community college. An upward trend can be seen across the case studies after the implementation of CCAP dual enrollment in 2017 (Figure 2).Error! 
Reference source not found. It is not possible to determine what percentage of this increase is directly attributable CCAP dual enrollment, but is reflective of the scope of dual enrollment in each environment and an increase in dual enrollment coincided with the creation of these agreements.

Alternative explanations for this increase of special admit students is that the CCAP dual enrollment initiative raised awareness at the high schools, which led to increased individual dual enrollment participation, or other early college credit initiatives

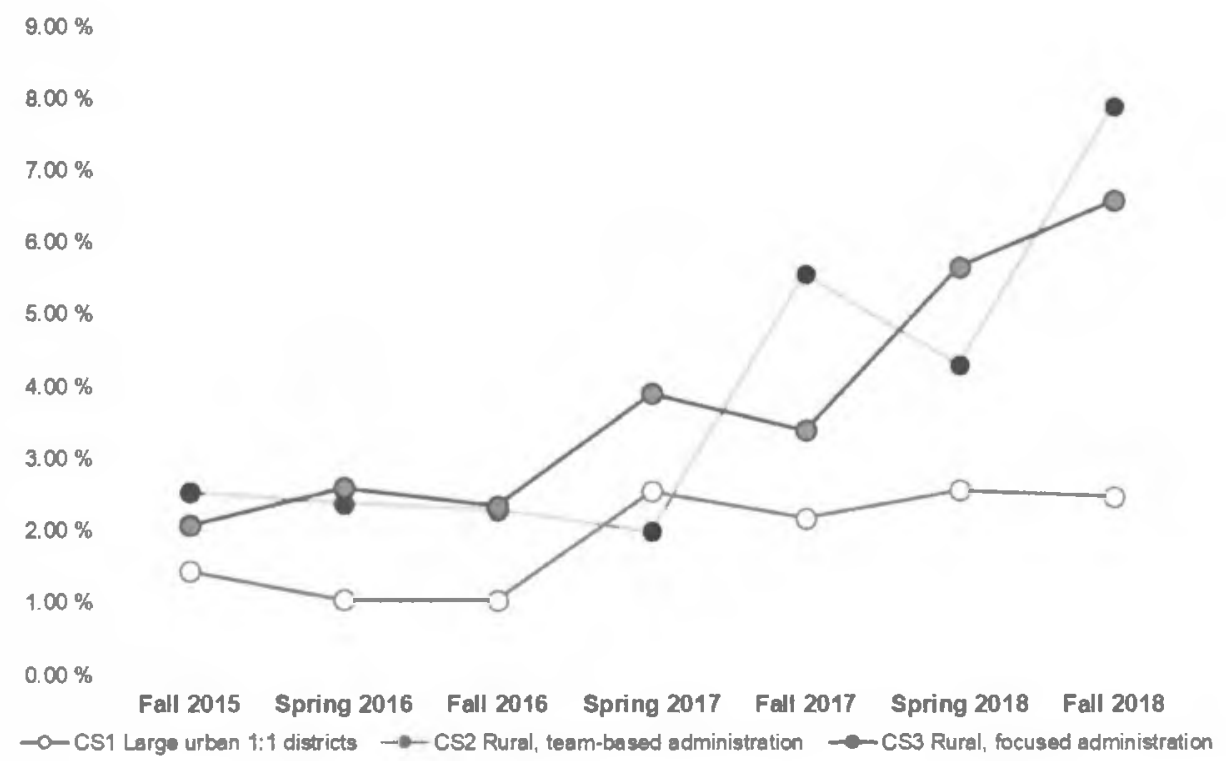

Figure 2 Special Admit Enrollment as a Percentage of Total Enrollments by Case Study

brought high school students to the community college. Figure 2 highlights a difference in the growth trajectory for special admit students between case study one and case studies two and three. Special admit students were a greater percentage of the student population in case studies two and three than they were in case study one, suggesting that 
the investments made in these environments resulted in higher proportional growth of this student population.

\section{Case Study One: Urban Community College and a Single Large High School District Partner}

Case study one represents the environment with the highest degree of complexity. It is a large community college in a large urban setting. It serves a large high school environment with twelve comprehensive high schools (

Table 9). This single high school district serves as many students as all the high schools in the other two case studies combined. Dual enrollment administration at this site is a single point of contact at the community college and at the high school district, with administrative support.

Table 9 Case Study One: Urban Single Community College and Large Multiple High School District

\begin{tabular}{|c|c|c|c|}
\hline \multicolumn{4}{|l|}{ Case Study One } \\
\hline \multirow{3}{*}{$\begin{array}{c}\text { Urban CC } \\
\text { (34k FTES) } \\
\text { CCAP Agreements: } 1\end{array}$} & \multirow{3}{*}{$1: 1$} & \multirow{3}{*}{$\begin{array}{l}\text { District High } \\
\text { Schools } \\
\text { (20k students) }\end{array}$} & $\begin{array}{l}\text { Comprehensive High Schools (12) } \\
\text { (14.5k students) } \\
\text { Underrepresented Students: } 43 \% \\
\text { Low-SES: } 53 \%\end{array}$ \\
\hline & & & $\begin{array}{l}\text { Continuation Schools (3) } \\
\text { (500 students) }\end{array}$ \\
\hline & & & $\begin{array}{l}\text { Charter Schools (8) } \\
\text { (5k students) }\end{array}$ \\
\hline
\end{tabular}

The racial make-up of the student populations varies widely within the schools in this district. Students in populations under-represented in higher education (which include Black, Native American, Filipino, and Latino students) make up $43 \%$ of the student population in this high school district. Fifty three percent of the students across 
the district are low-socioeconomic status (SES), based on eligibility for free and reduced meals. These statistics indicate that there is potential for meeting the intention of $\mathrm{AB} 288$ legislation.

Just over fifty-nine percent of the population in the schools which offered CCAP dual enrollment courses in Spring of 2019 are students in under-represented populations. It is possible that the high school principals at these high schools wanted to undertake CCAP dual enrollment to create access for students in these populations. It is equally possible that there was some other motivation, like a need to expand course offerings, and that the student demographics were incidental. CCAP dual enrollment is offered in neither the largest nor the smallest schools. Lack of staff to offer a broad range of courses is a driver for some schools undertaking dual enrollment, according to the Supervisor of Student Learning Supports at the high school. It is possible that the largest schools do not have as many limitations on the courses they offer and therefore did not seek to initiate CCAP dual enrollment. It is also possible that the smaller number of students at these schools simplified the adoption of CCAP dual enrollment. Smaller numbers of students mean a less complicated Master schedule, which is a challenge for high schools.

To develop an understanding of this complex environment, interviews were done at both the community college and the high school district. Interviews were done with the three people who advocated for and created the initial CCAP agreement: an Associate Vice Chancellor at the Community College, a high school district representative who moved into the role of Dean of High School Programs (HSP) at the Community College 
after the CCAP agreement was established, and a representative from a statewide nonprofit who was tasked to provide support in the agreement process. To understand the current implementation from the high district school side, the Supervisor from the Division of Learning and Curriculum, the dual enrollment administrator at the high school district, was interviewed. The Dean of Health, and Social Services (HSS), who was involved in the creation of dual enrollment programs at the community college, was interviewed for historical context. This administrator came into this position when her predecessor moved to the community college as the Dean of HSP. These interviews represent all key leaders in the creation of the CCAP agreement in this partnership. A strong partnership currently exists between the community college district and high school district in the form of a long-term individual dual enrollment program, although the increase in special admit students has been smaller than in the other case study districts. In Figure 3, there is a clear drop off in high school special admit students between Fall of 2015 and Fall of 2016. In 2018, special admit students, made up about $2.5 \%$ of total enroliments, up from $1.5 \%$ in 2015 (Figure 2), showing the impact of a reengagement with the high schools and increased focus on dual enrollment initiatives by the Vice Chancellor in 2016. As AB 288 came-out, creating a CCAP agreement became one of his focuses as part of the goal to reinvigorate high school partnerships, despite challenges created by leadership changes at the individual high schools. The increase in special admit students is attributable to the increase in enrollments created by the CCAP 
sections added in Spring of 2017, in addition to a continued focus on individual dual enrollment and the early college dual enrollment.

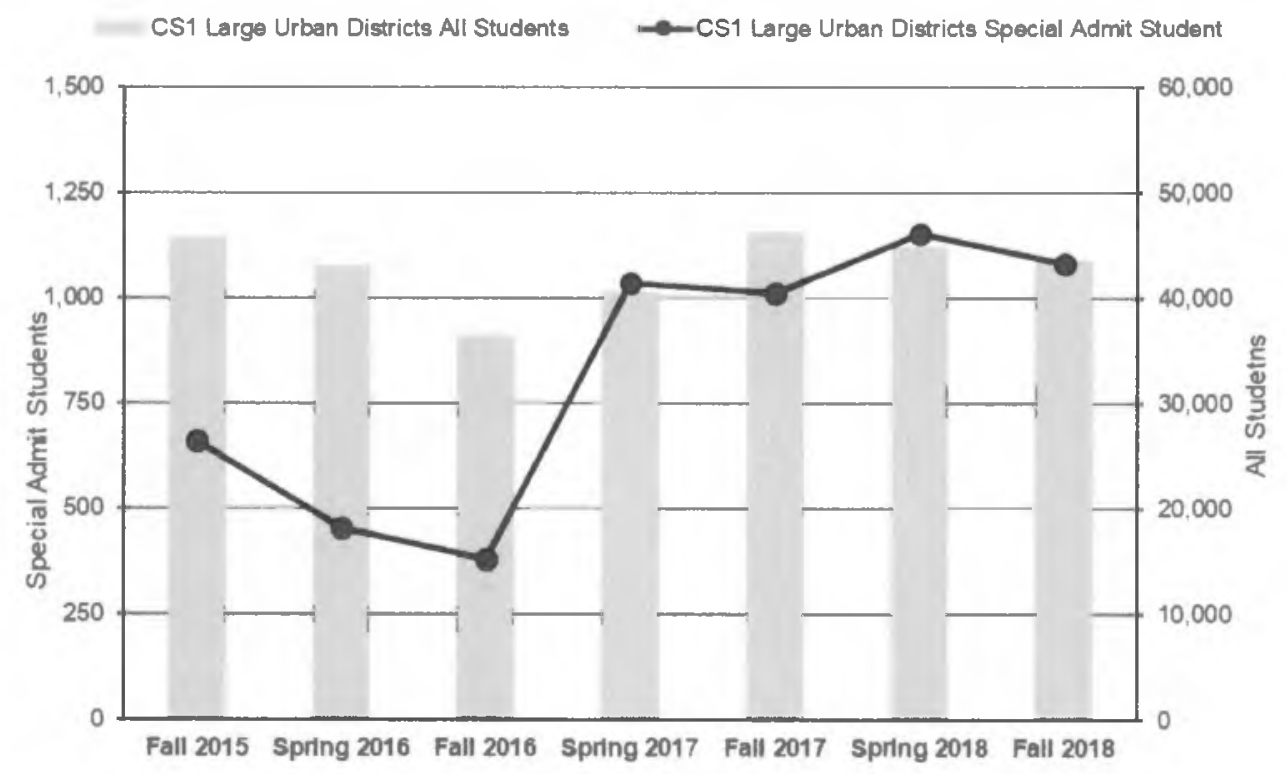

Figure 3 Case Study One: Community College Enrollment Patterns

Dual enrollment of all types is considered by the community college leadership to be strategy for increasing enrollment, as reported by the Chancellor of the District in an update in January of 2017. Dual enrollment comes in three forms at this community college. First, there is traditional dual enrollment, where individual students take classes of their choice after school and on weekends at the college. Unlike many high schools, this district requires that individual dual enrollment students have completed 120 of the 230 high school credits required to graduate, putting them in $11^{\text {th }}$ or $12^{\text {th }}$ grade when they take their first dual enrollment course. Second, there is an "early college program", where small schools choose to arrange their schedule and send groups of students to the 
community college to take several courses each semester. This program has pathway focused courses and additional support for students, including the ability to borrow textbooks. All classes are on the college campus. Interestingly, this program was included in the Concurrent Courses Initiative which informed AB 288 (Hughes, Rodriquez, Edwards, \& Belfield, 2012). According to the Dean of Health and Social Services (HSS), "It's limited currently to high schools that will rearrange their bell schedule to allow that". The third and most recent form of dual enrollment adopted is CCAP dual enrollment, which the community college defines as dual enrollment classes offered at the high school. Despite having pathways and additional support, the early college program is separate from the CCAP initiative because it was under different leadership. The organization defines CCAP dual enrollment as being only at the high school, although this is not part of the legislation and conflicts with what is considered ideal by the support research.

In 2016 , a team made up of a dual enrollment adopter from the community college, a dual enrollment administrator from the high school who was directed by the high school superintendent, and a pathway specialist from a local non-profit, came together to create a CCAP agreement under $\mathrm{AB} 288$. The Vice Chancellor describes the trio as a strong team, bringing the legal and technical knowledge of the non-profit resource, knowledge of and connections in the high school system, and knowledge of and connections in the community college system. 
When the CCAP agreement was in place, the representative from the high school was hired by the community college district, into the role of Dean of High School Programs (HSP). This staffing decision was an important leadership decision because it further strengthened the partnership. At the high school district, dual enrollment is supported through the Student Learning Supports Department, with a focused Supervisor for dual enrollment and a team of nine administrative people to support dual enrollment, particularly the registration and enrollment process. The dual enrollment administrator at the community college is supported by a contractor who is co-funded by the high school and community college. This bridging position is critical to success, identified in interviews on both the high school and community college site, but the position is tenuous, depending on grant funding.

According the Associate Vice Chancellor, when the CCAP initiative started "the more experimental high schools were the first ones to want to try [CCAP dual enrollment] out." The Associate Vice Chancellor says that "we see our high school students in our district as being our future students, and so we're interested in having that relationship and garnering that relationship to be healthy and trustworthy with each other as well." A benefit of dual enrollment is having an opportunity to build trust and an awareness of the community college with students.

Based on funding cuts, the dual enrollment Supervisor at the high school anticipates that the team at the high school will shrink. As the program matures and budgets are cut, the high school district dual enrollment supervisor hopes that the 
individual high schools, particularly the counselors, will become more self-sufficient, which may be a difficult transition. The dual enrollment administrator at the high school district say that there are CTE funded site coordinators at some of the high schools that could be focused on also supporting AB 288 dual enrollment, which provides support despite the reduction in grant funding.

\section{Case Study Two and Case Study Three: Two Approaches}

Case study two and case study three come from the same rural area and both serve a geographically dispersed population. The community colleges serve a similar number of students and both are single district community colleges partnering with multiple high school districts. What differentiates these two case studies is that each found its own distinct approach to developing dual enrollment initiatives. In case study two, a team was created in preparation for the launch of dual enrollment, with designated leadership for student services and for curriculum. In case study three, the community college has created a single position to oversee high school partnerships. This role is responsible for overseeing dual enrollment, leading the creation of the program, and leveraging existing programs and personnel to implement dual enrollment.

\section{Case Study Two: Rural Community College with Team-Based Leadership}

Case study two looks at the smaller of the two colleges in this region, with approximately 8,500 FTES. Despite being the smaller of the two rural community college districts and serving a smaller number of high school districts, the investment made by this community college was focused and extensive. This college has creating leadership 
positions under both student services and academics, resulting in increased structure and support for dual enrollment.

As reported in an update to the board by the Vice President of Student Services in December of 2017, the high school partners were engaged early in the development of CCAP dual enrollment through intentional conversations. Four workgroups were created to guide the implementation plan for dual enrollment: agreement (including materials and textbook costs), academic pathways and policies, student support and services, and staffing and labor. These work groups were made up of both community college and high school representatives. Leaders at the community college were assigned under both academic and the student services. This team-based administration is unique among the case studies.

Given the high-level staffing commitment made to the CCAP dual enrollment initiative, interviews were done with the two dual enrollment leaders: the pathway specialist on the academic side and the Director of Student Success and Equity on the student services side. On the student services side, interviews were done with the counseling division chair and a general counselor, both of whom were involved with both students and with program implementation. To inform the academic side, a faculty member involved with implementing dual enrollment courses with the multi-high school district was included. For historical context, a consultant involved in the grant initiatives used to provide funding was also interviewed, as well as the current and previous principals in the initial single college district. 
The three high school partners in this community college district included two single high school districts and a high school district with three comprehensive high schools (Table 10). The single high school districts have a much smaller population of under-represented students when looked at by race and by SES. The multi-high school district has three comprehensive high schools, including one with an early college program for all students. In contrast to the single high schools in this district, the multiple high school district serves a much larger low-SES and underrepresented student population. This district serves students who are in line with the intention of the CCAP dual enrollment legislation, although CCAP dual enrollment is being offered in all districts.

Table 10 Case study two: Rural single community college district with multiple high school districts and team-based administration

\begin{tabular}{|c|c|c|c|}
\hline \multicolumn{4}{|l|}{ Case Study Two } \\
\hline \multirow[t]{6}{*}{$\begin{array}{l}\text { Rural CC } \\
(8.5 \mathrm{k} \text { FTES) } \\
\text { CCAP Agreements: } 3\end{array}$} & \multirow{6}{*}{$1: M$} & \multirow[t]{2}{*}{$\begin{array}{l}\text { District } 1 \\
\text { ( } 641 \text { high school } \\
\text { students) }\end{array}$} & $\begin{array}{l}\text { Comprehensive High Schools (1) } \\
\text { (621 students) } \\
\text { Underrepresented Students: } 31 \% \\
\text { Low-SES: } 21 \%\end{array}$ \\
\hline & & & $\begin{array}{l}\text { Continuation Schools (1) } \\
\text { (21 students) }\end{array}$ \\
\hline & & \multirow[t]{2}{*}{$\begin{array}{l}\text { District } 2 \\
\text { ( } 859 \text { high school } \\
\text { students) }\end{array}$} & $\begin{array}{l}\text { Comprehensive High Schools (1) } \\
\text { ( } 845 \text { students) } \\
\text { Underrepresented Students: } 27 \% \\
\text { Low-SES: } 17 \%\end{array}$ \\
\hline & & & $\begin{array}{l}\text { Continuation Schools (1) } \\
\text { (14 students) }\end{array}$ \\
\hline & & \multirow[t]{2}{*}{$\begin{array}{l}\text { District } 3 \\
\text { (3,158 high school } \\
\text { students) }\end{array}$} & $\begin{array}{l}\text { Comprehensive High Schools (3) } \\
\text { (3,055 students) } \\
\text { Underrepresented Students: } 76 \% \\
\text { Low-SES: } 62 \%\end{array}$ \\
\hline & & & $\begin{array}{l}\text { Continuation Schools (1) } \\
\text { (103 students) }\end{array}$ \\
\hline
\end{tabular}


In an update to the board of trustees in January of 2017, the Vice President of Student Services laid out the plan for CCAP dual enrollment. The first CCAP dual enrollment agreements were reviewed and approved in March and April of 2017. The intention from the beginning was to offer courses in all three high school districts, a decision that did not seem to consider the demographics of the single high school districts or the intention of $\mathrm{AB} 288$.

\section{Case Study Three: Rural Community College with Focused Leadership}

Case study three examines the larger of the two rural community colleges. It is both geographically larger and has a larger student population. This district has almost 10,000 FTES, about $15 \%$ larger than the district in case study two. In addition, the demographics in this district are more homogenous and containing predominantly students in groups identified by AB 288 legislation. This community college district serves primarily Latino students (77\%). It partners with five high school districts: three single high school districts and two multiple high school districts, one with four comprehensive high schools and one with two comprehensive high schools (In this case study, the student demographics clearly meet the intent of $A B 288$ legislation, putting more focus on other aspects of the legislation, like staffing, funding, and pathway creation, as critical factors in understanding how the legislation is being upheld. 
Table 11). The three single high school districts, unlike the single high school districts in case study two, have populations more in line with both the county $(80 \%$ Latino) and community college (77\% Latino) demographics. These districts have $85 \%$, 95\%, and 97\% Latino populations, respectively. Similarly, the multiple high school districts have $89 \%$ and $94 \%$ Latino populations. In this case study, the student demographics clearly meet the intent of $A B 288$ legislation, putting more focus on other aspects of the legislation, like staffing, funding, and pathway creation, as critical factors in understanding how the legislation is being upheld. 
Table 11 Case study three: Rural, focused administration, single and multiple comprehensive high school districts

\begin{tabular}{|c|c|c|c|}
\hline \multicolumn{4}{|l|}{ Case Study Three } \\
\hline \multirow[t]{10}{*}{$\begin{array}{l}\text { Rural CC } \\
\text { (10k FTES) } \\
\text { CCAP Agreements: } 5\end{array}$} & \multirow{10}{*}{$1: M$} & \multirow{2}{*}{$\begin{array}{l}\text { District } 1 \\
\text { (1,302 high } \\
\text { school students) }\end{array}$} & $\begin{array}{l}\text { Comprehensive high schools (1) } \\
\text { (1,263 students) } \\
\text { Underrepresented Students: } 87 \% \\
\text { Low-SES: } 81 \%\end{array}$ \\
\hline & & & $\begin{array}{l}\text { Continuation schools (1) } \\
\text { (39 students) }\end{array}$ \\
\hline & & \multirow{2}{*}{$\begin{array}{l}\text { District } 2 \\
\text { (1,536 high } \\
\text { school students) }\end{array}$} & $\begin{array}{l}\text { Comprehensive high schools (1) } \\
\text { (1,492 students) } \\
\text { Underrepresented Students: } 96 \% \\
\text { Low-SES: } 89 \%\end{array}$ \\
\hline & & & $\begin{array}{l}\text { Continuation Schools (1) } \\
\text { (44 students) }\end{array}$ \\
\hline & & \multirow[t]{2}{*}{$\begin{array}{l}\text { District } 3 \\
\text { ( } 845 \text { high school } \\
\text { students) }\end{array}$} & $\begin{array}{l}\text { Comprehensive high schools (1) } \\
\text { ( } 817 \text { students) } \\
\text { Underrepresented Students: } 76 \% \\
\text { Low-SES: } 66 \%\end{array}$ \\
\hline & & & $\begin{array}{l}\text { Continuation schools (1) } \\
\text { (28 students) }\end{array}$ \\
\hline & & \multirow{2}{*}{$\begin{array}{l}\text { District } 4 \\
\text { (10,689 high } \\
\text { school students) }\end{array}$} & $\begin{array}{l}\text { Comprehensive high schools (4) } \\
\text { (10,514 students) } \\
\text { Underrepresented Students: } 98 \% \\
\text { Low-SES: } 83 \%\end{array}$ \\
\hline & & & $\begin{array}{l}\text { Continuation schools (1) } \\
\text { (175 students) }\end{array}$ \\
\hline & & \multirow{2}{*}{$\begin{array}{l}\text { District } 5 \\
(2,421 \text { high } \\
\text { school students })\end{array}$} & $\begin{array}{l}\text { Comprehensive high schools ( } 2) \\
\text { (2,302 students) } \\
\text { Underrepresented Students: } 96 \% \\
\text { Low-SES: } 81 \%\end{array}$ \\
\hline & & & $\begin{array}{l}\text { Continuation Schools (2) } \\
\text { (119 students) }\end{array}$ \\
\hline
\end{tabular}

Since the leadership for dual enrollment in this case study is focused, interviews were done with the Vice President of Student Affairs, who undertook the initial dual enrollment agreement, and with the Director of College Readiness, who joined the organization in Spring of 2018 and administers the dual enrollment program. Interviews were done in three high school districts: the largest comprehensive district and the two largest single high school districts. In the larger single high school district, district 2, 
interviews were done with the Director of $21^{\text {st }}$ Century Learning and Innovation at the district level, and with the principal, $12^{\text {th }}$ grade counselor and junior counselor at the high school, all of whom supported the CCAP dual enrollment initiative. In district one, in contrast, interviews were done with the principal, who acts as the dual enrollment administrator, and the counselor who supports the dual enrollment initiative. In the multihigh school district, only the pupil personnel specialist was interviewed, as they are the single point of contact for the dual enrollment initiative at the three high schools. Having a single point position focused on dual enrollment as a secondary activity is typical in smaller high school districts.

Like the community college in case study two, there was a focus on and a commitment to supporting the dual enrollment initiative, except with a single administrative position focused on it at the community college. In addition, the dual enrollment administrator changed between the first and the second year. High school partners commented that this community college sent someone out to support them whenever they had need, either planned, in the case of registration, or unplanned, when an unexpected problem arose. This model of having a central point of leadership for all dual enrollment activities and development of agreements across all partner high schools has resulted in steady growth of special admit students, which grew from $2 \%$ of total enrollment to over $6.5 \%$ of total enrollment between Fall of 2015 and Fall of 2018 (Figure 2 on page 75 ). 


\section{Dual Enrollment Policy Adopters, Administrators, and Supporters through a Bottom-up Implementation Lens.}

The policy-making roles of street level bureaucrats are built upon two interrelated facets of their positions: relatively high degrees of discretion and relative autonomy from organizational authority. (Lipsky, 2010, p. 13)

The framework of bottom-up policy implementation is useful in understanding the environments in which CCAP dual enrollment environments are adopted because both the high school and the community colleges are under-resourced and the policy adopters, administrators, and supporters are overworked. This leads to a de-emphasis of the intent of the policy and to the potential recreation of the limitations in dual enrollment that the legislation seeks to rectify. After the initial creation of the agreement, community college dual enrollment administrators are given a large degree of autonomy in shaping the resulting CCAP dual enrollment program, negotiating the resources they can, and working with deans and other decisionmakers to shape the dual enrollment programs. It can be a delicate negotiation, depending on the role that has been created. The Director of College Readiness says she is always walking that fine line, recognizing that she is not a Dean, but saying that she is developing skills that help her to alleviate the workload of the deans in the process.

Street level bureaucracy expands the understanding of the impact of dual enrollment administrators at the high school and community college, allowing for the analysis of motivations and pressures that may detract from meeting the intent of the legislation. Administrators at the high school act as street level bureaucrats to their high 
school student clients, creating the providing or restricting access to the dual enrollment courses offered through the CCAP agreement (Figure 4). The community college administrators help support and shape the program, in some cases supporting and working directly with students to resolve problems.

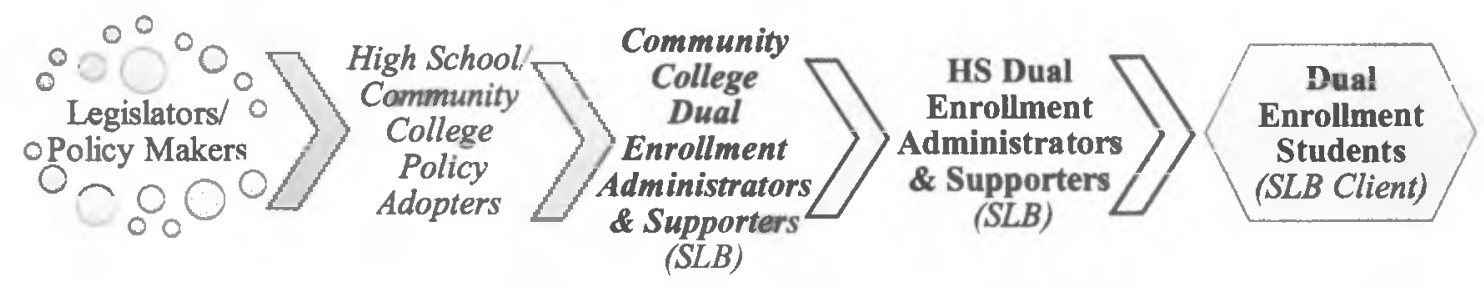

Figure 4 Street-level Bureaucrats: High School Districts

Across the case studies, dual enrollment administrators report little direction or oversight. Knowledge about dual enrollment is limited in both the high school and the dual enrollment environments, so across all case studies the people are selected or hired for their expertise and left to develop and implement the dual enrollment program. This is also true at the high schools. The Counselor from case study two's high school district two describes creating her own forms "to make sure that students are aware of the expectations of a college course." This counselor had taught at the community college and had a high level of awareness about the processes and the courses. She was tasked with supporting dual enrollment at her school because she had unique specialized knowledge that did not exist elsewhere in the organization. When she describes her role, she describes herself as "the key person if [anyone on campus] has any concerns." In describing her role, the Director of College Readiness in case study three describes one that includes all high school enrollment initiatives, articulation, a capacity building initiative between the high schools and the state schools, and grant responsibilities. This 
breadth of high detail, high demand work which contributes to the overload that is a characteristic of the bottom-up implementation environment.

The position that high school dual enrollment administrators and supporters are street level bureaucrats is further strengthened by the breadth of their roles combined with their responsibility in guiding and placing students (Lipsky, 2010). The high school district"s Director of 21 st Century Learning \& Innovation in case study two describes a broad set of responsibilities that includes CTE programs, adult education, supervising the college and career planning initiative, and working with both the elementary and high schools. She reports to the superintendent, but the complexity of her responsibility does not leave room for close oversight. She is prioritizing initiatives and activities continuously.

At the high schools, the same is true. The Associate Vice Chancellor in case study one describes the attitudes of the high school superintendent that gives a view of the high school administration in their role as the manager of streetlevel bureaucrats. The superintendent in this case study is described as not hands on, leaving the individual high schools to make decisions.

\section{Policy Implementers' Understanding and Externalization of AB 288 Goals}

AB 288 creates a new and hopefully improved form of dual enrollment that provides broader access and greater accountability. Understanding the objectives that differentiate CCAP dual enrollment initiatives from traditional dual enrollment is critical in judging if the intent of the legislation is being met. The primary intent of the legislation is that access should be created for underrepresented student populations and 
for students who are not college bound. This is at the heart of AB 288 legislation, but high schools and community college are left to define this for themselves, based on their specific circumstances. According to Vince Stewart:

We didn't define eligibility of schools that can put in place an $\mathrm{AB} 288$ agreement, based on the school demographics [or] student population. What we said is that if you create these partnerships then this is the intended student population that [...] we want you to serve (Stewart. 2019).

The policy adopters and administrators must decide what this means in practical terms. They are called to think about three fundamental characteristics that differentiate CCAP dual enrollment: access by under-represented student populations and by students who do not think of themselves as college bound, expansion of dual enrollment beyond high performing students, and creation of defined pathways. These three characteristics overlap but each lead to specific decisions that point to an understanding of the fundamental intent of CCAP dual enrollment.

Expanding access to under-represented student populations is complicated by a characteristic of high schools. Since high schools serve all students in their districts, students are allowed to self-select into dual enrollment limited only by any prerequisites of the class. In some cases, dual enrollment is limited to students participating in a specific CTE pathway or to those in a certain grade level. The open access inherent in the 
high school placement process means that we need to look for clues to a community college leader's understanding of dual enrollment in their choice of partnerships. How dual enrollment is positioned with students and in how counselors are coached to guide students into or away from selecting dual enrollment illustrates the understanding of high school leaders.

The legislative intent is to expand access to dual enrollment to a more academically diverse population from the high performing students who have historically participated in dual enrollment. This is fundamental to increasing access of students who may not be college bound. This academic shift means that student supports must be intentionally created, where students previously were expected to seek out their own supports and advocate for themselves.

The creation of pathways is also a key difference. Up until now, students took any course that interested them. Under CCAP dual enrollment, the intention is that thought will be put into the selection of courses and pathways that will help a student complete high school and put them on the path to certificate or degree completion at the community college. Looking for intentionality in how each of these legislative intents are met is key in evaluating leaders' understanding of the legislative intent and in differentiating CCAP dual enrollment initiatives from the dual enrollment that has been the norm previously. The staffing of CCAP dual enrollment and the funding of the initiative indicate if this is being approached as a new initiative or if the benefits of 
CCAP dual enrollment are simply being leveraged to streamline existing dual enrollment implementations.

\section{Supporting Dual Enrollment as a New Initiative Understandings of equity and program creation.}

The legislative intent of $\mathrm{AB} 288$ is left up to interpretation, which creates goal ambiguity, reinforced by the lack a definition of who is being served within the partnerships being evaluated. It is necessary to raise awareness around who is not being served and to have a clear understanding about who is being served. Within the partnership, conversations about equity and the definition of underserved student populations is critical, because understandings about varies widely across the dual enrollment initiative ( 
Table 12). In addition, there needs to be clear understanding that this is not traditional dual enrollment, but rather a brand-new initiative that leverages dual enrollment to expand access and support underrepresented student populations and providing thoughtful support for students. 
Table 12 Understanding of Legislative Goals by Role

\begin{tabular}{|c|c|c|c|}
\hline & Case Study 1 & Case Study 2 & Case Study 3 \\
\hline 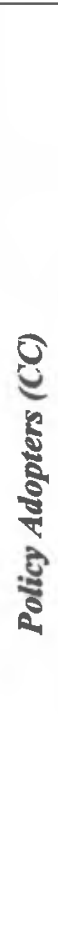 & $\begin{array}{l}\text { 1. CCAP Agreement } \\
\text { quotes education } \\
\text { code that supports } \\
\text { the creation of an } \\
\text { agreement for } \\
\text { offering dual } \\
\text { enrollment to } \\
\text { expand } \\
\text { opportunities for } \\
\text { students who are } \\
\text { not college bound } \\
\text { or who are } \\
\text { underrepresented } \\
\text { in higher } \\
\text { education. } \\
\text { 2. Closed sections } \\
\text { are critical and } \\
\text { appealing to high } \\
\text { school partners. }\end{array}$ & $\begin{array}{l}\text { 1. CCAP Agreement quotes } \\
\text { education code that supports the } \\
\text { creation of an agreement for } \\
\text { offering dual enrollment to expand } \\
\text { opportunities for students who are } \\
\text { not college bound or who are } \\
\text { underrepresented in higher } \\
\text { education and additionally in the } \\
\text { appendix makes it the high schools } \\
\text { responsibility to select students } \\
\text { consistent with the intent of the } \\
\text { legislation. } \\
\text { 2. Per the Director of Student Success } \\
\text { and Equity, the CC President came } \\
\text { from another state that had a "fully } \\
\text { fleshed out dual enrollment } \\
\text { program" and saw the potential of } \\
\text { AB } 288 \text {. } \\
\text { 3. First meeting focused on what "AB } \\
288 \text { would allow us to do" - the } \\
\text { program characteristics. }\end{array}$ & $\begin{array}{l}\text { 1. CCAP Agreement } \\
\text { quotes education code } \\
\text { that supports the } \\
\text { creation of an } \\
\text { agreement for } \\
\text { offering dual } \\
\text { enrollment to expand } \\
\text { opportunities for } \\
\text { students who are not } \\
\text { college bound or who } \\
\text { are underrepresented } \\
\text { in higher education. } \\
\text { 2. No charge for } \\
\text { materials and } \\
\text { textbooks - equity } \\
\text { money used to fund } \\
\text { 3. Per the Director of } \\
\text { College Readiness, } \\
\text { the President who } \\
\text { initially supported } \\
\text { AB } 288 \text { was heavily } \\
\text { involved in local } \\
\text { communities. }\end{array}$ \\
\hline$\frac{2}{3}$ & $\begin{array}{l}\text { 1. } \mathrm{A} \overline{\mathrm{B}} 288 \text { opened } \\
\text { access for Latino } \\
\text { and black } \\
\text { students. } \\
\text { 2. No knowledge of } \\
\text { how students } \\
\text { were selected at } \\
\text { the high school. }\end{array}$ & $\begin{array}{l}\text { Academic: } \\
\text { 1. High schools choose their } \\
\text { approach to equity and which } \\
\text { students are enrolled } \\
\text { 2. CTE is being offered to support } \\
\text { career goals } \\
\text { Student Services: } \\
\text { 1. Allowed closed courses to be } \\
\text { offered on the high school } \\
\text { campus. }\end{array}$ & $\begin{array}{l}\text { 1. Chose to apply for } \\
\text { Director of College } \\
\text { Readiness to have } \\
\text { the opportunity to } \\
\text { implement CCAP } \\
\text { dual enrollment } \\
\text { because she saw it } \\
\text { as a great } \\
\text { opportunity for "our } \\
\text { students." } \\
\text { 2. Believes in an } \\
\text { "equity mindset" } \\
\text { and that the } \\
\text { populations they are } \\
\text { serving need to be } \\
\text { able to think of } \\
\text { themselves as } \\
\text { college students. }\end{array}$ \\
\hline
\end{tabular}




\begin{tabular}{|c|c|c|c|}
\hline & Case Study 1 & Case Study 2 & Case Study 3 \\
\hline 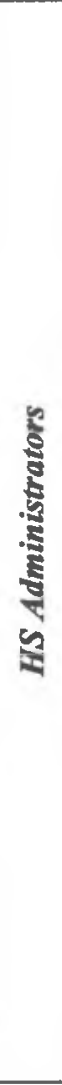 & $\begin{array}{l}\text { 1. Growth focused } \\
\text { on } \\
\text { underachieving } \\
\text { students who are } \\
\text { not successful in } \\
\text { regular high } \\
\text { school model } \\
\text { (dual enrollment } \\
\text { generally) } \\
\text { 2. Access to AB } \\
288 \text { driven by } \\
\text { interest at the } \\
\text { individual high } \\
\text { school. } \\
\text { Enrollment of } \\
\text { self-selection } \\
\text { based on student } \\
\text { interest. }\end{array}$ & $\begin{array}{l}\text { 1. Both the current and the previous } \\
\text { Assistant Principals see CTE as a } \\
\text { way of getting mid-range kids } \\
\text { (2.5/3.0 GPA) college ready. } \\
\text { 2. Current Assistant Principal has } \\
\text { limited knowledge of CCAP } \\
\text { agreement so meeting the } \\
\text { legislative goals are not on his } \\
\text { radar. }\end{array}$ & $\begin{array}{l}\text { 1. District level } \\
\text { administration } \\
\text { focused on the } \\
\text { ability to earn } \\
\text { college credit. } \\
\text { 2. Principal in District } \\
\text { 1 says that equity is } \\
\text { not an explicit } \\
\text { discussion... they } \\
\text { want to make dual } \\
\text { enrollment available } \\
\text { to all students. } \\
\text { Master schedule } \\
\text { limitations can } \\
\text { impact equity. } \\
\text { Wants to identify } \\
\text { pathway level data } \\
\text { to make decisions } \\
\text { about equity based } \\
\text { on socio-economic } \\
\text { status and gender at } \\
\text { a pathway level. } \\
\text { Principal in District } \\
2 \text { wants to "level the } \\
\text { playing field" and } \\
\text { "give the students a } \\
\text { leg up" }\end{array}$ \\
\hline$\frac{5}{\frac{5}{5}}$ & N/A & $\begin{array}{l}\text { 1. Instructor coordinates dual } \\
\text { enrollment because she sees it as } \\
\text { an important equity tool. } \\
\text { 2. A counselor meeting speaks about } \\
\text { a counselors' breakfast focused } \\
\text { on equity. }\end{array}$ & $\begin{array}{l}\text { 1. High school } \\
\text { counselor focuser } \\
\text { on the benefits of } \\
\text { college courses. } \\
\text { 2. The counselor in } \\
\text { HSD3 talked about } \\
\text { CCAP dual } \\
\text { enrollment } \\
\text { providing access to } \\
\text { students who would } \\
\text { not have otherwise } \\
\text { had access. Clearly } \\
\text { understood the } \\
\text { intention of the } \\
\text { CCAP as increasing } \\
\text { access. } \\
\text { Communicated the } \\
\text { benefits to parents. }\end{array}$ \\
\hline
\end{tabular}

The administrators of dual enrollment at the college have a much clearer connection to the intent of the legislation than the policy adopters. This is critical because they are the ones who 
move the program from what is outlined in the agreement to the program that students experience. The administrator roles are critical in shaping CCAP as an equity initiative, but the workload and complexity distract at time from the focus on the fulfilling the intention of the legislation. One administrator identifies three critical access issues that the dual enrollment work, saying "I'm interested strongly in organizational change, effective service delivery, and structural inequalities." Another administrator says "what really drew me to this position was our ability to, the manager's role to implement $\mathrm{AB} 288$. I had been following the legislation and I just see it as an extremely amazing opportunity for students." Much more than the policy adopters, the administrators see their dual enrollment work as focusing on equity.

On both sides of the partnership, leaders' attitudes about equity and access shape the prioritization of the dual enrollment program and create the working environment that will either support or detract from the CCAP dual enrollment initiative. This is externalized in funding and staffing decisions. Recognizing that both high schools and community colleges are resource constrained and have an abundance of initiatives, policy adopters have a choice about advocating for funding in their environment, decisions about how to staff the administration of the dual enrollment program, and choices about how to communicate the initiative to the broader community, creating an understanding of the initiative gives clues about leaders' understanding of the policy.

Equity and access are closely linked by dual enrollment leaders in case study two and three. In these case studies, the dual enrollment administrators have a keen awareness that CCAP dual enrollment is an equity tool that will benefit students, but the focus is on the specific characteristics of the legislation that were meant to make dual enrollment 
more accessible to students, like free textbooks and closed sections, instead of on looking more broadly at what is being implemented through the lenses of access and equity. In case study two, the Director of Student Success and Equity says that having the course during the school day and not paying for textbooks or fees, making it "completely free" is a critical equity piece for the students that they are serving, but it is just a feature of CCAP dual enrollment and does not get at the heart of the intent.

When asked what where the characteristics of leadership that would best support the CCAP initiative, the Dean of HSP in case study one said, on the high school side: It would be good to have someone with a vision and practical approach to what's doable and who is able to see the potential consequences of too much growth... it's better to kind of take our time and be successful. This concern is about leadership not being thoughtful about growth, as opposed to leadership creating barriers to growth. This program administrator, like many bottom-up implementors, is concerned that the goals of the policy adopters in an environment that is understaffed and underfunded will create growth that cannot be supported. In this district, growth as a proportion of total enrollment has been the most modest. Despite this concern, she doesn't question the motivations of leadership saying that "they want to do everything that they can for every student... particularly you know students who traditionally were not successful college."

The Dean of HSP in case study one says that they have been focusing on shifting the demographics of dual enrollment in their environment, saying: 
I think we've doubled our percentage of Latino and African-American students. We totally did change our demographics in dual enrollment. And a lot of that was because of both early release [from the high schools] and AB 288 which opened up access.

The Director of College Readiness in case study three, focusing on both the receipt of college credit and shifting students' beliefs about themselves. She said, "Having that equity mindset and realizing that that's one more student with three units who are being told that they are not only college ready, that [they] are a college student." This is an important shift for the student population, because this may be the first time that they think of themselves as a college student. Clearly, she believes that dual enrollment impacts students that are not currently college bound.

In case study one, having the courses at the high school the key differentiator between their early college and individual dual enrollment initiatives. The community college's Vice President of Student Affairs says "that's why I see this as a form of college access, ... taking instruction to the students." This narrow view of access precludes creative solutions which might provide students with greater exposure to the college campus, which is has the highest impact on students (Hughes, Rodriquez, Edwards, \& Belfield, 2012).

Relying on strong partnerships and the development of well thought out pathways to reach and impact a broader range of students, $\mathrm{AB} 288$ dual enrollment is fundamentally different than traditional dual enrollment. Policy adopters and 
administrators might show their understanding of the intent of the legislation in several ways. First, they will create broad conversations that will allow key people like instructors and counselors to help shape a program that is different than traditional dual enrollment and expand student supports. Second, they will intentionally define pathways which will support students in entering college and developing career skills. In each case study, policy adopters and dual enrollment administrators grappled with both.

High school and community college administrators' ability to act on their beliefs about the intent of CCAP dual enrollment and equity are limited by the systems in which they work. The district one Principal in case study three describes the need for leaders to look broadly for options that will meet the needs of students, saying "that is where the equitable conversation happens":

[If] Dual enrollment at our high school is not working for [some students], then what other options do these kids have and how do we help get them to those options? Because it doesn't just have to happen on our campus for it to be for them... If it's not here, have you held the hand to get them to where they need to be because there's other things out there for them. The principal in case study three also pushed to extend dual enrollment down into lower grades, including $11^{\text {th }}$ in addition to $12^{\text {th }}$ graders, encouraging her team to be open to trying it: "Let's get them in and let's see how they progress." This willingness to question the status quo and focus on what the students need instead 
of what the system demands is essential to the implementation of dual enrollment as a new initiative.

Awareness of who a program is intending to serve and who is actually being served is critical. In case study one, the non-profit partner noted that Dean of High School Programs and the Dean of Health, Physical Education and Social Services were at the early college enrollment events and "observing which students were not there," viewing critically how existing programs are serving all students and particularly those who have been least served, showing a high level of awareness of the intent CCAP dual enrollment, but this conversation did not continue. The dual enrollment administrator is responding to requests, rather than partnering to critically evaluate who is being served and how students are being placed with the high schools. The level of staffing and the complexity in this environment are both factors that redirect focus away from big picture conversations. The community college in case study two is looking critically at who is enrolling in CCAP dual enrollment at the individual course level. In addition to race, they are looking at gender in their Computer Science pathway in district one. They are working with the high school to evaluate how they can make the course more open to females. Knowledge of CCAP dual enrollment, awareness of who is being served, and supporting data are integral. This is a critical conversation when partnering with a high school district where the student populations do not appear to meet the intent of the legislation in terms of race and socio-economic status and where leadership changes have reduced the understanding of CCAP dual enrollment. Under $20 \%$ of the students are 
Latino, in a county with a predominantly Latino population, almost $80 \%$. The Assistant Principal in district one has been in the position for one year, and at the school for eleven years. He understands dual enrollment generally but has no specific knowledge of what differentiates CCAP dual enrollment and was unclear if a CCAP dual enrollment agreement was still in place, despite having well thought out plans around the expansion of the school's CTE offerings leveraging dual enrollment. Interviews with the previous Assistant Principal who initiated CCAP dual enrollment revealed a strong understanding of CCAP dual enrollment and the requirements of the AB 288 legislation, highlighting the benefit of both sides of the partnership centralizing the intent of $A B 288$ in program creation, particularly in times of transition.

Across all case studies, implementors were focused on creating and finalizing the CCAP agreement and were making plans to provide the required reports to the Chancellor's Office about program demographics and courses, with little opportunity to formally evaluate the program and how it is working. In no case was there a formai documented program review plan to guide evaluation of the program, although administrator's in all cases are interested in trying to determine if they are successful. In case study one, the Dean of High School Programs, says: "What we really need is sort of more of a vision of... Where are we going with this? And I don't think we've done that yet." The Director of Student Success and Equity in case study two say that they look at retention and completion. They would like to look more closely to understand if there is a period in a course when students tend to drop and to evaluate what changes might 
enhance student success. The Pathway Specialist reports that they do go through the completion rates with their high school districts and that they have found a higher success rate with dual enrollment, which she attributes to the high schools moderating attendance. Meetings are held across all partnerships to evaluate what courses will be offered in the next year, but nobody reported meetings to critically review the challenges faced within the programs or evaluate approaches for improving the initiatives. By the time the one semester ends, the pressure and focus are preparing for the next one, limiting the time for critical reflection.

\section{Administrative staffing decisions.}

The decisions that community colleges make about how to staff CCAP dual enrollment initiatives reflect the requirements of their environment, understanding of $A B$ 288 legislation and commitment to CCAP dual enrollment. Each community college has its own approach to administrative staffing for dual enrollment. In addition, in every district but the large high school district in case study one, no single individual has the administration of dual enrollment as their primary focus, rather one of many. 
Table 13 provides and overview of staffing and funding across the case studies. 
Table 13 Case Study Staffing and Funding Overview

\begin{tabular}{|c|c|c|c|}
\hline & CC Staffing & High School Staffing & Funding \\
\hline Case Study 1 & $\begin{array}{l}\text { Single Administrator } \\
\text { with administrative } \\
\text { support funded by high } \\
\text { school district }\end{array}$ & $\begin{array}{l}\text { Single administrator with } \\
\text { dedicated staff, shrinking } \\
\text { due to funding changes. } \\
\text { Leverages instructors as a } \\
\text { support resource. }\end{array}$ & Grant funded \\
\hline Case Study 2 & $\begin{array}{l}\text { Two Administrators } \\
\text { with funded } \\
\text { administrative and } \\
\text { counseling support }\end{array}$ & $\begin{array}{l}\text { District support through } \\
\text { existing counselors }\end{array}$ & $\begin{array}{l}\text { Budget } \\
\text { funding }\end{array}$ \\
\hline Case Study 3 & $\begin{array}{l}\text { Single administrator } \\
\text { working to develop }\end{array}$ & $\begin{array}{l}\text { Principals and counselors } \\
\text { at high school sites } \\
\text { supporting the initiative } \\
\text { with a district level } \\
\text { resource in one high } \\
\text { school }\end{array}$ & $\begin{array}{l}\text { HSI funding, } \\
\text { some grant } \\
\text { funding }\end{array}$ \\
\hline
\end{tabular}

In case study one, the decision was made to create positions at both the high school and the community college to oversee the implementation. Since this is a complex environment with one large community college and one large high school district, this is appropriate. Given the number of high schools, a single position may be inadequate to allow for tailored solutions based on the needs of individual high schools. In this partnership, they were struggling to find a balance between automation to improve efficiency in a resource constrained system and a more interactive process which allows more discussion and provides more information. The Director of High School Partnerships describes this:

It was one layer of being removed from being able to dig...because I wasn't directly working with the principals which...I don't even know if I could because there's so many of them. 
A process was created to streamline course requests, but it was at the loss of direct and iterative communication. In case study one, the staffing decisions and financial investment being made reflect a belief that $\mathrm{AB} 288$ is not fundamentally different than the other early college credit initiatives on the campus. The dual enrollment administrators are committed to implementing this form of dual enrollment to leverage the benefits it offers, but the complexity of the environment precludes them from doing much beyond leveraging the existing dual enrollment mechanisms.

Case study two has implemented a large team to manage the dual enrollment initiative, allowing for deeper thought about the finer points of their CCAP implementation. This has resulted in increased structure and support-formalized meetings across high school districts, recognition and welcome events for dual enrollment students, processes that support program development and data sharing, and focused and predictable program support. These processes and procedures were represented in supporting documents that were reviewed, including a student conduct map to bridge high school and community college discipline practices; a counseling referral form to support communication between high school and community college counselors; a counseling support services meeting agenda to plan for CCAP dual enrollment support; a records request form to allow transcript access by the high school to CCAP students; and a College 101 workshop outline in preparation for CCAP student onboarding. The dedicated staff allows for documentation and intentional communication of the CCAP program, which has the benefit of providing historical context and support 
for decision-making. This also bridges staff changes, which this organization has faced with the loss of their dual enrollment coordinator, mentioned across multiple interviews at the community college. The program growth in this environment has been intentional and tailored to the needs of the individual high schools. This model has yielded many benefits in terms of a strong well-documented program with processes that support both partners and students. It has also created communication challenges, fundamental in a large team, and it has not yielded critical conversations about meeting the intent of the legislation, particularly in the two single high school districts whose demographics show smaller populations of underrepresented and low-SES students. Dual enrollment is being proactively and extensively staffed by the community college in case study two. This trend is continuing. Consistent with their full staffing of the initiative, the Pathway Specialist indicates that her role is going from part time at twenty-nine hours to full-time, in recognition of the growth of the program, a necessary change because "with only twenty nine hours, you can get behind very, very, very quickly." This high level of staffing brings with it the opportunity to create good supports and communication because of the resources. It also brings with it the challenge of communication across the roles and clarity around responsibility. Communication is leadership issues that can impact the effectiveness of the dual enrollment initiative. The Counseling Division Chair describes a failure in communication between the academics and student services: That person's perception is that they are communicating but everybody else is saying it's not happening. There's a disconnect. People start shutting 
down and so you do what you need to do to contribute, but that's it.

Because you're not feeling engaged. You're not feeling communicated with. You're not feeling listened to.

She summarizes,: "I think we're lacking a conductor. Someone who pulis the entire team together and talks about the picture from a holistic perspective." This large team provides resources that allow them to interact extensively with parents and maintain multiple partnerships, being very responsive. Maintaining a clear vision and communication across a large team is also a challenge.

In case study three, a single position, the Director of College Readiness, has been created to direct the dual enrollment initiative. While the staffing on the community college side is similar to that in case study one, the complexity is lower, with fewer high school partners to manage. This position has the benefit of focusing on preparing students to enter college, so it combines oversight of bridging programs and all forms of dual enrollment. The holistic focus on all forms of dual enrollment allows both for consistency across and for differentiation between the dual enrollment programs. This provides control over groups of programs that can be leveraged to support students as they undertake dual enrollment and subsequently transfer to the community college. It also involves participation in the Guided Pathways initiative, in the pre-enrollment group, further leveraging the knowledge in this position. There is also a focused administrative support position in this environment, although the position is currently empty. Staff turnover is a serious problem in a specialized program area like CCAP dual enrollment. 
In case study three, the Director of College Readiness describes working to enroll students herself, because while they have been promised an enrollment services specialist, that position has not yet been implemented. She says that this is "not the most efficient, but if that's what needs to be done..." also saying that is good for people to "see her in the trenches."

CCAP dual enrollment is treated as an additional initiative at the high school sites and added on to the already complex workloads of existing principals and counselors. Only in case study one was a dedicated staff hired to support the CCAP dual enrollment initiative. While the complexity of a district with twelve high schools creates challenges, it also affords the benefit of being large enough to justify a focused resource. In other case studies high schools assigned resources to coordinate and support dual enrollment on top of their normal duties. In case study two and three, the lack of a designated resource meant that CCAP dual enrollment was one responsibility among many at the high school level. The Counseling Division Chair in case study two describes the impact of this lack of focused staffing: "What we quickly learned is that some high schools click, while [with] others, there [are] administrative issues," which results in a reticence to commit to the activities required to support the partnership. In response, the community college started to limit what they would do to education plans and follow-up with the counselor, because "we can't be the only ones leading this ship... other people need to step up." This is a reaction to the constraint on resources that typifies the street level bureaucrat (Lipsky, 2010). The energy put in on each side of the partnership must be balanced, or resentment 
occurs. Across the high school districts, the focus was on resolving rather than avoiding problems, with a few exceptions. In case study three, the $12^{\text {th }}$ grade counselor reached out to other counselors at schools with active CCAP agreements, borrowing best practices and trying to anticipate the challenges. This may have been because she was focused on a single group of students, the $12^{\text {th }}$ graders, narrowing her focus and giving her room to think critically.

Across the high schools, counselors are a critical part of the process, but universally dual enrollment is another initiative they must keep track of and understand in an environment where they have many students and many activities to track. In case study three, the counselor in district two describes being responsible for orientation for incoming dual enrollment instructors. Counselors were described as key contributors in case study two because they have knowledge about how individual classes fit degree, certificate, and transfer pathways.

Communication is a leadership issue that can impact the effectiveness of the dual enrollment initiative. In case study two, there is a clear understanding that a higher level of staffing is required to support this new initiative. Responsibility for dual enrollment is divided between leaders under academics and student services. The Counseling Division Chair describes a failure in communication between the two groups:

That person's perception is that they are communicating but everybody else is saying it's not happening. There's a disconnect. People start shutting down and so you do what you need to do to contribute, but that's it. 
Because you're not feeling engaged. You're not feeling communicated with. You're not feeling listened to.

\section{Funding.}

The funding of dual enrollment is also an indication of the attitudes of policy adopters toward the dual enrollment initiative (

Table 14). The community college in case study two showed a commitment to the initiative, funding in the budget multiple roles responsible for supporting dual enrollment. In the other case studies, dual enrollment funding was cobbled together from a variety of grant initiatives, including Strong Workforce and equity funding.

Table 14 Findings on Funding by Case Study

\begin{tabular}{|c|c|c|c|}
\hline & Case Study 1 & Case Study 2 & Case Study 3 \\
\hline : & $\begin{array}{l}\text { No mention of } \\
\text { discussions of how to } \\
\text { fund the initiative as } \\
\text { part of the agreement } \\
\text { creation process. }\end{array}$ & - N/A & $\begin{array}{l}\text { - Equity money used to } \\
\text { pay for textbooks. }\end{array}$ \\
\hline है & $\begin{array}{l}\text { - CC position is partially } \\
\text { grant funded. Also } \\
\text { using Strong } \\
\text { Workforce money. } \\
\text { - Changes in grant } \\
\text { funding support are } \\
\text { affecting support at the } \\
\text { high school. } \\
\text { - Support person at the } \\
\text { CC is a contractor } \\
\text { funded by the high } \\
\text { school and changes in } \\
\text { funding may also } \\
\text { impact this position. }\end{array}$ & $\begin{array}{l}\text { Academic: } \\
\text { - Positions are funded under } \\
\text { the general budget. } \\
\text { - Academic administrator } \\
\text { being increased to full } \\
\text { time. } \\
\text { Student Services } \\
\text { - One issue that was worked } \\
\text { though was compensating } \\
\text { community college } \\
\text { instructors for training and } \\
\text { onboarding dual enrollment } \\
\text { instructors from the high } \\
\text { school. }\end{array}$ & $\begin{array}{l}\text { - Equity funding allows } \\
\text { for field trips, like } \\
\text { bringing students to } \\
\text { campus for Transfer day. } \\
\text { - Use Hispanic Serving } \\
\text { Institution (HSI) funding } \\
\text { to fund administrative } \\
\text { positions. }\end{array}$ \\
\hline
\end{tabular}




\begin{tabular}{|c|c|c|c|}
\hline & Case Study 1 & Case Study 2 & Case Study 3 \\
\hline $\begin{array}{l}5 \\
\frac{5}{5} \\
\frac{5}{5} \\
\frac{5}{5} \\
\frac{5}{5} \\
\frac{5}{2} \\
5\end{array}$ & $\begin{array}{l}\text { - A lot of funding goes } \\
\text { toward enrolling and } \\
\text { supporting students. } \\
\text { - Funding is being cut so } \\
\text { individual high schools } \\
\text { need to become self- } \\
\text { sufficient around } \\
\text { enrolling students. } \\
\text { - Dual enrollment } \\
\text { administrator position } \\
\text { is grant funded. } \\
\text { - Grant funding } \\
\text { reimburses the } \\
\text { community college for } \\
\text { half of a position that } \\
\text { supports application } \\
\text { and enrollment of dual } \\
\text { enrollment students. }\end{array}$ & $\begin{array}{l}\text { Outreach counselor is } \\
\text { funded with CTIEG funds. } \\
\text { - Planning to use Strong } \\
\text { Workforce funds to expand } \\
\text { CTE focused dual } \\
\text { enrollment. }\end{array}$ & $\begin{array}{l}\text { No additional positions } \\
\text { created. Dual enrollment } \\
\text { added on as a } \\
\text { responsibility to existing } \\
\text { positions. }\end{array}$ \\
\hline
\end{tabular}

The loss of grant funding will require the reduction of support in case study one, which will impact the growth of this initiative. In case study three, grant money is used to enhance the dual enrollment initiative, providing funding for field trips. Administrative positions are funded as a Hispanic Serving Institution (HSI), a potentially more stable form of funding and one tied to the equity goals of the legislation. The administrative position is grant funded. Unless this program is funded as part of the budget, there are not enough resources to intentionally create administration and support systems above the ones available in the system, which is necessary as the focus of dual enrollment is shifted. In case study three, a dual enrollment instructor also takes on training counselors and other adjuncts on the content of the dual enrollment courses. The history faculty in case study two describes acting as a resource to dual enrollment instructors at the high school, in addition to teaching her full course load. This assumption that existing roles will take 
on additional responsibilities with no reduction in existing duties is problematic because it does not create time to proactively focus on the dual enrollment initiative.

\section{Expanding Access to Underrepresented Student Populations}

Creating access for underrepresented student populations and creating opportunity for students who are not college bound are at the heart of $\mathrm{AB} 288$ legislation, but it is a small focus in the dual enrollment initiatives studied. Universally, there was very little conversation at the community colleges or the high schools about the intent of $\mathrm{AB} 288$ legislation and how these two goals will be met or about student selection. There is an assumption at the community college that the high schools are responsible for student placement. The high schools provide access to all courses to all students in the school. In order to evaluate the policy adopters, administrators and supporters understanding of these goals and how they externalize this understanding, it is necessary to understand how these leaders talk about the legislation, look at the demographics of the resulting partnerships, including the funding of the initiative, consider the student selection process, and the creation of pathways.

Evaluation of the CCAP agreements show recognition of the intent of the legislation, but no definition of what it means in the specific context of the partnership being created. All agreements restate the education code around the intent of CCAP dual enrollment to expand access. Only in case study two was the responsibility for individual student selection to meet these goals clearly placed on the high school district. This is consistent with the early planning and broad conversations that characterized case study two. While this definition of responsibility for monitoring the intent is an improvement 
over the other case studies, no explicit conversations between the partners about student selection to meet these goals were documented. More importantly, no processes were created to enforce or support this part of agreement. Across all case studies, existing dual enrollment processes were leveraged instead of creating expanded processes to help guide the selection, placement, and support of students specific to the CCAP agreement. Despite the large dedicated team, there are resource challenges. The pathway specialist in case study two says that she would like to have monthly meetings with key stakeholders and a clear project plan for each month listing key activities. She believes it would help the high schools to understand the complexity of the community college system.

The lack of time and the speed with which dual enrollment agreements were undertaken may be a factor in the limited discussion of the intent of $\mathrm{AB} 288$ dual enrollment since administrators in case studies one and three were all supporting multiple initiatives. Organizations spent focused time on developing the agreement and negotiating with their partners. Addressing concerns of unions and instructors and clarifying the needs of the high school partners, a complicated process, was the primary concern. Another factor is the busy schedules of all involved. Across all partnerships, there was a desire to have more regular meetings, but recognition that many of the key stakeholders were involved in a wide variety of initiatives which made communication a challenge. 


\section{Attention to partnership demographics.}

The community college policy adopters in this study acknowledged equity and reaching under-represented student as the goal for their $\mathrm{AB} 288$ initiatives, but when asked directly how under-represented students and students not currently college bound was understood in their context, the answer did not provide a definition. Instead they focused on the characteristics of $\mathrm{AB} 288$ dual enrollment that they felt offered equity, like closed sections during the school day and the requirement that students not be charged for materials and textbooks. In one case, a policy adopter acknowledged that initial courses reached predominantly white and Asian students, explaining that getting courses started was the focus, not the populations that the courses reached. As community college administrators, they recognized that many students come to the community college from the local high schools and therefore would immediately benefit from AB 288 dual enrollment credit. There was no attempt to create a definition, but rather an assumption that the correct student would end up in the program. Concern about self-selection bias regarding these classes makes the omission of a well-defined focus population a serious issue, because students who would and should benefit from the program may not enter it without intentional program marketing and student counseling.

Knowledge of the demographics of individual high schools are left to the high school administrators. Review of these demographics gives insight about the potential for CCAP dual enrollment at a given site (see Appendix B). CCAP courses are offered in seven out of twelve schools in case study one. Unlike in case study two, the schools that 
have the largest underrepresented student populations are offering CCAP dual enrollment, but the community college administrator says that the sites self-selected, instead of being identified through intentional discussion with high school district leadership or with site leadership. As the partnership in case study one progressed, the Vice Chancellor questioned the high school district, asking "why are we only picking these couple of schools? I kind of wanted to spread around the course offerings at different places." Here is a missed opportunity. Broadening access across the district has not been combined with evaluation of the student demographics. In the push to create dual enrollment and work through the complexity, the discussion about specifically who will be served and how will they be identified seems to be missed. One high school where CCAP dual enrollment is offered, has a smaller population of underrepresented students. Only $37 \%$ of the students are in racially under-represented populations and only $22 \%$ are FRMP eligible. Here is another case where student placement should be a focus. The community college is not specifically recruiting schools to undertake CCAP dual enrollment. One high school in the district that does not have CCAP dual enrollment serves a student population that is $85 \%$ FRMP and has $67 \%$ that are in populations that are racially underrepresented in higher education. The Dean of High School Programs says that she does not have time to speak with the individual high schools. The staffing limitation is a factor that limits the community college's ability to be intentional in its creation of CCAP dual enrollment offerings. The reliance on the high school side of the partnership to self-select impacts the ability to create intentional programs that meet the 
intent of the legislation. This is a symptom of not providing institutionalized funding. The Supervisor talks about the loss of grant funding that will impact staffing to support dual enrollment. Reliance on grant funding with no plan to support the program through planned funding indicates a lack of leadership support for the initiative, belying the strong support for the program voiced by policy adopters.

One barrier to creating a clear definition may be that $\mathrm{AB} 2288$ provides no definition of the populations who should be served through this form of dual enrollment, simply saying that it should extend access to underrepresented student populations and to students who may not be already college bound. In order to consider if the partnerships had the potential of meeting the intent of the legislation, I evaluated data for each site to see if the high school districts had a significant population who would meet the intent of the legislation, considering how underrepresented students and students who are not college bound might be identified. In case study two and three, every school within every district is included in the CCAP agreement. I would have expected that some schools, particularly in case study two, would have been precluded from CCAP dual enrollment based on their demographics. While these two groups overlap, I considered them separately to get richer understanding of how well each of the districts are meeting the intention of $\mathrm{AB} 288$ dual enrollment. I analyzed two data points to identify underrepresented students: the percentage of students who are in racial groups that are underrepresented in higher education and students who are low socioeconomic status. I defined the race of underrepresented students as all students who identified as Black, 
Latino, Pacific Islander, Filipino and those who reported multiple races. I defined lowsocioeconomic status as student who are eligible for free and reduced meal plan (FRMP) as an indication of low-socioeconomic status.

I analyzed data to determine the representation of the target student populations in the partner high schools (See Appendix C). Although the definition of under-represented is left to the determination of each partnership, I used race data, because Policy Adopters and Administrators across the case studies identified race when articulating the student populations that they hoped to reach Case study 2 , and socioeconomic status because throughout dual enrollment research socioeconomic status is a key indicator. This resulted in some clear differentiation between case studies. Both case study two and case study three offered CCAP dual enrollment classes at all high schools in their districts, but an evaluation of the student populations yielded key differences.

High schools under case study three clearly served a majority of underrepresented students, with a median of $93.99 \%$ being students who were in underrepresented racial groups and having between $50.6 \%$ and $88.9 \%$ of students eligible for FRMP. The focus for leaders in this case study did not need to be on ensuring that the right students were being served, but rather on student selection and placement and on the creation of pathways that would best serve their students. In addition, between $60.5 \%$ and $97 \%$ of students from these districts went to college went to a California community college, making the need for well-thought out and well-designed pathways even more 
critical, because it was likely that the students would be leveraging the credits they earned in a community college environment.

Case study two, in contrast, had two of five high school districts who clearly had only a limited number of students who fell into under-represented student populations. These two districts had between $26 \%$ and $31 \%$ students who were in under-represented racial groups and between $16.7 \%$ and $22 \%$ FRMP, indicating a predominantly affluent population. These two schools also had the highest graduation across these districts, both over $95 \%$, and the highest rate of students meeting A-G requirements, indicating that a high percentage of students are already college bound. The lack of focus on what student population is being served and discussions around student selection lead to partnerships that may not be meeting the intention of the legislation. Interviews with the Assistant Principal who created the CCAP agreement and the Assistant Principal who is now leading it showed that no concerted effort was being made to market classes to the student populations appropriate for the CCAP initiative.

\section{Student Selection process}

The administrators spoke eloquently about their commitment to equity and their desire to support the students in their districts. Much like the policy adopters, community college administrators did not define a student selection process, leaving it to the high

schools. Dual enrollment administrators at the high school want to make sure students are successful in dual enrollment classes. Given resource constraints and the complexity of the environment, administrators fall back on trying to identify students who will be 
successful rather than creating supports that will support students in being successful. In some case studies, the age of the students, limiting access to the course to only $12^{\text {th }}$ graders, or requiring a specific GPA was used to pre-screen to find students were likely to be successful.

In the section of the CCAP agreement for case study two that requires a description of the criteria used to assess the ability of pupils to benefit from the course the justification says that "in consultation with their school district counselors, students selfselect a pathway based on their academic readiness and alignment of course content to students' educational and career goals." This boilerplate language was used across agreements for all high school districts. This agreement does not clearly articulate any decision-making process for selection of students but leaves to the discretion of the high school counselor.

Administrators at the community colleges are drawn to the positions they are in because they believe that dual enrollment will benefit students. Across all case studies, clear identification of student populations was not an explicit conversation and the focus was on the benefits that $A B 288$ offered to the student populations. At the high schools, presentations of dual enrollment held no mention of the student populations who would benefit from a CCAP initiative, but rather universally focused on role of dual enrollment in Smarter Balanced Assessment Consortium (SBAC) metrics, which includes participation in dual enrollment as an indicator of college readiness. The focus was on giving access to college credit to the high school students they serve, but they did not 
have a formalized process for identifying students who might benefit from the dual enrollment courses. Allowing students to choose their own classes is central to high school cultures. High school administrators and supporters all focused on raising student awareness of dual enrollment with all students and allowing all students to access the dual enrollment classes.

Although serving students who are in underrepresented populations is central to realizing the goals of $\mathrm{AB} 288$, the intent of the legislation is broad and undefined and there is no accountability measure to evaluate adherence to the goal. In addition, the legislators have missed something key: high schools serve their whole population. Across all case studies, dual enrollment courses created under the CCAP agreement are available to all students in the high school. Adherence is further complicated because it is dependent on a partnership across two very different systems. Within each partnership, placement of the students, central to equitable outcomes in the dual enrollment process, is under control of the high schools and no data about the demographics of dual enrollment participants was available. The Director of Student Success and Equity in case study one at the community college recognizes that student selection is central to the intent of the legislation:

We're still having conversations about in terms of how to identify students... it's a difficult thing for me in my role as Equity Coordinator, since the goal and the intention of $\mathrm{AB} 288$ is making sure that all students have access to these courses, is tempering that with the reality that we 
don't want to put anybody in these courses at the high school level, have them not do well, and then think college is not for them or that they're not going to succeed in college.

She centralizes students, balancing the opportunity and risk. This is a balance that exists for dual enrollment administrators between the potential benefit of dual enrollment and the potential harm it can do to students. The Pathway Specialist in case study two describes trying to find this balance too: "We trying to make sure that we are identifying students that have the higher likelihood of success while not ruling out anybody who potentially could succeed and do well." The concern that is raised is that without a strong understanding of quantifiable student characteristics, there is an opportunity for students to be precluded based on the bias of the person making the placement decision, an issue that was not raised when discussing student selection. This is the balance that those who place students across all case studies are working to find.

High schools must be thoughtful about their placement of students. In case study one, the Supervisor of Learning Supports for the high school district, says that traditional dual enrollment was serving one set of students, "our high achieving students", but there has been an intentional shift with the CCAP agreement: "Our growth has really been focused on actually underachieving students and students who have not been successful in the regular high school model." This commitment to shifting the demographics came from a review of the 2014-2015 data, according to the consultant that was included in case study one: 
[Only] one African American student had gotten dual enrollment credit and there was a real commitment of the two leaders at the table, the Vice Chancellor and the Executive Director of Curriculum Instruction that this was not ok and they were going to have to do intensive on the ground outreach that really ensured that they were going to reach more students of color.

According the Vice Chancellor in case study one, the high schools self-selected as the site of dual enrollment classes, saying that the high school districts chose schools that "had a better mix of high achievers, moderate achievers and low achievers," not working with the largest comprehensive schools. An issue here is that this was not based on a review of data, but rather on suspicions of the implementors. The demographics of the high school show a larger percentage of African American, Filipino, Latino and Pacific Islander populations in schools that offered dual enrollment than in the total high school population, indicating that this initiative is being undertaken in environments that potentially serve the populations in line with the intent of the legislation ( 
Table 15). This does not give insight into which students are in the dual enrollment classroom. 
Table 15 Case study one: Demographic comparison of dual enrollment students to all comprehensive high school students

\begin{tabular}{llllllll} 
& \multicolumn{3}{c}{$\begin{array}{l}\text { American } \\
\text { Indian/ }\end{array}$} & & & & \\
& $\begin{array}{l}\text { African } \\
\text { American }\end{array}$ & $\begin{array}{l}\text { Alaska } \\
\text { Native }\end{array}$ & Asian & Filipino & Latino & Lanicl & Pacific \\
Islander & White \\
$\begin{array}{l}\text { \% of Total } \\
\begin{array}{l}\text { Population } \\
\text { \% of Pop. }\end{array}\end{array}$ & $6.17 \%$ & $0.26 \%$ & $40.81 \%$ & $6.25 \%$ & $26.45 \%$ & $1.01 \%$ & $11.07 \%$ \\
$\begin{array}{l}\text { At DE } \\
\text { Sites }\end{array}$ & $10.10 \%$ & $0.41 \%$ & $22.78 \%$ & $7.75 \%$ & $38.95 \%$ & $2.03 \%$ & $10.08 \%$ \\
\hline
\end{tabular}

According to the Vice Chancellor, they "wanted to start off with what they thought would be the best place to start and give this a solid launch... a little bit more of the higher achiever kind of high school." While this is his perception, the data shows something different. In looking at the characteristics of the high schools where dual enrollment was being offered in the first two years, dual enrollment was offered at the smaller high schools. No dual enrollment courses were offered in the four largest comprehensive high schools. In case study one, according to the Vice Chancellor, the community college had started to build relationships at the high schools to expand where dual enrollment was offered: "We have started to reach out to the principals... and saying wouldn't you be interested in some course being offered during your instructional hours?" When asked how partnerships were developed, in all case studies the community college partners relied on the high schools to determine if they could meet the intent of the legislation. 


\section{Expanding the Academic Population Served}

\section{Creation of student supports.}

In delivering policy street-level bureaucrats make decisions about people that affect their life chances. (Lipsky, 2010, p. 9)

With the shift away from high performing students, student supports are a unique and critical part of AB 288 dual enrollment. Another indicator of an understanding of and a commitment to the intentions of $\mathrm{AB} 288$ dual enrollment is the approach to student services. AB 288 is made up of a course offering in a pathway, combined with an instructor, either from the community college, or a teacher from the high school who meets minimum

qualifications and is hired as an adjunct, and the location of the course. Surrounding these are the core of what differentiates CCAP dual enrollment,

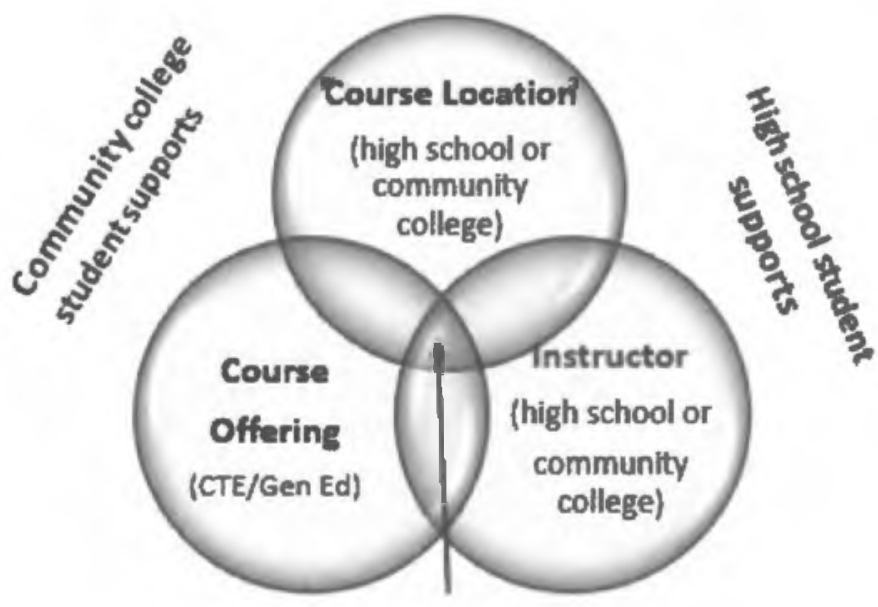
Students experience of cCAP Dual Enrollment academic supports from Figure 5 CCAP Dual Enrollment both the high school and the community college (Figure 7), although this aspect is not mandated by the legislation. Across all case studies, the agreement shares this responsibility between the high school and the community college partners. AB 288 dual enrollment does not provide funding over and above the apportionment provided, which may be a factor in the creation of new supports being deprioritized. The new community 
college funding formula is complex, but there are still aspects which need to be clarified around student success measures, which appear differently for dual enrollment students (Career Ladders Project, 2018). In case study one, support teachers were used to provide focused support for dual enrollment students. In the other case studies, the dual enrollment program relied existing programs at the community college and high school, with grant funded positions to support the registration and enrollment process, which was a challenge across all case studies. The administrators and the supporters spoke clearly about the need to support the student populations which they serve. They articulated a commitment to equity, but clearly had not thought about it in terms of how that could be intentionally externalized in response to the stated goals of $\mathrm{AB} 288$. The focus was instead on how to support the high schools in a resource constrained environment, reinforcing the argument that the high school administrators are clients of these street level bureaucrats.

Interestingly, the dual enrollment administrator in case study three specifically stated that they do not want to provide any support to dual enrollment students over and above what any student on campus or online would receive. These students are younger and may have different needs, in the same way that language leamers or students with disabilities may have different needs. Administrators across the case studies did not take the opportunity to explore additional supports that would specifically benefit CCAP dual enrollment students. 
In a CCAP agreement supports may come from several places: the dual enrollment instructor in the classroom, assigned support teachers, high school and community college counselors, existing supports at the high school, or existing supports at the community college. Ideally, these supports mesh seamlessly, providing support and the opportunity for success for dual enrollment students. For this to happen, the supports must exist and be accessible and students must be aware of them.

Support is necessary in the enrollment and registration process. In case study three, according to the Director of College Readiness, they have assigned an Enrollment Services Specialist from Admissions and Records, to manage the onboarding and forms, but that at times, she's "literally out there doing things too."

Each partnership approaches student supports in its own way (

Table 16). In some cases, supports will vary based on the individual high school or the course selected. For example, in case study three, the largest district, with four comprehensive high schools, the high school district has assigned a dedicated dual enrollment liaison with the community college. The Director of College Readiness says that "without their support, we wouldn't be where we are." She says that this person helps coordinate enrollment workshops, follows up with students, monitors the college deadlines, follow-up with faculty... "any sort of follow-up at the school level." Having focused support from the high school district to match the focused support at the community college has been critical to success. In case study one, the Supervisor of Learning Supports at the high school district describes filling a similar function but is 
also responsible for developing new agreements and has three times more high schools in her district.

Table 16 Definition of Student Supports by Role

\begin{tabular}{|c|c|c|c|}
\hline & Case Study 1 & Case Study 2 & Case Study 3 \\
\hline 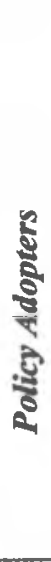 & $\begin{array}{l}\text { 1. Assigned academic } \\
\text { support teachers } \\
\text { from the high } \\
\text { school. }\end{array}$ & $\mathbf{N} / \mathbf{A}$ & $\begin{array}{l}\text { 1. On-site registration with } \\
\text { provided Chromebooks. } \\
\text { 2. Counseling course as a } \\
\text { "hinge" course, an } \\
\text { opportunity to train students } \\
\text { about being a college } \\
\text { student, with presentations } \\
\text { from support programs } \\
\text { 3. Support in onboarding } \\
\text { students } \\
\text { 4. Presentation from Student } \\
\text { Life Director to provide } \\
\text { information about college } \\
\text { student conduct }\end{array}$ \\
\hline 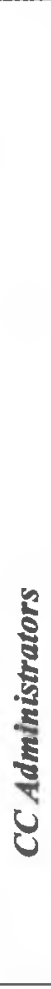 & $\begin{array}{l}\text { 1. Students are } \\
\text { provided with an } \\
\text { orientation and } \\
\text { application } \\
\text { workshops. } \\
\text { 2. Built in support with } \\
\text { the support teacher, } \\
\text { who works with the } \\
\text { community college } \\
\text { instructor and is } \\
\text { added to the Canvas } \\
\text { shell. }\end{array}$ & $\begin{array}{l}\text { Academic: } \\
\text { 1. Work with the high } \\
\text { schools to determine } \\
\text { how the high schools } \\
\text { can better support } \\
\text { students, but the } \\
\text { academic } \\
\text { administrator would } \\
\text { know more about it. } \\
\text { 2. Designated counselors } \\
\text { go to the high school. } \\
\text { Student Services } \\
\text { 1. Want to make sure } \\
\text { that no more supports } \\
\text { were being offered to } \\
\text { high school students } \\
\text { than students on } \\
\text { campus or online. } \\
\text { 2. Assigned a part time } \\
\text { counselor and a dual } \\
\text { enrollment } \\
\text { coordinator for } \\
\text { follow-up support of } \\
\text { students. }\end{array}$ & $\begin{array}{l}\text { 1. Choosing Counseling as the } \\
\text { first dual enrollment course } \\
\text { provides training and } \\
\text { support for students to } \\
\text { develop skills to be } \\
\text { successful. } \\
\text { 2. Still working to create dual } \\
\text { enrollment workshops for } \\
\text { students to support the } \\
\text { application process. } \\
\text { 3. Students are informed about } \\
\text { supports available to them } \\
\text { on campus. }\end{array}$ \\
\hline
\end{tabular}




\begin{tabular}{|c|c|c|c|}
\hline & Case Study 1 & Case Study 2 & Case Study 3 \\
\hline है & $\begin{array}{l}\text { 1. Student application } \\
\text { and registration is } \\
\text { one of the biggest } \\
\text { challenges. }\end{array}$ & $\begin{array}{l}\text { 1. Support is provided } \\
\text { by an outreach } \\
\text { counselor as part of } \\
\text { her role to support } \\
\text { CTE. } \\
\text { 2. Support focused on } \\
\text { the application } \\
\text { process and was } \\
\text { supported through a } \\
\text { community college } \\
\text { resource coming on } \\
\text { campus. } \\
\text { 3. No explicit discussion } \\
\text { of additional academic } \\
\text { support for CCAP } \\
\text { dual enrollment } \\
\text { students. } \\
\text { 4. Per counselor } \\
\text { supporter, CTE } \\
\text { Transitions funds } \\
\text { were used for } \\
\text { Counselor meetings } \\
\text { focused on equity. }\end{array}$ & $\begin{array}{l}\text { 1. Definition of student } \\
\text { supports are not in the } \\
\text { purview of the district level } \\
\text { administrator. Left to the } \\
\text { principal. }\end{array}$ \\
\hline
\end{tabular}

CCAP dual enrollment is a new initiative in all case studies. Often the first focus of student supports is making sure that students do not fail. The Director of College Readiness in case study one says:

We would rather a student not have a $\mathrm{W}$ if they decided to withdraw from the classes [if it] isn't a good fit, so what we do is let... liaison know of the no rate of record date and let's get them out before as if they never existed. In district two in case study three, the high school counselor has this responsibility. She describes approaching students if when an instructor lets her know that there is an attendance issue or a concern about passing. If a student decides to withdraw, the counselor helps them through the process and helps them register for a high school class for the balance of the semester. In case study three, the Director of College Readiness 
says that they have developed a notification process for the high school counselors to make sure that they are aware of the community college deadlines and that the instructor will not automatically withdraw students who are not passing. The Pupil Personnel Specialist in district three responds, communicating proactively with the teachers, asking them to identify students who are struggling in the course. These high school districts work with the same community college, but the emphasis when there is a liaison is more proactive, while what is described here is reactive, indicating that both sides of the partnership's attitudes shape the resulting dual enrollment program and the support of students. In all cases, the focus is not yet on creating proactive supports for students, but rather responding to identify students so that they are removed from the course if they are not successful. Also left to the judgement of high schools is what will happen to students who are removed from the course. If there is not a proactive plan, while students are saved from a W or a failing grade on their transcript, they lose the opportunity for high school credit.

The community college Dean of High School Programs in case study one describes the mismatch that CCAP dual enrollment seeks to bridge iike this:

The philosophies between that high school and the college sometimes clash because the high schools do have a much more supportive safety net in place for every student and the colleges really don't... it's up to the students to seek out the resources. 
She echoes the Associate Vice Chancellor of Student Services, who describes "a gap in the hand-off to high school to the college," created because "the high schools have a really strong urge to see their students be successful and they want them to succeed and they want them to get through high school and they want them to graduate."

There are contrasting examples of approaches to support in the classroom across the case studies. In case study one, the large urban community college and high school district, use a "support teacher" model. In this partnership, a majority of the instructors come from the community college, but a teacher from the high school is also assigned to each course section as a support teacher for the students. They are responsible for the students for the days where the course is in the high school schedule, but the college course is not scheduled to meet. They review the assignments with students and support them in staying on track with the college course. It is important to note that they are not subject matter experts, but rather participate as a specific support to students in developing the skills required to be successful in a college course. The high school dual enrollment administrator names this model as a key part of their success:

Not all of our high schools have this support mode... when [the support teacher] is not there, it's not as successful because they're not meeting on those off days and going over the materials being presented, so I'm wanting to promote that more at sites.

In case study two and case study three, students are made aware of the supports at the community college campus, transportation or transplantation of supports is not discussed. 
Existing high school tutoring is available to students in these classes, but not integrated or modified to provide any additional support. In case study three, the instructor for dual enrollment in District one does hold weekend tutorials. Students are expected to selfrefer. This instructor is a high school instructor who has been hired as an adjunct. In case study three, the principal in high school district one had previous experience with dual enrollment where "we actually initiated supports right alongside parallel to the adoption of dual enrollment courses because we were aware that students would need them." In her current role, they "have not done a great job with that." She goes on to say, that they knew that the instructors teaching the courses were very supportive of students and depended on that. Relying individuals to meet the needs of the students instead of systematizing support is a symptom of being under-resourced, a typical limitation in bottom-up implementations. The Director of College Readiness in case study three says: "We want to make sure that in terms of equity, we're providing sufficient support, but we're not... putting any more pressure on the dual enrollment faculty than any other adjunct." This is the risk that the Principal partner district one faces, the risk of burning out her faculty by relying on them to provide student supports. Despite recognition of this issue, no specific supports have been created yet, although she is starting with disability resources.

Interestingly, in case study two, the Counseling division chair provides a contrast between two of their partner high schools that had her asking "How much ownership does [the community college] have at those high schools with those kids?' One high 
school expected and relied on the community college to do everything, creating the need for boundaries, while the other was extremely independent. She describes it in this way: "[The high school] didn't even bother to call us. They were like 'We've got it. They are our kids... we'll take care of them"" which caused her to ask, "Can we at least have a little bit of them?" Being clear on the division of labor in this new world is difficult because both sides share the students and the support should be shared, but different partners may have different levels of resources available. The critical issue here is that

CCAP dual enrollment seeks to serve

\section{Exposure to college level coursework.}

The maintenance of rigor is a concern, because it can vary from instructor to instructor, a problem in any classroom, but the Director of Student Success \& Equity in case study 2 says, "We're not adapting, modifying, or lessening the courses because we are offering them on a high school campus." Rigor varies across disciplines and across courses, depending on the alignment between skills developed in high school curriculum and what is expected in the college course. When expanding the students served, reducing the rigor of college coursework is not an option, but courses vary in what is required.

Despite many mentions of the importance of maintaining rigor in these case studies, rigor is used without a clear agreement on definition. As students with a broader range of demonstrated academic performance are included in dual enrollment, the 
communication around what is expected becomes critical. Generally, students are only given the information available in the community college course catalog.

Honest discussion about what the requirements of the course are and what preparation of the students is critical. The Director of Student Success in case study two is clear on this: "We need to make sure that what we are offering is actually an appropriate course for that population group." Similarly, the Associate Vice Chancellor acknowledges college level courses may require different levels of rigor: "There are a lot of different types of classes. Some classes require more writing and more analysis." Understanding the requirements of courses selected for dual enrollment is essential. The Pathway Specialist in case study says "We worry about content. We worry that the quality is going to be dumbed down [and] we worry that students might get lost." She describes the outcome of the computer information system pathway that was created. They had been assured that the students were academically prepared for the course, but of the one hundred and twenty in the pathway, half ended up not continuing, because "a heck of a lot of them that weren't up to speed." The community college depends on the high school to counsel students into courses but there was no rubric or definition of what skills were required for the course.

\section{Pathway Creation and Program Growth}

Program growth varied across the case studies. The largest growth was seen in case study three, because of a standardization on a counseling course as the first dual enrollment course. The smallest growth was seen in the largest district, possibly due to the complexity of the environment. The investment in staffing in case study two resulted 
in the development of processes and a wider range of course offerings. While growth of the program is not a measure of quality or focus, it reflects the level of commitment that the leadership of the organization has to the CCAP dual enrollment initiative. When looking across case studies, there are two trends. All programs saw growth in the between the first and second year. In addition, across all case studies there was a reduction in CTE course offerings and an increase in general education courses. In both case study one and case study two, request from the high school were the driver. In case study three, a counseling course was offered to all high school sites in the district, driving a significant increase in general education course offerings.

In case study one, only data for the spring terms was available, but this gives a sense of how the CCAP dual enrollment was shifting (Table 17). The Associate Vice Chancellor in case study one describes how it started in their district, focusing on general education courses that were transferrable to four-year schools, saying that "we're a partnership and because we want to have a good mutual relationship with our high schools, [so] that's where we would start our conversations." In this high school district, only one site maintained a CTE pathway but reduced the number of sections to one. A second site (site ten) dropped the hospitality and tourism pathway and did not offer classes. Two sites moved from CTE to general education (site two and site six). A total of four sites added general education courses. The Dean of HSP indicated that some reductions were made because the collegewas not able to fund the teaching units required, so she was required to work with the high schools to remove some courses. 
Table 17 Case study one: Overview of course offerings (Spring 2017 \& Spring 2019)

\begin{tabular}{|c|c|c|c|c|}
\hline $\begin{array}{c}\text { Agreement } \\
\text { Year } \\
\end{array}$ & $\begin{array}{l}\text { CTE/General } \\
\text { Education }\end{array}$ & High School Pathway & $\begin{array}{l}\text { High } \\
\text { School }\end{array}$ & $\begin{array}{c}\text { \# of } \\
\text { Sections }\end{array}$ \\
\hline \multirow{4}{*}{ Spring 2017} & \multirow{4}{*}{ CTE } & Health Sciences & S1 & 2 \\
\hline & & Law & S2 & 1 \\
\hline & & Health Sciences & S6 & 2 \\
\hline & & Hospitality \& Tourism & S10 & 2 \\
\hline \multicolumn{4}{|r|}{ CTE Total: } & 7 \\
\hline \multirow{9}{*}{ Spring 2019} & \multirow{3}{*}{ CTE } & Health Sciences & S1 & 1 \\
\hline & & Health & S4 & 1 \\
\hline & & Public Service & S5 & 1 \\
\hline & \multirow{6}{*}{$\begin{array}{l}\text { General Education \& } \\
\text { Transfer }\end{array}$} & \multirow[t]{6}{*}{ General Ed \& Transfer } & S2 & 1 \\
\hline & & & S3 & 1 \\
\hline & & & S4 & 1 \\
\hline & & & S13 & 1 \\
\hline & & & S6 & 2 \\
\hline & & & S7 & 1 \\
\hline \multicolumn{4}{|r|}{ CTE Total: } & 3 \\
\hline \multicolumn{4}{|c|}{ General Education Total: } & 7 \\
\hline
\end{tabular}

There were also some impacted courses, like computer science, which could not be offered, since $\mathrm{AB} 288$ prohibits the displacement of existing college students. In some cases, she also says, the schools found that the high schools were not able to fill the courses. There is also tension around not displacing community college instructors, according to the Supervisor of Student learning and supports for the high school district: In our CTE pathways, a lot of our teachers have a master's degree in that discipline, so they could actually be teaching the AB 288 courses, but that would be taking away from a [community college] instructor who teaches that course... it's a balance that we need to figure out how to meet. 
These issues are ones that are part of the complex negotiations required to create a CCAP initiative, but not of them are part of meeting the intent of the legislation, but rather meeting the individual requirements of the partner organizations or soothing the concerns of unions. All are examples of top-down pressures on both sides of the partnership that detract from or undermine the ability of the implementors to prioritize the students they are trying to serve and the intent of the legislation.

In case study 2 , leadership made a commitment to planning early and providing strong staffing for the CCAP dual enrollment initiative, starting conversations across their partner districts early. The result was that courses were offered at all sites in the multiple high school district and at one of the two single high school districts (Table 18). By the second year, a variety of classes were being offered at all high schools in all districts. In addition, their CTE pathways remained strong between year one and year two.

Table 18 Case Study Two: Overview of CCAP Courses and Pathways in the Single High School Districts

\begin{tabular}{|r|c|c|}
\hline & \multicolumn{2}{|c|}{ IItet 1 } \\
\hline General Education & 0 & 0 \\
\hline CTE & 2 & 2 \\
\hline Pathways & Computer Information Systems & Computer Information Systems \\
\hline & \multicolumn{2}{|c|}{ Ditrief 2 } \\
\hline General Education & 0 & 0 \\
\hline CTE & 0 & 2 \\
\hline Pathways & & Automotive Technology \\
\hline
\end{tabular}

Interestingly, in the multi-site high school district, schools varied in their mix of CTE and general education, indicating that they were not using a one size fits all set of 
course offerings, but rather working to respond to the needs of the students at each site, working with the high school leadership to support their requests (

Table 19). In the second year, site one was $100 \%$ general education, site two was $100 \%$ general education, and site three was a mix of CTE and general education. Plans for the 2019-2020 school year show continued growth across all schools and continued variation between the sites.

Table 19 Case Study Two: Multiple High School District CCAP Course Offerings

\begin{tabular}{|c|c|c|c|}
\hline Agreement Year & $2017-2018$ & $2018-2019$ & 2019-2020 (Projected) \\
\hline & \multicolumn{3}{|c|}{ Site 1} \\
\hline General Education & 4 & 10 & 27 \\
\hline$C T E$ & 9 & 0 & 0 \\
\hline \multirow[t]{2}{*}{ Pathways } & $\begin{array}{c}\text { Hospitality \& } \\
\text { Tourism, Health }\end{array}$ & & \\
\hline & \multicolumn{3}{|c|}{ Site 2} \\
\hline General Education & 0 & 0 & 4 \\
\hline$C T E$ & 5 & 9 & 13 \\
\hline \multirow[t]{2}{*}{ Pathways } & $\begin{array}{c}\text { Computer } \\
\text { Programming/ } \\
\text { Video Game Design }\end{array}$ & $\begin{array}{l}\text { Computer Science, } \\
\text { Theatre Arts }\end{array}$ & $\begin{array}{c}\text { Computer Science, } \\
\text { Graphic Arts, Theatre } \\
\text { Arts }\end{array}$ \\
\hline & \multicolumn{3}{|c|}{ Site 3} \\
\hline General Education & 0 & 5 & 17 \\
\hline$C T E$ & 4 & 4 & 10 \\
\hline \multirow[t]{2}{*}{ Pathways } & Theatre Arts & $\begin{array}{c}\text { Business, Theatre } \\
\text { Arts }\end{array}$ & $\begin{array}{l}\text { Business, Computer } \\
\text { Science, Theatre Arts }\end{array}$ \\
\hline & \multicolumn{3}{|c|}{ District Wide } \\
\hline General Education & 0 & 0 & 0 \\
\hline$C T E$ & 0 & 0 & 2 \\
\hline Pathways & & & $\mathrm{ECE}$ \\
\hline Total General Ed & 4 & 15 & 48 \\
\hline Total CTE & 18 & 13 & 25 \\
\hline
\end{tabular}


In the initial year of the agreement, one of the single high school districts offered courses to in a Computer Information Systems (CIS) pathway. The academic dean presented this to the board of trustees as having been "designed primarily to prepare students for high wage careers in networking and security information systems," and resulting in an industry recognized certificate. This pathway is a high wage, high demand pathway, but it was being developed in a school with predominantly high socioeconomic students from populations which are not underrepresented in higher education. The assistant principal did not describe a selection criterion for this class that would focus on identifying students that meet the intention of $\mathrm{AB} 288$ dual enrollment.

Across the multiple high school district, there was a ciear shift from CTE offerings to general education offerings overall (Figure 6). The projections for the next school year show a significant move toward increased general education offerings. This raises a question about why general education has become the priority. It is possible that as counselors became involved in the discussions, awareness of general education courses was enhanced, shifting the focus to a transfer pathway. In addition, staffing may be a factor. CTE generally have a smaller number of faculty, limiting the ability to offer classes at other sites. In addition, faculty may be working in the CTE area, limiting their availability during the school day. The challenge of identifying and hiring qualified CTE instructors hampers the expansion of CTE programs at the community college and may also limit the growth of CCAP dual enrollment in the high schools. 


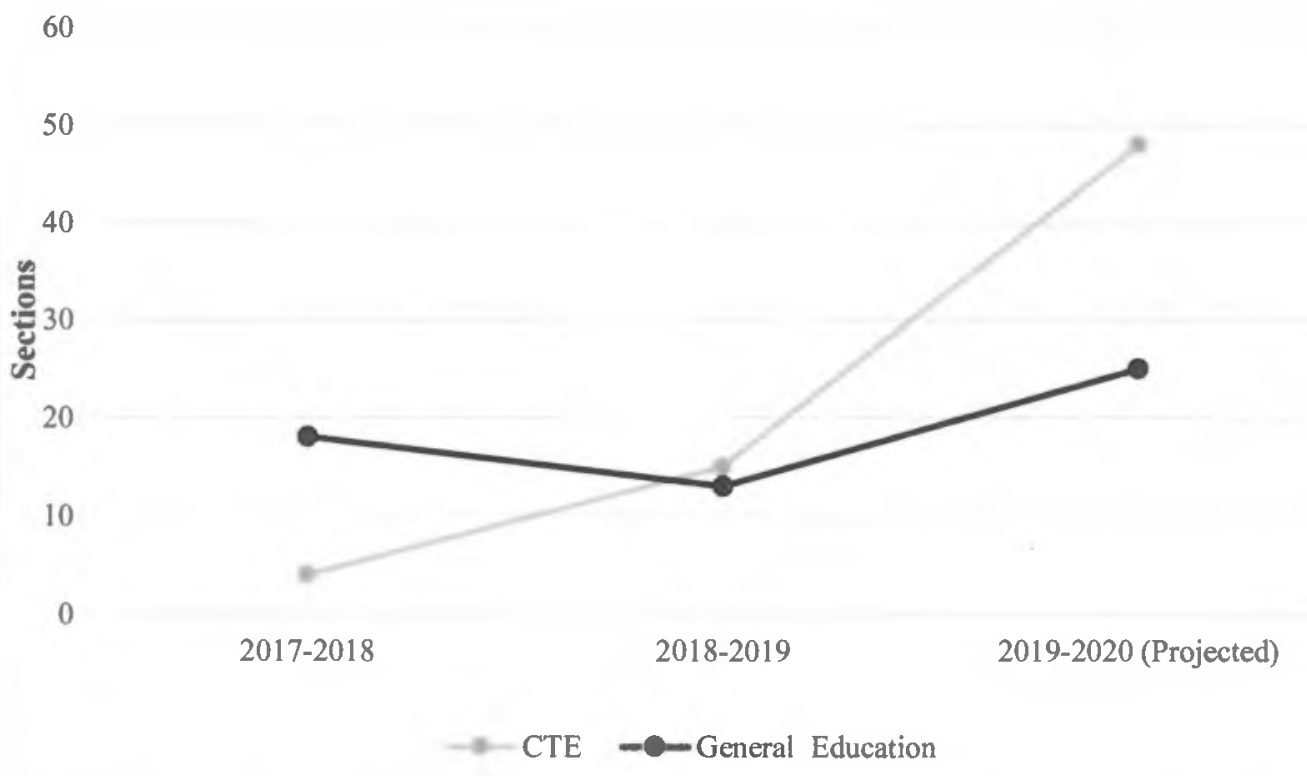

Figure 6 A Comparison of CTE \& General Education Pathways Across the Multiple High School District

In case study three, a different course selection approach was taken from the high schools. Unlike in the other two case studies, the community college suggested the course selection, recommending a counseling course as the dual enrollment course to be offered as first dual enrollment course for students. Counseling courses provide students with three units of transferable credit and which meet general education requirements for the associate degree and provides a course selection for high schools that don't have defined needs in a CTE pathway. The Director of College Readiness calls counseling "a hinge course," saying that she tells schools that it is a "gateway to our dual enrollment program." In the first year of the dual enrollment initiative, CCAP agreements were initiated out four of the five partner high school districts and in all district in the second year (Table $20 \&$ Table 21). This growth is attributable to the model offering a single 
class across all high schools. It reduces the conversation and decision-makers in the community college environment that must be influenced in order to add courses. In addition, high school counselors are more likely to hold a Master's degree in counseling and, therefore, meet the minimum qualifications to teach the classes as community college adjunct instructors than teachers in other disciplines.

Table 20 Case study three - Single High School Districts

\begin{tabular}{|r|c|c|}
\hline \multicolumn{1}{|c|}{ Agreeneut Year } & $2017-2018$ & $2018-2019$ \\
\hline & \multicolumn{2}{|c|}{ District 1 } \\
\hline Unknown & 1 & 0 \\
\hline General Education & 0 & 8 \\
\hline General Education & 4 & \multicolumn{2}{|c|}{ District 2 } \\
\hline CTE & 2 & 2 \\
\hline Pathways & Administration of Justice & Administration of Justice \\
\hline & \multicolumn{2}{|c|}{ District 3 } \\
\hline General Education & 4 & 11 \\
\hline General Education & Non-Profit Credit Recovery \\
\hline Total General Ed & 0 & 3 \\
\hline Total CTE & 4 & 19 \\
\hline Total Unknown & 2 & 0 \\
\hline
\end{tabular}

Table 21 Case study three - Multiple High School District

\begin{tabular}{|l|c|c|}
\hline Agreernent Year & $2017-2018$ & $2018-2019$ \\
\hline & \multicolumn{2}{|c|}{ District 4 } \\
\hline General Education & 0 & 9 \\
\hline School Sites & $0 / 5$ & $\begin{array}{c}4 / 4 \text { \& } \\
\text { credit recovery }\end{array}$ \\
\hline & \multicolumn{2}{|c|}{ District 5 } \\
\hline General Education & 0 & 2 \\
\hline Unknown & 1 & 0 \\
\hline School Sites & $1 / 2$ & $2 / 2$ \\
\hline Total General Ed & 0 & 11 \\
\hline Total Unknown & 1 & 0 \\
\hline
\end{tabular}


The new course offerings in 2018 to 2019 with district 5 were initiated by the newly hired Director of College Readiness who is the sole administrator of dual enrollment at the community college. She described looking for "the low hanging fruit" when she started in May of 2018. She discovered, she said, that this multi-high school district wants:

Every high school to participate in $\mathrm{AB} 288$ at the same rate, at the same level, [with the] same number of classes, saying no one's going faster than the other. And they were following an equality model, which was my approach then, now, and will continue to be is that this is a partnership, as the agreement states. This is not going to be [the community college] coming in and saying 'This is what we're going to do.' and quite frankly, we'll follow the lead of the high school district and so we'l provide that deference and so asking those questions, meeting with the districts, being the face of $\mathrm{AB} 288$, making them feel comfortable and learning what some of the hang-ups were for them.

The Vice President of Student Affairs explained that district two, a single high school district, had a very progressive Superintendent who had experience with dual enrollment, saying: "She was the first one in line. She reached out to our President and said 'Hey, let's do something for our students in [district 2]. I have some ideas."' The Community College responded, creating a team including the Vice President of Student Affairs, the Vice President of Academic Affairs, the Dean of Student Success and the 
Dean of Enrollment Services and Dean in Academic Affairs. They "met with her assistant superintendents and principle of [the high school]. And we hammered out some pathways starting with the Administration of Justice pathway." The leadership at the high school, supported by support from the community college, was a critical force in ensuring that CCAP dual enrollment was undertaken for students in that district, showing how important awareness at the support and advocacy of Superintendents is in CCAP adoption. This district had the most sections in the first year and also showed strong growth in the second year. The multiple high school districts started slower, with one course in the smaller of the two districts, but growing rapidly in the second year, to a total of 13 sections across the two multiple high school districts (Table 21). The complexity of developing an agreement across multiple high school sites may account for only having a single course in the first year.

The question then becomes what is the next course that should be provided to students to extend their transfer or CTE pathways. Counseling courses provide skills development in skills required in college, which is a goal of $\mathrm{AB} 288$, but attention must also be given to the next dual enrollment course offered to students. The Pupil Personnel Specialist in high school district three of case study three raised the concern that only a single counseling course had been identified and that no course had planned for these students in the second semester. Based on this the partners "entered into a pretty late conversation" and identified a second counseling course, a career development course, to 
offer in the second semester. Of the three schools in the district, two added this second class to the master schedule, while one decided that it was too late to make the change.

The Pupil Personnel Specialist was involved conversations with the community college to determine next steps. They have only had a few meetings, but she was sure it would be an ongoing conversation. She goes on to say that they are trying to decide between CTE and general education, asking: "What are some of the goals? In providing these options for students, do we want it to be a transfer pathway? Do we want it to be focused around a vocation?" She says that next year they are adding a transfer level English course, indicating a continuation of the trend toward general education. She also drove the addition of a second counseling course when she was brought on, since high school students are enrolled for a year, not a single semester.

Another thing that differentiates case study three is that this community college is the only one across all case studies that partnered with a credit recovery program, which would clearly be a population that was not currently college bound. An interesting partnership was created with a non-profit program in district 5 whose mission it is "to transform the lives of at-risk youth," offering a single section of a course. It shows some willingness in this district to explore the potential of dual enrollment in populations outside the comprehensive high schools that were the focus of CCAP agreements across all case studies.

Across all case studies, there was reduction in CTE courses and an increase in general education course between the first and the second year of courses being offered. 
Looking at case study one and case study two data, the trend toward the development of general education offerings over CTE (Figure 7). In the case study two, this is driven by the requests of the high school and in case study three this is being driven by the adoption of counseling courses as an initial dual enrollment course for all CCAP students. This has expanded access to dual enrollment by allowing rapid growth, but the efficacy of this strategy for connecting students to college and career.

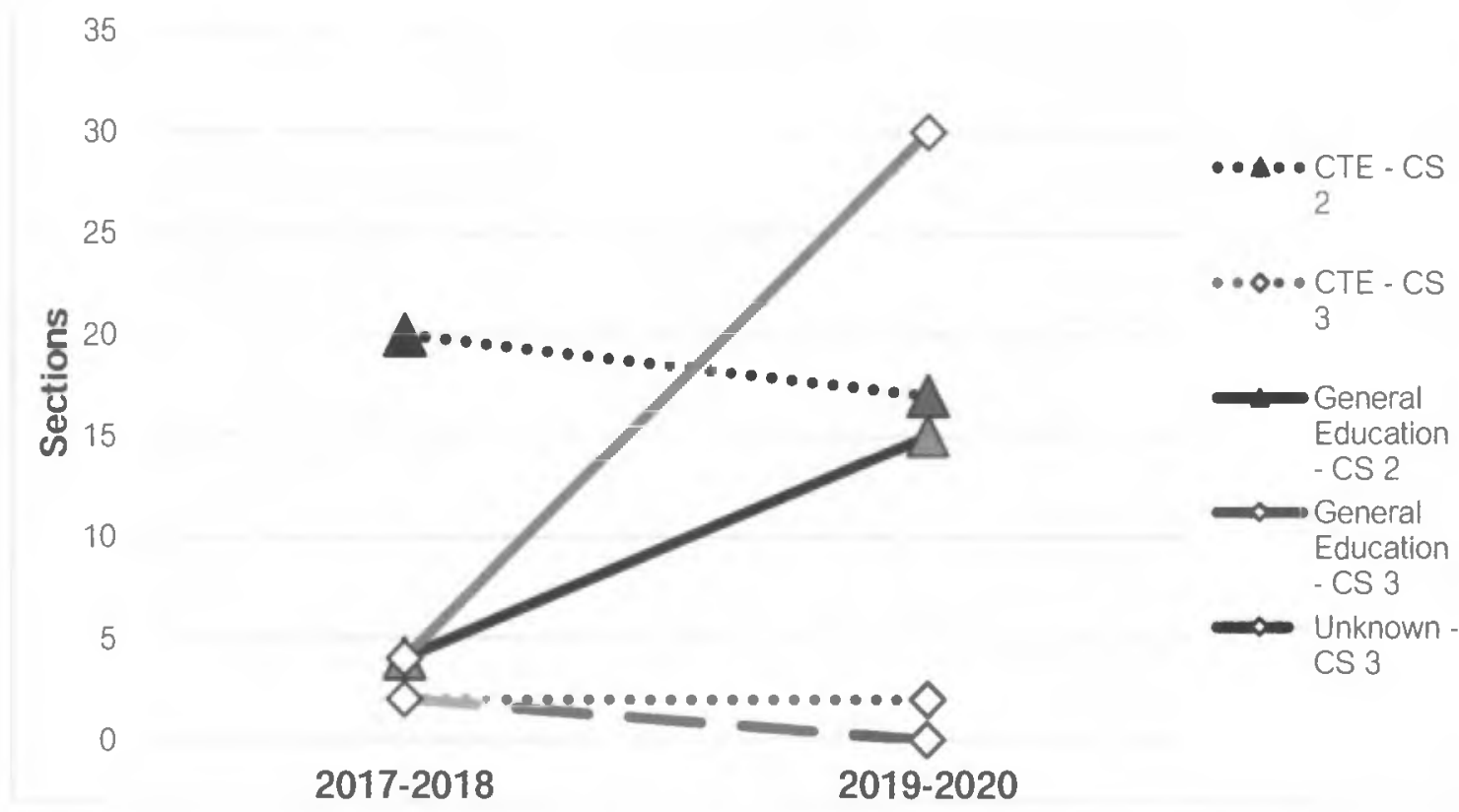

Figure 7 Comparison of CTE and General Education Course Offerings (Case Study One and Case Study Two)

Creating clear pathways of aligned, sequenced coursework.

When speaking about writing the AB 288 legislation, Vincent Stewart provided

the follow perspective on the legislation's intent around pathway development and course selection: 
The idea was to have structured pathways with articulated courses so... they're sort of scaffolded, building one upon the other...[and] within the broad definition of either leading toward college ready or career ready, and not to be so prescriptive in the statute that there would be some flexibility at the local level to determine what specifically should those courses look like.. it has to be based upon the students that you're serving and what you have capacity and the ability to provide, what the colleges in your area can provide.

The legislation left room for the partnership to decide what pathways and courses would best benefit their shared students and the capacity on both sides to provide those courses. There are two key points here that should drive conversations: courses should be an intentional and structured series and a clear intent (leading to college or to career). This is a critical conversation that is often missing between high school and community college partners. In practice, the high school partners drive the choice of courses, although the community college may make suggestions and present options. In case study one, the dual enrollment administrator at the high school says: "I found was that they were just randomly selecting courses, picking different ones each semester." This practice is closer to how dual enrollment has been used historically, as enrichment or a method for providing courses not currently available at the high school. Intentional conversations focused on pathway development were not part of the process. There has been education about this initiative, through an annual principals' breakfast. The agenda for this event 
lays out the intent for this meeting: gain a deeper understanding of the history of dual enrollment, learn about local best practices, learn about the course request and enrollment process for CCAP dual enrollment in this district, and reflect, discuss, and plan with others in the district. Instead of leading to discernment about pathway development in a specific environment, these conversations may have led to increased demand for course offerings that have been tried in other schools. There was a missed opportunity here for a focus on discussion about how pathways might be designed to benefit student populations.

In case study three, instead of being a barrier to growth, offering the same course, a counseling course, across many high school partners, has created incredible growth in the CCAP dual enrollment program in this case study. It may also support students in developing skills that will help them succeed in college. This approach does not, however, look critically at the needs of students nor does it clearly connect students to a community college program.

CCAP is a single initiative that is part of the broader initiatives on both sides, the challenge is understanding and leveraging the potential of CCAP dual enrollment despite the complexities of the systems on both sides. Many factors impact the ability to offer a course in a dual enrollment format. On the community college side, some factors that impact course selection are the availability of teaching units, whether a program is impacted, and availability of faculty. On the high school side, the interest of their faculty in a course, the concern about supplanting instructors, the perceived interest of students 
and parents, beliefs about students' abilities, student graduation requirements, A-G requirements, the belief that there will be enough students to fill the class, and the master schedule. This is made more complex because these interests are held at different levels, so that a course selection and pathway completion can be derailed at multiple points in the process.

\section{Conclusion}

To determine how policy adopters, administrators, and supporters understand the intention of CCAP dual enrollment, it is important to look at how the factors that differentiate CCAP dual enrollment from traditional dual enrollment appear in each environment.

Table 22 provides an overview of findings. Two best practices that stand out are the creation of a support teacher role that partners with the community college instructor to support students and the benefits of early engagement with partners to support in depth conversations and development of processes. Greater intentionality around identifying and articulating the goals of dual enrollment partnership is necessary.

Externalizations of the intent of CCAP dual enrollment can be seen in how the initiative is staffed and funded. Since high schools provide do not limit students access to courses, the demographics of the partner high school districts to considered to see the implementation were in alignment with underrepresented student populations and lowSES students. Two aspects of the program creation that reflect the understanding of CCAP dual enrollment are the creation of focused student services designed for CCAP 
dual enrollment, which is not happening currently, and the intentional creation of pathways, which can be either general education or CTE.

Table 22 Table of Findings

\section{Findings: Cross-case analysis of CCAP dual enrollment programs}

Policy Implementers' Understanding and Externalization of AB 288 Goals

1. CCAP dual enrollment is a new initiative, designed to serve a new expanded population of students, and must include the creation of pathways.

2. The expansion to new groups of students makes the intentional creation of expanded student supports critical.

3. The level of focus on these aspects of CCAP dual enrollment are indictors leaders' understanding of the intentions of CCAP dual enrollment.

\section{Supporting Dual Enrollment as a New Initiative}

\section{Understandings of Equity and Program Creation}

1. The intent of legislation is left up to interpretation.

2. See Table 12. Understanding of Legislative Goals by Role.

3. Differentiating CCAP dual enrollment from other dual enrollment initiatives is critical.

4. Administrators have a clearer connection to the intent of the legislation than the policy adopters.

5. Awareness of who a program is intending to serve and who is actually being served is critical. Awareness of this varied across case studies.

6. Focus of policy adopters and administrators is the complexities of creating the agreement and the logistics of delivering dual enrollment, rather than on detailed discussions of the intent of the legislation.

\section{Administrative Staffing Decisions}

1. See Table 13: Case Study Staffing and Funding Overview.

2. Case study one has focused administration on both sides, but reduction grant funding is reducing support staff and the size of the district makes a single person unable to sufficiently communicate across the district.

3. Case study two has the largest investment in staffing, but communication across this larger staff is a challenge.

4. Case study three has similar staffing to one, but less complexity. In addition, this administrator has a span of control that encompasses multiple high school facing initiatives.

5. High schools typically do not have focused administration. It is assigned to principals, vide principals, and counselors who already have a wide range of responsibilities.

\section{Funding}




\section{Findings: Cross-case analysis of CCAP dual enrollment programs}

1. See Table 14. Findings on Funding by Case Study

\section{Expanding Access to Under-Represented Student Populations}

- Existing dual enrollment processes were leveraged instead of creating expanded processes to help guide the selection, placement, and support of students specific to the CCAP agreement.

\section{Expanding the Academic Population Served}

1. Creating access for underrepresented student populations and creating opportunity for students who are not college bound are at the heart of $\mathrm{AB} 288$ legislation, but it is a small focus in the dual enrollment initiatives studied.

2. The lack of time and the speed with which dual enrollment agreements were undertaken may be a factor in the limited discussion of the intent of AB 288 dual enrollment.

3. There was no attempt to create a definition of the students who should be in the program, but rather an assumption that the correct student would end up in the program.

\section{Student Selection Process}

1. While there are some examples data being used to evaluate some aspects of dual enrollment, typical demographic data (Appendix B) is not accessed or discussed in the creation CCAP dual enrollment initiatives.

2. High schools serve all students and CCAP dual enrollment courses are typically open to all students.

3. High schools focus on choosing students who they believe will be successful in the classes.

\section{Expanding the Academic Population Served}

\section{Creation of Student Supports}

1. Support of students is a key characteristic in for $A B 288$, but what it includes is not outlined in the legislation.

2. A unique approach is found in case study one, where a high school teacher outside the discipline is assigned to support CCAP dual enrollment courses.

3. In other case studies, students are offered the supports typically available in both the high school and the community college environments.

4. See Table 16. Definition of Student Supports by Role.

5. Dual enrollment is a new initiative in all case studies. While support focuses on ensuring that students are removed if they are in danger of failing, there is an interest in expanding student supports in the future. 


\section{Exposure to College Level Course Work}

1. Maintenance of rigor is a focus across all case studies.

2. Despite many mentions of the importance of maintaining rigor in these case studies, rigor is used without a clear agreement on definition.

3. Rigor varies across courses, so discussion of course selection is important.

\section{Pathway Creation and Program Growth}

1. Program growth is not a measure of quality, but it is clearly impacted by the attitudes of dual enrollment administrators.

2. Across all case studies, there is a movement away from CTE courses and toward general education courses, possibly due to a larger pool of potential instructors and the appeal to a broader range of students.

3. Growth in courses and shifts in course type open a discussion about how pathways should be created.

\section{Creating Clear Pathways of Aligned, Sequenced Coursework}

1. Pathways area an important part of CCAP dual enrollment.

2. On the community college side, some factors that impact course selection are the availability of teaching units, whether a program is impacted, and availability of faculty.

3. On the high school side, the interest of their faculty in a course, the concern about supplanting instructors, the perceived interest of students and parents, beliefs about students' abilities, student graduation requirements, A-G requirements, the belief that there will be enough students to fill the class, and the master schedule. 


\section{Chapter Five: Discussion and Recommendations}

\section{Overview}

This multiple case study explored the CCAP initiatives in three community colleges partnering with a varying number of multiple and single high school districts. The goal of this study was to evaluate how the legislative goals of $A B 288$ dual enrollment are understood and externalized by the policy adopters, administrators, and supporters of dual enrollment in high schools and community colleges, and to evaluate the impact of those understandings on the resulting CCAP dual enrollment programs. These partnerships varied in complexity, ranging from single comprehensive high school districts up to a district with twelve high school districts. Policy adopters, administrators, and supporters shared a commitment to students, and all struggled with the complexities inherent in the broad definitions supplied by AB 288 .

How policy adopters and administrators talked about and implemented the aspects of CCAP dual enrollment that are different than traditional dual enrollment provided insight into their understanding. CCAP dual enrollment is unique in that it focuses on underrepresented student populations or on students who are not college bound, it expands the focus of the dual enrollment initiative to an academically broader group of students, and it relies on the creation of defined pathways. Based on the findings of this study, recommendations are being made to policy adopters, dual enrollment administrators and to improve dual enrollment legislation. 


\section{Limitations}

In this study, enrollment and outcomes of the CCAP dual enrollment initiatives were not measured. All implementations had not yet completed the second year of dual enrollment courses. First year data was not available either from the Chancellor's Office or from the dual enrollment administrators. Staff turnover exacerbated issues with tracking first year demographics and outcomes.

While the intentions and attitudes that guided student selection and the demographics of the participating organizations were evaluated, it was not possible to measure which student populations were placed in the courses. In addition, no outcome data were available to measure the efficacy of the initiatives.

CCAP course data information presented in this study is not from a single, consistent source. It was gathered from CCAP agreements, planning documents of the administrators, and publicly available presentations, but the Agreements provided to the Chancellor's Office. This gives insight into the trends but cannot be analyzed statistically.

Access to high school partners was also limited. High school district level participants provided information across multiple high school sites. Ideally, interviews would have been completed across all high school partners at the site level, but staff changes at the high school and the lack of focused staff at the high school sites limited the sites that were included in this study. Where interviews were not included, the demographic data, and website documents, and Board of Trustees documentation data provides insight into all high school districts in the partnership, but interviews at all sites would have enriched the findings. 


\section{Case Study Variance}

The case studies provided are homogenous, with seemingly little variance. This homogeneity is indicative of trends across California. My affiliation with dual in a regional dual enrollment consortium, review dual enrollment websites and documentation across California, and participation in dual enrollment conferences has provided me with the opportunity to evaluate many dual enrollment programs and to speak with dual enrollment colleagues. These conversations have convinced me that the focus on the details of the dual enrollment implementation rather than the meeting the intent of the legislation is typical. California community colleges and public high school districts are resource constrained and this initiative is new, which means that it either requires the creation of a focused position, which takes time and money, or the assignment to an existing resource, who is potentially already overloaded with other duties and initiatives. All CCAP dual enrollment initiative faces this tension. These constraints lead to limiting activities to the practical decisions required to launch a CCAP dual enrollment program.

\section{Recommendations for State Level Support}

Recent legislation, $A B$ 30, extends the operation of the CCAP partnership provisions until January 1, 2027, extended it past its initial end date in 2022. This will give dual enrollment administrators an opportunity to respond to the findings in the CCAP summary reports which are due in the Chancellor's office no later than January $1^{\text {st }}$, 2021. It has changes that make the registration of students easier, but like $A B 288$, it does not give any guidance or requirements around the student supports that are necessary to 
expand the groups of students being served under CCAP agreements. Since student services are central to student success, it should be mentioned in the legislation.

To understand the impact of dual enrollment and who is being reached, the required annual reports to the California Community Colleges Chancellor's Office should be in a standardized format. The information required should include details of what courses were offered, the pathways that they are in, and the demographics of the students enrolled. Trainings for dual enrollment administrators and the data people at each site should be provided by the chancellor's office, to support consistency in data.

Dual enrollment implementors would benefit from a centralized source of information from the California Community College Chancellor's Office. Intersegmental data is something that California has struggled with as a state, both tracking students between secondary education and community college, between two-year and four-year, and also tracking students as they move into employment. Longitudinal data would allow statewide tracking of dual enrollment student outcomes.

In an attempt to allow flexibility to create CCAP dual enrollment programs that will meet the diverse needs of the wide variety environments found in California, the legislation does not require a clear definition of the goals of the partnership and an understanding of the students that these initiatives will serve. The current agreement requires that information be included about the courses being offered, the location of the course and the instructor. Exact location and instructor are the most likely to change and are not reflective of the legislative intent. Instead, the initial agreement should be 
required to include a justification of the courses being offered and how they fit into the high school, the community college, and if possible, the four-year pathway. Analysis of student demographics and a discussion of how the existing population will benefit from CCAP dual enrollment should be required.

There is a statewide opportunity to explore development of stronger, more integrated support services for CCAP students. While AB 288 is considered funded because both sides of the partnership are eligible to receive apportionment, there are costs to reworking and expanding support services across high school sites. In addition, there is administrative overhead to register and enroll students. Proposed Senate Bill 563 provides a competitive grant to three community college (one per region, north south and central California) to pursue explore program improvements that would better support CCAP students. A few of the targeted initiatives are reducing paper-based registrations and permissions for pupils, improved tracking and monitoring of CCAP students, developing and enhancing wrap-around services, developing and disseminating best practices, professional development for community college faculty on how to teach pupils who are used to a high school environment, and ensuring dual enrollment program completers are counted for all statewide metrics, dashboards, and funding formulas. This senate bill succinctly targets a set of student service enhancements that would benefit any dual enrollment program and can act as a punch list for administrators in the creation of intentional supports for students. Ideally, limited grant funding that will be offered will 
be made more widely available, to support the critical thoughts in these areas by dual enrollment professionals.

An easier process, ideally digital, for submitting agreements, with a definition for reporting of the key pieces of required information is sorely needed. In reviewing course offerings across the case studies, the submitted agreements were often incomplete, not providing information about the courses being offered. In case study two, all dual enrollment agreements were posted for review as part of the approval process by the board of trustees at the community college. The documents provided to the board were more complete than the documents provided to the Chancellor's Office. Soon, reports will be due to the California Community Colleges Chancellor's Office and it is my hope that there will be a way to access and evaluate the data provided in these reports to leverage for program improvements by practitioners.

\section{Recommendations for Policy Adopters}

A framework for partnership discussions is needed that focuses partnership discussion on the aspects of CCAP dual enrollment that differentiate it from traditional dual enrollment. This framework would lay out a timeline of key conversations and identify critical participants. Early discussions should include a definition of the student populations being served, clear understanding of the goals on both sides, and discussions about staffing and support. Metrics that would be of interest that are currently available from the California Department of Education include: the graduation rate and the college going rate to identify the size of the population who are not college bound and the percentage of students who meet $\mathrm{UC} / \mathrm{CSU}$ graduation requirement, to evaluate for the 
opportunity to increase academic rigor parts of the student population (Appendix B). Based on my observation of the disconnect between the legislation and the implementation, in my practice I have created a spreadsheet that assigns stakeholders, activities and key questions for each section of the dual enrollment agreement. It acts as an accountability tool during the implementation, connecting the agreement to the practice. It has allowed me to create productive and timely conversations in the CCAP implementation that I am currently guiding.

The key to meeting the intent of $\mathrm{AB} 288$ legislation is seriously considering which students would most benefit from the dual enrollment initiative. As the agreement is created, the focus should be on looking critically at where the students to be served are being served. This might be considering the CTE pathways that exist in the program. It might require looking critically at how to partner not just with the comprehensive high schools, but also with the continuation schools, to specifically support students who are not college bound. This would require thoughtful course selection and supports, since comprehensive high school students generally are under-performing and in need of credit recovery, rather than the mid-range performers that were envisioned.

Another critical part of the CCAP initiative is pathway development and course selection. The focus must be on a multi-year pathway that results in a CTE certificate, or defined progress toward completing general education requirements, not just the courses that will be offered in the next semester or school year. Ideally, planned sequences should 
also have connections to programs at the four-year schools with which the community college partners.

Policy adopters have the responsibility to advocate for staffing that is in line with the complexity of the potential partnerships and the number and size of the high school district partners. The dual enrollment team at the community college must reflect the size and complexity of the high school partners if the desire is to create a program that supports the existing student population. In case study one, where modest program growth is seen, the dual enrollment administrator for the high schools is at the district level. There is not a focused person at the individual high school, which is a barrier to program support and growth. In comparing case study two and case study three, it is clear that there are administrative benefits to having a large team, but there is also overhead in communication. Thoughtful staffing is critical. Staffing decisions need to consider the growth that is targeted for dual enrollment and the characteristics of the high school partners. In addition, consistency of standards will be higher when there are focused resources on both sides of the partnership. In case study two, the creation of a large team did not impact the growth of the CCAP dual enrollment initiative, possibly because communication is more complex in a larger team. In this case, a clear communication plan and mapping of partner roles across the academic and the support side might have resulted in clearer communication and better initiative support.

\section{Recommendations for Dual Enrollment Administrators}

Ideally, dual enrollment administrators and their teams should be responsible for all and have control over all forms of dual enrollment. For example, in case study one, 
the early college initiative and the CCAP dual enrollment initiative were kept separate. If they were looked at together, it is possible that both programs would benefit through critical consideration of which form of dual enrollment would best meet the needs of the students. The centralization of responsibility for dual enrollment facilitates conversations with partners. Instead of forcing a single form of dual enrollment to meet a partner's needs, an administrator that has control of all forms of dual enrollment has the opportunity to fully evaluation the needs of the students in a partner organization and design the dual enrollment program or programs that best fit the needs and demographics of those students.

The top priority for dual enrollment administrators at the high school and the community college should be the development of a support plan. Both sides of the partnership must work together to create an integrated support plan. While all partners showed the desire to support students, many relied on the teacher as the primary support, expanding the instructor's role and potentially risking burnout. In addition, connecting students with supports was primarily making them aware of what is available. Ideally, students would be connected intentionally with the supports available. This could be in the form of a scheduled campus visit to become aware of available services on the community college campus, a website or resource list that is developed groups resources based on the challenge a student is facing, and processes and discussions between faculty and counselors on both sides about how to connect students to support services. This will require dedicated funding. 
Creation of dual enrollment supports must start from the needs of the student population and requirements of the courses being offered. In addition to choosing courses in the context of high school and college pathways, the context of the supports required and the supports available on both sides be understood as the courses are selected. Documentation for all course selections should be based on input from both sides of the partnership (see Appendix B). This sample document is designed to stimulate conversation about the shared support of dual enrollment students in the third space and create documentation of the course decisions made and the commitments on both sides.

The intentional creation of pathways should also take priority in the creation of CCAP agreements. This discussion should continue as part of the implementation process, and should include deans, faculty and counselors from both organizations. Planning should focus on creating course sequences made up of high school course offerings, articulated courses, and dual enrollment courses, documented through formal pathway maps. ${ }^{2}$ The high school counselors should be included so that their input should inform how the courses fit into the high school graduation requirements. The community college counselor has insight into the prerequisites and how the courses fit into the degree, certificate and transfer requirements at the community college. If a pathway starts

${ }^{2}$ Career Ladders Project provides a toolkit with resources to help guide in depth conversations about pathway creation: https:/www.careerladdersproject.org/tools-for-the-field/career-pathways-mappingtoolkit/ 
in $9^{\text {th }}$ grade, the pathway mapping should include documentation of the courses that should have been undertaken in junior high. This allows educators to create a series or courses that will ensure that students have the knowledge and skills necessary they move through the pathway. Leaders at the community college should be guiding conversations about creating pathways for the identified student populations and the high school leadership should be focusing on offering the courses to the students who would most benefit. In this study, courses selections were driven by the high school. Ideally, pathway development should be driven by the community college. High school faculty and counselors should be included in the discussion.

In the creation of CCAP dual enrollment initiatives, communication must be intentional and consistent, particularly in highly complex environments. Administrators must think critically about how to engage the right resources at the right time in the process. Initially, initiative visibility and awareness must be created through a structured communication plan that reaches out to key parts of the organization with a consistent message about the CCAP dual enrollment initiative. In case study two, a reading of the dual enroliment website shows an announcement about how dual enrollment is being promoted through the community college: through campus ambassadors at the high school, the new dual enrollment website, and planned dual enrollment workshops and information nights which will be scheduled. This raises initiative visibility on the campus. Across all high schools in this study, schools had no mention of the dual enrollment initiative on their website as part of their lager academic programs, despite the 
desire to raise visibility of the opportunity on the high school campus. Community college managed CCAP dual enrollment would be a communication tool for high schools to proactively provide parents and students information about this opportunity and resources once they had committed to participating in a CCAP dual enrollment class. A high school CCAP website should include resources and links to the college partner website would be valuable to participants, but also would help normalize dual enrollment as part of the academic offering and raise visibility of the initiative.

Ensuring that communication is bilingual is also a critical part of ensuring that the right student populations are being reached, particularly since course selection by students is so ingrained in the high school cultures across all case studies. This means meetings, websites, forms, and marketing materials in the languages of the students and parents that they intend to reach. During the pathway development discussions, the choice of students should also be centralized. The selection of pathway and the marketing of the pathway should be done in the context of a clearly defined interpretation of how the goals of the legislation will be realized.

\section{Recommendations for Further Study}

CCAP dual enrollment is working to shift dual enrollment in California. Community college may offer a variety of dual enrollment options to the students of high school partners, but CCAP dual enrollment is unique since it is implemented through a pathway focused partnership and with a specific intention of creating access. I have not found any studies focusing specifically on CCAP implementations. Future study of CCAP dual enrollment should focus on the outcomes for and voices of CCAP dual 
enrollment students. Student voices are absent from dual enrollment generally. Ideally, longitudinal data would allow researchers to determine if these early dual enrollment initiatives are resulting in better access and persistence in college and in eventual transitions to career or transfer to community college.

Student services is an integral part of any CCAP injtiative. Research should also focus on student services and how they are delivered, to evaluate which supports students have access to, how much students utilize them, and how those resources impact both student outcomes and student perceptions of their dual enrollment experience. This research could also be used to inform first year experience and bridging programs.

There are clear differences in the level of staffing and the complexity of partnering based on the number of high schools in a district. Additional studies could focus on best practices when working with a small high school district and best practices for working with more complex, multi-high school districts. Ideally, these studies could focus on the staffing required at the community college and the high school and the division of roles and responsibilities. Currently, a broad range of positions are tasked with supporting dual enrollment, so it would be interesting to consider how to give this initiative the appropriate level of support on both sides.

\section{Reflections on the Research Process}

As I pursued this research, I had the opportunity to join an organization and create a series of CCAP partnerships from scratch. This research centralized for me the importance of communication with partners at multiple levels within the organization and the importance of documenting and distributing policies and procedures widely and often. 
It has caused me to be thoughtful in my engagement with my partners and in my quest to engage in conversation across both organizations.

\section{Conclusion}

When undertaking a CCAP agreement, a high level of commitment is required by both the high school districts and the community college district. The focus needs to be on clearly defining the partnerships, the processes, and the pathways. Participation of counselors is particularly important. The processes must be documented and communicated predictably, frequently and broadly.

Identification of the pathways that will best support the target students should be the foundation of any CCAP agreement. In addition, both sides must be committed to ongoing conversations. The goal is that each side of the partnership will benefit from these conversations and that a stronger K14 pathway will be created. That provide the opportunity for community colleges to provide feedback around student preparation, for high schools to have visibility input into the community college programs and pathways.

A broader focus on student supports is essential as well. Partners must work together to create intentional supports that are based on the needs of the students and the requirements of the courses.

By seeing CCAP dual enrollment as a brand new initiative and looking critically at how it should be implemented, it will be possible to reach a broader range of student and increase access for underrepresented student populations.

High schools offer the courses under the CCAP agreement to all students, since the high school charter is to serve all students in their district. This means that attention to 
meeting the legislative goals needs to be a focused discussion early in the partnership discussions. The partners must work together to decide whether they believe that offering the class at a high school site will meet the intent of the legislation. In some districts, like those in case study three, there is little concern because a high percentage of the population are in racial groups that are underrepresented in higher education, are economically disadvantaged, or are first generation college students. In districts with a less homogenous population, the partners need to come to a clear decision about who they are trying to serve and how they are going to position the courses to meet the needs of students. The conversation should start with looking at the demographics of the individual high school, but this is not the end of the conversation. If a school has a mixed population, critical thought should be given to marketing the courses to students and parents in the groups that the partnership is trying to serve. In addition, the conversation needs to be broadened from looking at just the comprehensive high schools but looking critically at how dual enrollment could be leveraged in a credit recovery environment.

From a legislative standpoint, accountability improvements should be the norm for all dual enrollment initiatives. 


\section{References}

Allen, D., \& Dadgar, M. (2012). Does dual enrollment increase students' success in college? Evidence from a quasi-experimental analysis of dual Enrollment in New York City. New Directions for Higher Education, 58, 11-20.

An, B. P. (2012). The influence of dual enrollment on academic performance and college readiness: Differences by socioeconomic status. Research in Higher Education, $54(4), 407-432$.

An, B. P. (2013). The impact of dual enrollment on college degree attainment: Do lowSES students benefit? Educational Evaluation and Policy Analysis, 35(1), 57-75.

An, B. P., \& Taylor, J. L. (2015). Are dual enrollment students college ready? Evidence from the Wabash national study of liberal arts education. Education Policy Analysis Archives, 58, 1-26.

Anyon, J. (2011). Marx and education. New York: Routledge.

Bailey, T., \& Karp, M. M. (2003). Promoting college access and success: $A$ review of credit-based transition programs. Washington D.C.: U.S. Department of Education, Office of Adult and Vocational Education.

Bourdieu, P. (1977). Cultural reproduction and social reproduction. In J. Karabel, \& A. H. Halsey, Power and Idealogy in Education (pp. 487-511). New York: Oxford University Press. 
Bragg, D. D. (2000). Maximizing the benefits of tech-prep initiatives for high school students. New Directions for Community Colleges, 111, 23-30.

Bragg, D. D., Kim, E., \& Barnett, E. A. (2006). Creating access and success: Academic pathways reaching underserved students. New Directions for Community Colleges, 135, 5-19.

California Community Colleges Chancellor's Office. (2017, May 4). CCCCO. Retrieved from Dual Enrollment Overview: extranet.cccco.edu/.../1/.../Dual\%20Enrollment\%20Presentation\%2005.03.17.pptx

California Competes: Higher Education for a Strong Economy. (2018). Opportunity imbalance: Race, gender, and Calffornia's education-to-employment pipeline. Oakland, CA: California Competes: Higher Education for a Strong Economy.

Career Ladders Project. (2018). The dual enrollment landscape in Callfornia: A CLP working paper. Oakland, CA: Career Ladders Project.

Collins, D. E., Weinbaum, A. T., Ramón, G., \& Vaughan, D. (2009). Laying the Groundwork: The Constant gardening of community-university -school partnerships for postsecondary access and success. Journal of Hispanic Higher Education, 8(4), $394-417$.

Cowan, J., \& Goldhaber, D. (2015). How much of a "running start" do dual enrollment programs provide students? The Review of Higher Education, 38(3), 425-460. 
Davidson, J. C. (2015). Precollege factors and leading indicators: Increasing transfer and degree completion in a community and technical college system. Community College Journal of Research and Practice, 39(11), 1007-1021.

Ferguson, C., Baker, P., \& Burnett, D. (2015). Faculty members' persceptions of rigor in dual enrollment, accelerated programs, and standard community college courses. Danvers: Wiley Periodicals, Inc.

Fry, R. (2002, May 9). Latinos in higher education: Many enroll, too few graduate. Retrieved from Pew Hispanic Center: https://eric.ed.gov/?id=ED468848

Ganzert, B. (2014). Dual enrollment credit and college readiness. Community College Journal of Research and Practice, 38(9), 783-793.

Giani, M., Alexander, C., \& Reyes, P. (2014). Exploring variation in the impact of dualcredit coursework on postsecondary outcomes: A quasi-experimental analysis of Texas students. The High School Journal, 97(4), 200-218.

Golann, J. W., \& Hughes, K. L. (2008). Dual enrollment policies and practices: Earning college credit in Calıfornia high schools. Columbia University, Community College Reserach Center. San Francisco: James Irvine Foundation.

Gonzalez, L. M., Cavanaugh, A. M., Taylor, L. K., Stein, G. L., \& Mayton, H. N. (2017). Latino adolescent educational affiliation profiles. Hispanic Journal of Behavioral Sciences, 39(4), $486-503$. 
Grubb, J. M., Scott, P. H., \& Good, D. W. (2017). The answer is yes: Dual enrollment benefits students at the community college. Community College Review, 45(2), 79-98.

Harris, B. W. (2016, March). AB 288 (Dual Enrollment) College and Career Access Pathways (CCAP) Partnership agreement guidelines for apportionment. Sacremento, California: California State Chancellor's Office.

Hoffman, N., Vargas, J., \& Santos, J. (2009). New directions for dual enrollment: Creating stronger pathways from high school through college. New Directions for Community Colleges, 145(Spring), 43-57.

Hofmann, E., \& Voloch, D. (2012). Dual enrollment as a liminal space. New Directions for Higher Education, 158, 101-107.

Holden, C. (2017, November 19). Bill Text-AB-288 Public schools: College and Career Access Pathways partnerships. Retrieved from California Legislative Information: https://leginfo.legislature.ca.gov/faces/billNavClient.xhtml?bill_id=201520160A B288

Howley, A., Howley, M. D., Howley, C. B., \& Duncan, T. (2013). Early college and dual enrollment challenges: Inroads and impediments to access. Journal of Advanced Academics, 24(2), 77-107.

Hughes, K. L., Rodriquez, O., Edwards, L., \& Belfield, C. (2012). Broadening the benefits of dual enrollment: Reaching underachieving and under-represented 
students with careeer-focused programs. San Francisco: The James Irvine Foundation.

Jones, M., Yonezawa, S., Ballesteros, E., \& Mehan, H. (2002). Shaping Pathways to Higher Education. Education Researcher, 2, 3-11.

Kanny, M. A. (2015). Dual enrollment participation from the student perspective. New Directions for Community Colleges, 169, 59-70.

Karp, M. M., \& Hughes, K. L. (2008). Supporting college transitions through collaborative programming: A conceptual model for guiding policy. Teachers College Record, 110(4), 838-866.

Karp, M. M., Calcagno, J. C., Hughes, K. L., Jeong, D. W., \& Bailey, T. R. (2007). The postsecondary achievement of participants in dual enrollment: An analysis of student outcomes in two states. Chicago: National Research Center for Career and Technical Education.

Khazem, J. H., \& Khazem, H. A. (2014). The changing policy framework of dual enrollment. International Journal of Educatrion Research, 9(1), 105-124.

Kim, J. (2014). Relationship of tech prep and dual credit to college readiness and retention. College Student Journal, 48(3), 337-346.

Kim, J., \& Bragg, D. D. (2008). The Impact of dual and articulated credit on college readiness and retention in four community colleges. Career and Technical Education Research, 33(2), 133-158. 
Kim, J., Barnett, E., \& Bragg, D. D. (2003). Dual credit in Mlinois: Results of expert panel deliberations and a Delphi study of definitions and priorities. Champaign, IL: Office of Community College Research and Leadership, University of Illinois at Urbana-Champaign.

Krogstad, J. M. (2015, May 26). 5 facts about Latinos and education. Retrieved from Pew Research Center: https://www.pewresearch.org/fact-tank/2015/05/26/5-factsabout-latinos-and-education/

Kurlaender, M., \& Larsen, M. F. (2013, February 27). K-12 and postsecondary alignment: Racial/ethnic differences in freshmen course-taking and performance at California's community colleges. Education Policy Analysis Archives, 21(6), 129.

Lee, J. M., Edwards, K, Menson, R., \& Rawls, A. (2011). The college completion agenda 2011 progress report. New York, NY: College Board Advocacy and Policy Center.

Lewis, M. V., \& Overman, L. (2008). Dual and concurrent enrollment and transition to postsecondary education. Career and Technical Education Research, 33(3), 189202.

Lipsky, M. (2010). Street-level bureacracy; Dilemmas of the individual in public services. New York: Russel Sage Foundation.

Lively, K, \& Klopfenstein, K. (2012). Dual enrollment in the broader context of collegelevel high school programs. New Directions for Higher Education, 59-68. 
Maitre, M. (2015, March 31). Lawmakers try and try again to expand dual enrollment. Retrieved from EdSource: Highlighting Strategies for School Success: https://edsource.org/2015/lawmakers-try-and-try-again-to-expand-dualenrollment/77487

Maynard-Moody, S., \& Musheno, M. (2003). Cops, teachers, counselors: Strories from the frontlines of public service. Ann Arbor: University of Michegan Press.

McCaskill, W. (2015, December 10). Fiscal Consultant, School Fiscal Services, California Department of Education. (C. L. Project, Interviewer)

Mokher, C. G., \& McLendon, M. K. (2009). Uniting Secondary and Postsecondary education: An event history analysis of state adoption of dual enrollment policies. American Journal of Education, 115(2), 249-277.

Morrison, M. C. (2008). The benefits of accleration: Graduation advantages. Mason City, IA: North Iowa Area Community College .

Núñez, A.-M., \& Oliva, M. (2009). Organizational collaboration to promote college access: A P-20 framework. Journal of Hispanic Higher Education, 8(4), 322 339.

Oliva, M. (2004). Reluctant partners, problem definition, and legislative intent: K-16 policy for Latino college success. Journal of Hispanic Higher Education, 209230. 
Plank, S. B., DeLuca, S., \& Estacion, A. (2008). High school dropout and the role of career and technical education: A survival analysis of surviving high school. Sociology of Education, 81, 345-370.

Pretlow, J., \& Wathington, H. D. (2014). Expanding dual enrollment: Increasing postsecondary access for all? Community College Review, I(42), 41-54.

Purnell, R. (2014). A guide to launching and expanding dual enrollment programs for historically underserved students in Calıfornia. San Rafael, California: The Research and Planning Group of California Community Colleges.

Riley, D. D., \& Brophy-Baermann, B. E. (2006). Bureaucracy and the policy process: Keeping the promises. Lanham: Rowman \& Littlefield Publishers, Inc. .

Shahjahan, R. A., \& Pitcher, E. N. (2017). From pipelines to tasting lemonade: Reconceptualizing college ccess. Educational Studies, 53(3), 216-232.

Shulock, N., \& Offenstein, J. (2012). Career opportunities: Career technical education and the college completion agenda. Sacramento: Institute for Higher Education Leadership \& Policy.

Speroni, C. (2011, December). Determinants of students' success: The role of advanced placement and dual enrollment programs. Columbia University, Teachers College. New York, NY: National Center for Post Secondary Research.

Stewart, V. (2019, May 31). Executive Director, California STEM Network, Children Now. (M. J. Stevens, Interviewer) 
Taylor, J. L. (2015). Accelerating pathways to college: The (in)equitable effects of community college dual credit. Community College Review, 43(4), 355-379.

The Center for Student Success; The RP Group; The Academic Senate for California Community Colleges. (2009). Effective practices for promoting the transition of high school students to college: A review of literature with implications for Calyfornia community college practitioners. Sacramento: Chancellor's Office of the California Community Colleges.

The Workforce Alliance (TWA). (2009). Calıfornia's forgotten middle-skill jobs:

Meeting the demands of a 21st century economy. Washington DC: National Skills Coalition .

Thomann, E., van Engen, N., \& Tummers, L. (2018). The necessity of discretion: A behavioral evaluation of bottom-up implementation theory. Journal of Public Adminisration Research and Theory, 28(4), 683-601.

Tinberg, H., \& Nadeau, J.-P. (2011, June). Contesting the space between high school and college in the era of dual-enrollment. College Composition and Communication, 62(4), 704-725.

Van Meter, D. S., \& Van Horn, C. E. (1975). The Policy Implimentation Process: A conceptual framework. Administration \& SOciety, 445-488.

Van Noy, M., Trimble, M., Jenkins, D., Barnett, E., \& Wachen, J. (2016). Guided pathways to careers: Four dimensions of structure in community college career technical programs. Community College Review, 44(4), 263 -285. 
Wang, X., Chan, H.-y., Phelps, L. A., \& Washbon, J. I. (2015). Fuel for success: Academic momentum as a mediator metween dual enrollment and educational outcomes of two-year technical college students. Community College Review, 43(2), 165-190.

White House Press Office. (2009, February 24). Remarks of President Barack Obama-As prepared for delivery address to joint session of Congress. Retrieved from https://obamawhitehouse.archives.gov/the-press-office/remarks-president-barackobama-address-joint-session-congress

Wozniak, C., \& Palmer, L. B. (2013). Stakeholder perceptions fo barriers and solutions to significant expansion of postsecondary enrollment options for high school students. International Journal of Education Policy \& Leadership, 8(2), 1-17.

Yin, R. K. (2018). Case study research and applications: Design and methods (6th ed.). Thousand Oaks: Sage.

Yosso, T. J. (2005). Whose culture has capital? A critical race theory discussion of community cultural wealth. Race Ethnicity and Education, 8(1), 69-91. 


\section{Appendices}

\section{Appendix A: Case Study Participant Overview}

\begin{tabular}{|c|c|c|c|c|}
\hline $\begin{array}{l}\text { Case } \\
\text { Study }\end{array}$ & Partmership & Organization & Role & Title \\
\hline \multirow[t]{5}{*}{1} & \multirow[t]{5}{*}{1} & Nonprofit & Policy Adopter & Director \\
\hline & & \multirow{3}{*}{$\begin{array}{l}\text { Community } \\
\text { College } 1\end{array}$} & Administrator & Dean of High School Programs \\
\hline & & & Policy Adopter & $\begin{array}{l}\text { Dean Health, Physical Education } \\
\text { and Social Services }\end{array}$ \\
\hline & & & Policy Adopter & $\begin{array}{l}\text { Associate Vice Chancellor } \\
\text { Instruction, General and Transfer } \\
\text { Education }\end{array}$ \\
\hline & & $\begin{array}{l}\text { High School } \\
\text { District } 1\end{array}$ & Administrator & $\begin{array}{l}\text { Supervisor, Student Learning } \\
\text { Supports, Division of Curriculum } \\
\text { \& Instruction }\end{array}$ \\
\hline \multirow[t]{8}{*}{2} & \multirow[t]{8}{*}{2} & \multirow{6}{*}{$\begin{array}{l}\text { Community } \\
\text { College } 2\end{array}$} & Administrator & Pathway Specialist \\
\hline & & & Administrator & $\begin{array}{l}\text { Director of Student Success and } \\
\text { Equity }\end{array}$ \\
\hline & & & Supporter & Counseling Division Chair \\
\hline & & & Supporter & History Faculty \\
\hline & & & Supporter & General Counselor \\
\hline & & & Supporter & Consultant \\
\hline & & \multirow{2}{*}{$\begin{array}{l}\text { High School } \\
\text { District } 1\end{array}$} & Administrator & Assistant Principal \\
\hline & & & Administrator & Assistant Principal (Previous) \\
\hline \multirow[t]{9}{*}{3} & \multirow[t]{2}{*}{$3,4,5$} & \multirow{2}{*}{$\begin{array}{l}\text { Compsunity } \\
\text { College } 3\end{array}$} & Administrator & Director of College Readiness \\
\hline & & & Policy Adopler & Vice Presidere of Studert Affaits \\
\hline & \multirow[t]{4}{*}{3} & \multirow[t]{4}{*}{$\begin{array}{l}\text { High School } \\
\text { Distriot I }\end{array}$} & Administrator & $\begin{array}{l}\text { Director, } 21 \text { st Century Learning } \\
\text { \& Inoovation }\end{array}$ \\
\hline & & & Administrator & Principal \\
\hline & & & Supporter & 12th Grade Counuclot \\
\hline & & & Supporter & Juntor Counselor \\
\hline & \multirow[t]{2}{*}{4} & \multirow{2}{*}{$\begin{array}{l}\text { High School } \\
\text { District } 2\end{array}$} & Alwinistrator & Frincipal \\
\hline & & & Supporter & Counselor \\
\hline & 5 & $\begin{array}{l}\text { High Schowl } \\
\text { District } 3\end{array}$ & Supporter & Pupil Personel Specialist \\
\hline
\end{tabular}




\section{Appendix B: 2017-2018 Student Demographics}

Source: California Department of Education

\begin{tabular}{|c|c|c|c|c|}
\hline & \multirow[b]{2}{*}{$\begin{array}{l}C C A P \\
\text { Site }\end{array}$} & \multicolumn{2}{|c|}{$\begin{array}{l}\text { Underrepresented } \\
\text { Stuftuts }\end{array}$} & \multirow{2}{*}{$\begin{array}{c}\begin{array}{c}\text { Not Currently } \\
\text { College Bound }\end{array} \\
\text { Completers Not } \\
\text { Enrolled in College }\end{array}$} \\
\hline & & Race & $\begin{array}{c}\text { SES } \\
\text { (FRMP) }\end{array}$ & \\
\hline \multicolumn{5}{|c|}{ Case Study 1} \\
\hline Figh School 1 & No & $23,43^{\mathrm{m}}$ & $35.00 \%$ & $10.73 \%$ \\
\hline High School 2 & No & $37.34 \%$ & $49.20 \%$ & $23.90 \%$ \\
\hline High School 3 & No & $30.03 \%$ & $54.20 \%$ & $21.44 \%$ \\
\hline High School 4 & No & $31.49 \%$ & $64.60 \%$ & $21.84 \%$ \\
\hline High School 5 & Yes & $52.75^{\circ}$ & $61.60 \%$ & $22.68 \%$ \\
\hline High School 6 & Yes & $75.52 \%$ & $83.40 \%$ & $40.80 \%$ \\
\hline High School 7 & Yes & $59.34 \%$ & $67.40 \%$ & $30.18 \%$ \\
\hline High School 8 & Yes & $37.36 \%$ & $22.30 \%$ & $17.73 \%$ \\
\hline High School 9 & Yes & $80.21 \%$ & $66.70 \%$ & $53.85 \%$ \\
\hline High School 10 & Yes & $72.12 \%$ & $67.50 \%$ & $44.05 \%$ \\
\hline High School 11 & No & $66.67 \%$ & $85.20 \%$ & $40.00 \%$ \\
\hline High School 12 & Yes & $90.99 \%$ & $72.60 \%$ & $30.43 \%$ \\
\hline \multicolumn{5}{|c|}{ Case Study 2} \\
\hline District 1 Higr School I & Yes & $26.73 \%$ & $22.00 \%$ & $29.51 \%$ \\
\hline District 2 High School 1 & Yes & $31.01 \%$ & $16.70 \%$ & $19.00 \%$ \\
\hline District 3 High School 1 & Yes & $73.46 \%$ & $49.00^{\mathrm{m} / \mathrm{s}}$ & $29.78 \%$ \\
\hline District 3 High School 2 & Yes & $66.15 \%$ & $73,50 \%$ & $41.10 \%$ \\
\hline District 3 Kigh School 3 & Yes & $38.27 \%$ & $66.80 \%$ & $34.78 \%$ \\
\hline \multicolumn{5}{|c|}{ Case Study 3} \\
\hline District 1 High School I & Yes & $87.25 \%$ & $81.30 \%$ & $46.88 \%$ \\
\hline District 2 High School I & Yes & $96.25^{\circ} \%$ & $88.90 \%$ & $38.27 \%$ \\
\hline District 3 High School 1 & Yes & $76.25 \%$ & $50.60 \%$ & $74.42 \%$ \\
\hline District 3 High School 2 & Yes & $98.86 \%$ & $82.00 \%$ & $37.86 \%$ \\
\hline District 3 High School 3 & Yes & $93.59 \%$ & $62.500 \%$ & $34.26 \%$ \\
\hline District 3 High School 4 & Yes & $90.68 \%$ & $66.00 \%$ & $38.66 \%$ \\
\hline District 4 High School I & Yes & $97.67 \%$ & $83.40 \%$ & $26.40 \%$ \\
\hline District 5 High School I & Yes & $98.36 \%$ & $60.30 \%$ & $39.69 \%$ \\
\hline District 5 High School 2 & Yes & $42.53 \%$ & $69.410 \%$ & $30.62 \%$ \\
\hline
\end{tabular}




\section{Appendix C: Data Points for AB 288 Student Selection}

Source: California Department of Education

\begin{tabular}{|c|c|c|c|c|c|}
\hline & $\begin{array}{l}\text { College } \\
\text { Going } \\
\text { Rate }\end{array}$ & $\begin{array}{c}\text { Met UClCSU } \\
\text { Grad } \\
\text { Requirements }\end{array}$ & $\begin{array}{c}\text { Craduation } \\
\text { Rate }\end{array}$ & $\begin{array}{c}\text { Department } \\
\text { of Education } \\
\text { Perfommance } \\
\text { Level } \\
\end{array}$ & $\begin{array}{l}\text { College } \\
\text { Coers } \\
\text { Attending } \\
\text { CC } \\
\end{array}$ \\
\hline \multicolumn{6}{|c|}{ Case Study 1} \\
\hline High School 1 & $89.30 \%$ & $85.64 \%$ & $99.14 \%$ & Very High & $19.63 \%$ \\
\hline High School 2 & $76.10 \%$ & $43.26 \%$ & $87.27 \%$ & Medium & $36.64 \%$ \\
\hline High School 3 & $78.60 \%$ & $54.26 \%$ & $88.83 \%$ & Medium & $40.31 \%$ \\
\hline High School 4 & $78.20 \%$ & $54.11 \%$ & $88.57 \%$ & Medium & $35.40 \%$ \\
\hline High School 5 & $77.30 \%$ & $42.99 \%$ & $91.37 \%$ & High & $39.42 \%$ \\
\hline High School 6 & $59.20 \%$ & $36.46 \%$ & $74.98 \%$ & Low & $33.78 \%$ \\
\hline High School 7 & $69.80 \%$ & $48.44 \%$ & $91.70 \%$ & High & $39.35 \%$ \\
\hline High School 8 & $82.30 \%$ & $63.21 \%$ & $90.70 \%$ & High & $20.69 \%$ \\
\hline High School 9 & $46.20 \%$ & $20.00 \%$ & $87.80 \%$ & Medium & $47.62 \%$ \\
\hline High School 10 & $56.00 \%$ & $17.47 \%$ & $54.37 \%$ & Low & $51.06 \%$ \\
\hline High School 11 & $60.00 \%$ & $2.19 \%$ & $68.86 \%$ & Low & $46.67 \%$ \\
\hline High School 12 & $69.60 \%$ & $74.64 \%$ & $79.90 \%$ & Low & $56.25 \%$ \\
\hline \multicolumn{6}{|c|}{ Case Study 2} \\
\hline District 1 High School 1 & $70.50 \%$ & $59.85 \%$ & $95.45 \%$ & Very High & $45.35 \%$ \\
\hline District 2 High School 1 & $81.00 \%$ & $72.20 \%$ & $97.83 \%$ & Very High & $33.95 \%$ \\
\hline High School 1 & $70.20 \%$ & $53.55 \%$ & $86.00 \%$ & Medium & $57.07 \%$ \\
\hline District 3 High School 2 & $58.90 \%$ & $67.76 \%$ & $93.97 \%$ & High & $68.35 \%$ \\
\hline High School 3 & $65.20 \%$ & $53.31 \%$ & $89.00 \%$ & Medium & $77.33 \%$ \\
\hline \multicolumn{6}{|c|}{ Case Study 3} \\
\hline District 1 High School 1 & $53.10 \%$ & $47.04 \%$ & $94.86 \%$ & High & $60.50 \%$ \\
\hline District 2 High School 1 & $61.70 \%$ & $41.44 \%$ & $97.32 \%$ & Very High & $67.00 \%$ \\
\hline District 3 High School 1 & $25.60 \%$ & $45.06 \%$ & $91.09 \%$ & High & $96.97 \%$ \\
\hline High School 2 & $62.10 \%$ & $30.56 \%$ & $92.88 \%$ & High & $68.58 \%$ \\
\hline High School 3 & $65.70 \%$ & $42.73 \%$ & $87.53 \%$ & Medium & $68.79 \%$ \\
\hline High School 4 & $61.30 \%$ & $37.15 \%$ & $96.46 \%$ & Very High & $77.82 \%$ \\
\hline District 4 High School 1 & $73.60 \%$ & $33.33 \%$ & $96.45 \%$ & Very High & $69.66 \%$ \\
\hline District 5 High School 1 & $60.30 \%$ & $15.63 \%$ & $83.00 \%$ & Medium & $84.62 \%$ \\
\hline High School 2 & $69.40 \%$ & $26.36 \%$ & $87.40 \%$ & Medium & $80.69 \%$ \\
\hline
\end{tabular}




\section{Appendix D: Dual Enrollment Checklist}

This checklist is intended to be used to develop a shared understanding of how to support students in being successful in a proposed dual enrollment course.

High School District:

\begin{tabular}{|c|c|}
\hline \multicolumn{2}{|l|}{ Course ID/Title: } \\
\hline Units: & Auditable: \\
\hline Prerequisites: & Transfer: \\
\hline Proposed Semester: & Agreement Type: \\
\hline Location: & Building/Room: \\
\hline
\end{tabular}

\section{High School Partner Questions:}

1. What high school requirements does this course fulfill (A-G, Graduation)?

2. Is this course in a CTE pathway at the high school? If so, where does this course fall in the pathway? List all courses in order, including this one, using the table below. Include articulations.

\begin{tabular}{|c|l|l|}
\hline \multicolumn{1}{|c|}{ Course 1 } & \multicolumn{1}{|c|}{ Course 2 } & \multicolumn{1}{c|}{ Course 3 } \\
\hline $\begin{array}{l}\text { HS Anly Articulated CCAP } \\
\text { (Circle one) }\end{array}$ & $\begin{array}{l}\text { HS Anly Articulated CCAP } \\
\text { (Circle one) }\end{array}$ & $\begin{array}{l}\text { HS } \\
\text { Only Articulated CCAP } \\
\text { (Circle one) }\end{array}$ \\
\hline
\end{tabular}

3. What grade levels are eligible to take this class? At which grade level will students typically take this course?

4. How are students being placed in this course? What student demographics/needs/academic levels are expected?

5. How will this be recognized on the high school transcript?

6. If a student withdraws from this class, what course will they transfer to? 
7. What student supports are available for this course on the high school campus?

8. What resources are available in the physical space assigned? Computer, movable desks, etc. (if located at high school)

\section{Completed by:}

\section{Community College Partner Questions}

1. What certificate and degree requirements does this course fulfill?

2. What prerequisites does this course have?

3. What are key student abilities that are critical for success in this course?

4. What course should the student take next?

5. What resources must students have access to? (e.g. Library, lab, equipment, computers)

6. What supports are available for students in this course on campus? Online?

\section{Completed by:}

